\title{
Phosphoinositide-3-Kinase $\gamma$ Is Not a Predominant Regulator of ATP-Dependent Directed Microglial Process Motility or Experience-Dependent Ocular Dominance Plasticity
}

\author{
${ }^{-}$Brendan S. Whitelaw, ${ }^{1,2}$ Evelyn K. Matei, ${ }^{1,3}$ and Ania K. Majewska ${ }^{1,3}$
}

https://doi.org/10.1523/ENEURO.0311-20.2020

${ }^{1}$ Department of Neuroscience, ${ }^{2}$ Medical Scientist Training Program and Neuroscience Graduate Program, and

${ }^{3}$ Center for Visual Science, University of Rochester Medical Center, Rochester, NY 14642

\section{Visual Abstract}

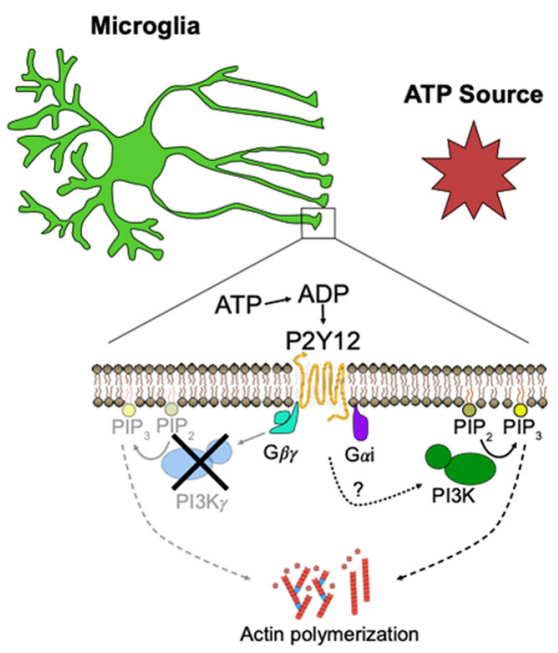

Microglia are dynamic cells whose extensive interactions with neurons and glia during development allow them to regulate neuronal development and function. The microglial P2Y12 receptor is crucial for microglial responsiveness to extracellular ATP and mediates numerous microglial functions, including ATP-dependent directional motility, microglia-neuron interactions, and experience-dependent synaptic plasticity. However, little is known about the downstream signaling effectors that mediate these diverse actions of P2Y12. Phosphoinositide-3-kinase $\gamma(\mathrm{PI} 3 \mathrm{~K} \gamma)$, a lipid kinase activated downstream of $\mathrm{G}_{i}$-protein-coupled receptors such as P2Y12, could translate localized extracellular ATP signals into directed

\section{Significance Statement}

Extracellular ATP acts as a chemoattractant for microglial processes via the microglial P2Y12 receptor, facilitating interactions between neurons and microglia. However, the intracellular pathways underlying this directional motility remain unknown. While phosphoinositide-3-kinase (PI3K) activity is required for ATPmediated microglial motility, $\mathrm{PI} 3 \mathrm{~K} \gamma$ specifically is largely dispensable but plays a subtle modulatory role. Because PI3K $\gamma$ is the only isoform directly activated by G-protein-coupled receptors, P2Y12 likely activates PI3K indirectly to promote directed microglial motility. 
microglial action and serve as a broad effector of P2Y12-dependent signaling. Here, we used pharmacological and genetic methods to manipulate $\mathrm{P} 2 \mathrm{Y} 12$ and $\mathrm{PI} 3 \mathrm{~K} \gamma$ signaling to determine whether inhibiting $\mathrm{PI} 3 \mathrm{~K} \gamma$ phenocopied the loss of P2Y12 signaling in mouse microglia. While pan-inhibition of all PI3K activity substantially affected P2Y12-dependent microglial responses, our results suggest that PI3K $\gamma$ specifically is only a minor part of the P2Y12 signaling pathway. PI3K $\gamma$ was not required to maintain homeostatic microglial morphology or their dynamic surveillance in vivo. Further, $\mathrm{PI} 3 \mathrm{~K} \gamma$ was not strictly required for P2Y12-dependent microglial responses ex vivo or in vivo, although we did observe subtle deficits in the recruitment of microglial process toward sources of ATP. Finally, PI3K $\gamma$ was not required for ocular dominance plasticity, a P2Y12-dependent form of experience-dependent synaptic plasticity that occurs in the developing visual cortex. Overall, our results demonstrate that PI3K $\gamma$ is not the major mediator of P2Y12 function in microglia, but may have a role in amplifying or fine-tuning the chemotactic response.

Key words: ATP; chemotaxis; microglia; P2Y12; PI3K; PI3K $\gamma$

\section{Introduction}

Microglia, the resident immune cells of the CNS, are critical mediators of neuronal development and function in the healthy brain. Active throughout the lifespan, microglia promote the generation, organization, and connectivity of neurons, and aberrant microglial activity likely contributes to both neuropsychiatric and neurodegenerative diseases (Li and Barres, 2018). Thus, investigation of how microglia interact with their environment is necessary to fully understand neuronal development and disease.

Signaling through extracellular nucleotides has emerged as one of several mechanisms by which microglia communicate and interact with other CNS cells (Vainchtein and Molofsky, 2020). ATP and its hydrolyzis products exhibit profound effects on microglia within minutes (Honda et al., 2001; Davalos et al., 2005), with ADP acting as a chemoattractant via the microglia-specific P2Y12 receptor in vitro and in vivo (Haynes et al., 2006). Neurons and astrocytes can release ATP through exocytic and nonexocytic mechanisms (Illes et al., 2019), promoting the recruitment of microglial processes to facilitate

Received July 11, 2020; accepted October 9, 2020; First published October 16, 2020.

The authors declare no competing financial interests.

Author contributions: B.S.W. and A.K.M. designed research; B.S.W. and E.K.M. performed research; B.S.W. and E.K.M. analyzed data; B.S.W. wrote the paper.

This work was supported by the Department of Health and Human Services (HHS) National Institutes of Health (NIH) National Institute of Mental Health (NIMH) Grant F30 MH120974 (to B.S.W), HHS NIH National Institute of Neurological Disorders and Stroke (NINDS) Grants R01 NS114480 and R21 NS099973 (to A.K.M), and the National Science Foundation Grant 1557971 (to A.K.M.).

Acknowledgements: We thank Matthias Wymann for providing the PI3K $\gamma$ $\mathrm{KO}$ and $\mathrm{PI} 3 \mathrm{~K} \gamma \mathrm{fl} / \mathrm{fl}$ mice, the members of the Majewska laboratory and Kaye Thomas and Julie Zhang of the University of Rochester Center for Advanced Light Microscopy and Nanoscopy for support, and Arun Venkataraman for help in generating estimation plots.

Correspondence should be addressed to Ania K. Majewska at ania majewska@urmc.rochester.edu.

https://doi.org/10.1523/ENEURO.0311-20.2020

Copyright @ 2020 Whitelaw et al.

This is an open-access article distributed under the terms of the Creative Commons Attribution 4.0 International license, which permits unrestricted use, distribution and reproduction in any medium provided that the original work is properly attributed. functional interactions. P2Y12 mediates microglial process recruitment to neuronal somas in an activity dependent manner, as observed during stroke or seizures (Eyo et al., 2014; Cserép et al., 2020). In the context of these metabolic or hyper-excitatory insults, the recruitment appears to be neuroprotective; however, the mechanisms of this protection are not yet known. $\mathrm{P} 2 \mathrm{Y} 12$ is also implicated in neurogenesis (DiazAparicio et al., 2020), microglial rearrangements (Eyo et al., 2018), virus response (Fekete et al., 2018), and critical-period synaptic plasticity (Sipe et al., 2016). Thus, microglial P2Y12, originally described as a chemotactic receptor, has diverse functions in the nervous system.

However, little is known about the intracellular effectors downstream of P2Y12 activation. Many chemoattractant receptors, including P2Y12, are $\mathrm{G}_{\mathrm{i}}$-coupled GPCRs, and chemotactic signaling pathways are often driven by the $\beta \gamma$ subunit of the $\mathrm{G}_{\mathrm{i}}$-protein heterotrimer $(\mathrm{G} \beta \gamma$; Haastert and Devreotes, 2004). $\mathrm{G} \beta \gamma$ activates diverse targets (Lin and Smrcka, 2011), including phosphoinositide-3-kinase $\gamma$ $(\mathrm{PI} 3 \mathrm{~K} \gamma)$, which translates an extracellular chemoattractant gradient into spatially biased intracellular signaling. PI3K $\gamma$ phosphorylates phosphatidylinositol 4,5-bisphosphate $\left(\mathrm{PIP}_{2}\right)$, a membrane phospholipid, forming phosphatidylinositol $(3,4,5)$-trisphosphate $\left(\mathrm{PIP}_{3}\right.$; Vanhaesebroeck et al., 2012). $\mathrm{PIP}_{3}$ then activates other proteins to induce directional cellular motility and chemotaxis (Devreotes and Horwitz, 2015). PI3K $\gamma$ is unique among the Class I PI3Ks in that it is activated by $\mathrm{G} \beta \gamma$, whereas $\operatorname{PI3K} \alpha$, $\mathrm{PI} 3 \mathrm{~K} \beta$, and $\mathrm{PI} 3 \mathrm{~K} \delta$ require activation by receptor tyrosine kinases (RTKs; Vanhaesebroeck et al., 2012). Thus, it is a promising candidate to mediate P2Y12dependent chemotaxis and directed microglial motility.

While $\mathrm{G} \beta \gamma$-PI3K $\gamma$ signaling has been well studied in the context of chemotaxis in the peripheral immune system, few studies have examined its role in ATP-dependent chemotaxis in microglia. In the CNS, PI3K $\gamma$ expression is highly enriched in microglia compared with other cell types (Zhang et al., 2014; He et al., 2018; Vanlandewijck et al., 2018; Zeisel et al., 2018). Studies of whole-cell microglial chemotaxis in vitro suggest that ATP-dependent chemotaxis is mediated, in part, by PI3K (Ohsawa et al., 2007; Irino et al., 2008). However, cell 
culture conditions affect both the microglial phenotype (Butovsky et al., 2014) and the cellular mechanisms underlying chemotaxis (Yamada and Sixt, 2019), so direct comparisons to in vivo function are difficult. In an ex vivo acute slice preparation, in which microglial morphology and ATP-dependent response is largely preserved, pan-inhibition of PI3K reduces the ability of microglial processes to respond to focal ATP release (Wu et al., 2007), although the role of PI3K $\gamma$ in particular was not addressed.

In this study, we sought to definitively determine whether $\mathrm{PI} 3 \mathrm{~K} \gamma$ is required as a potential downstream effector of P2Y12 in both ATP-mediated directed microglial motility and experience-dependent synaptic plasticity. First, we characterized the morphology and homeostatic surveillance of microglia in PI3K $\gamma$-deficient mice. We then used a combination of pharmacology and transgenic studies in an acute slice preparation to demonstrate that $\mathrm{PI} 3 \mathrm{~K} \gamma$ is not a predominant mediator of the microglial response to focal damage or ATP-release. It is important to note that the absence or inhibition of PI3K $\gamma$ had an intermediate effect on the coordinated movement of microglial processes toward the source of ATP, suggesting that $\mathrm{PI} 3 \mathrm{~K} \gamma$ may be playing a modulatory role. We found similar results in vivo where the gross response to focal injury was largely preserved but subtle deficits in long-range process motility were observed. Finally, we found that critical-period ocular dominance plasticity in the visual cortex was largely unaffected in PI3K $\gamma$ knock-out (KO) mice. Altogether, our work suggests that $\mathrm{PI} 3 \mathrm{~K} \gamma$ is not a major effector of P2Y12 activation in microglial roles in directed motility and synaptic remodeling.

\section{Materials and Methods}

\section{Animals}

All animal protocols were approved by the Institutional Animal Care and Use Committee at the University of Rochester Medical Center and conform to NIH guidelines. Male and female mice between the ages postnatal day $(P)$ 21-P120 were used for all experiments. All animals were bred in-house under standard 12/12 h light/dark cycle and fed ad libitum with standard chow. All mice are on a C57/BL6 background. P2Y12 KO and PI3K $\gamma$ KO mice were provided by the Nedergaard laboratory (Haynes et al., 2006) and the Wymann laboratory (Hirsch et al., $2000)$, respectively. To visualize microglia in acute slices and in vivo, Cx3cr1-EGFP/+ heterozygous mice (Jung et al., 2000; JAX 005582) were used and crossed with $\mathrm{KO}$ strains where indicated. To selectively delete $\mathrm{PI} 3 \mathrm{~K} \gamma$ in microglia, the $\mathrm{C} \times 3 \mathrm{cr} 1-\mathrm{CreERT} 2$ line (Parkhurst et al., 2013; JAX 021160) was crossed with floxed $\mathrm{PI} 3 \mathrm{~K} \gamma$ mouse $(\mathrm{PI} 3 \mathrm{~K} \gamma \mathrm{fl} / \mathrm{fl})$, provided by the Wymann laboratory (Breasson et al., 2017).

\section{Histology}

Experiments were conducted on wild-type, P2Y12 KO, and $\mathrm{PI} 3 \mathrm{~K} \gamma \mathrm{KO}$ mice during the visual critical period (P30P34). Mice were anesthetized with a lethal dose of sodium pentobarbital. Whole brains were collected following transcardial perfusion and overnight postfixation with $4 \%$ paraformaldehyde solution $\left(4^{\circ} \mathrm{C}\right)$. After dehydration in $30 \%$ sucrose $(\mathrm{w} / \mathrm{v}), 50-\mu \mathrm{m}$ coronal sections were obtained using a freezing microtome (Microm; Global Medical Instrumentation). Sections were processed free-floating at room temperature (RT). To prevent non-specific antibody and antigen binding, sections were blocked in peroxidase and bovine serum albumin (BSA) solutions. Sections were incubated overnight in a primary antibody solution $\left(4^{\circ} \mathrm{C}\right.$, rabbit anti-lba- $1,1: 2500$, Wako \#019-19741), followed by a secondary antibody solution ( $2 \mathrm{~h}$, at RT, goat-anti-rabbit Alexa Fluor 594, 1:500, Invitrogen \#A-11037), mounted, and coverslipped with Prolong Gold antifade reagent with DAPI (Invitrogen P36935). Imaging and analysis were conducted blind to genotype of the samples. For analysis of microglial density and distribution, Iba1-labeled microglia located in the primary visual cortex were identified and imaged on an Olympus BX51 epifluorescent microscope equipped with a SPOT pursuit camera (SPOT Imaging) using a $10 \times$ $(N A=0.3)$ objective lens (Olympus). For density analysis, the number of Iba1-positive microglia within a region of interest (ROI) was manually counted using the Cell Counter plugin in ImageJ/FIJI (https://imagej.net/Fiji). This number was then divided by the area of the ROI to generate density. For distribution analysis, the coordinates of each cell obtained from the Cell Counter were then used as the input in a custom MATLAB (MathWorks) script to find the nearest neighbor distance for each cell and then averaged for all cells in the ROI. The spacing index was then calculated as the square of the nearest neighbor multiplied by the density. Three to six slices of visual cortex were analyzed per animal and averaged such that one animal represents one data point. Cell density and nearest neighbor distribution were compared across genotypes using one-way ANOVA with Tukey's post hoc multiple comparisons tests.

For analysis of ramification, microglia were imaged on a Nikon A1R HD confocal microscope. For each section, a 30-step z-stack encompassing the entirety of a few microglia was collected with a z-step of $0.375 \mu \mathrm{m}, x y$-pixel width of $0.12 \mu \mathrm{m}$ with a $40 \times$ objective lens (Nikon Apochromat $\lambda$ LWD; $N A=1.15)$. All image processing was performed in ImageJ/FIJI. Maximum Z-projections were generated, and microglia entirely encompassed in the stack were isolated. Images were then passed through a median filter (for despeckling) and a Gaussian filter (for smoothing), and then manually thresholded such that the fine processes were preserved. Small unconnected particles ( $<100$ pixels), and staining artifacts, were removed using the Analyze Particles tool. To quantify the ramification of each microglia, Sholl analysis was then performed on each thresholded projection using ImageJ/FIJI. 15 microglia were analyzed from each animal and averaged such that one animal represents one data point. The maximum and total number of intersections were used to compare genotypes using one-way ANOVA with Tukey's post hoc multiple comparisons tests. 


\section{Chronic cranial window preparation}

For anesthesia, a fentanyl cocktail containing fentanyl $(0.05 \mathrm{mg} / \mathrm{kg})$, midazolam $(5.0 \mathrm{mg} / \mathrm{kg})$, and dexmedetomidine $(0.5 \mathrm{mg} / \mathrm{kg})$ was administered intraperitoneally for cranial window procedures and two-photon in vivo imaging sessions. During surgery and imaging, body temperature was maintained at $37^{\circ} \mathrm{C}$ using a heating pad and rectal temperature probe and a lubricating eye ointment was used to prevent eye drying. Aseptic technique was used throughout the surgery, and tools were sterilized in between surgeries using a bead sterilizer. Mice were mounted to a stereotaxic frame and head fixed. The scalp was removed, and the skull exposed and cleared of debris. A 3$\mathrm{mm}$ biopsy punch was used to mark the skull over left V1. A craniotomy was performed using a dental drill and a $0.5-\mathrm{mm}$ drill bit (Fine Science Tools) to drill through the skull, tracing the marking, while frequently irrigating with sterile saline. The window, consisting of a circular 5-mm glass cover slip glued to a 3-mm glass coverslip (Warner Instruments) with UV glue (Norland Optical Adhesive) was placed ( $3 \mathrm{~mm}$ side down) over the exposed dura. The window, surrounding skull, and incision site were sealed with C\&B Metabond dental cement (Parkell). A custom headplate (emachineshop. com; design courtesy of the Mriganka Sur lab, MIT) was attached with dental cement. Slow-release buprenorphine $(5 \mathrm{mg} / \mathrm{kg}, \mathrm{sc})$ was administered after surgery, and mice were monitored for $72 \mathrm{~h}$ postoperative. Mice were imaged at least two weeks after surgery. For imaging, mice were anesthetized with fentanyl cocktail, head fixed onto a stage, and imaged for $\sim 1 \mathrm{~h}$ with body temperature maintained at $37^{\circ} \mathrm{C}$.

\section{Acute slice preparation}

For all slice experiments, slices were imaged between $30 \mathrm{~min}$ to $3 \mathrm{~h}$ from the time of slicing to avoid the overt microglial activation (Gyoneva and Traynelis, 2013). For focal laser injury experiments in acute slices, mice were decapitated and the brain was rapidly removed into icecold bicarbonate-buffered artificial cerebrospinal fluid, containing the following (obtained from Fisher): $126 \mathrm{~mm}$ $\mathrm{NaCl}, 2.5 \mathrm{~mm} \mathrm{KCl}, 1.25 \mathrm{~mm} \mathrm{KH}_{2} \mathrm{PO}_{4}, 10 \mathrm{~mm}$ glucose, 1.3 $\mathrm{mm} \mathrm{MgSO}$, $26 \mathrm{~mm} \mathrm{NaHCO}$, and $2.5 \mathrm{~mm} \mathrm{CaCl}$; constantly bubbled with $95 \% \mathrm{O}_{2}, 5 \% \mathrm{CO}_{2}$ (bicarb-ACSF; $\sim 297 \mathrm{mOsm}$ ). Coronal sections $400-\mu \mathrm{m}$ thickness encompassing V1 were prepared using a vibratome (Vibratome 1000), with the brain submerged in ice-cold bicarb-ACSF. Slices were transferred to a recovery chamber containing RT bicarb-ACSF. Bicarb-ACSF (heated to $34-36^{\circ} \mathrm{C}$ ) was also used as the extracellular solution during imaging. Slices for focal ATP release experiments were performed in a similar manner, with a few modifications: ice-cold sucrose-based slicing solution was used for initial submersion of the brain and for slicing, containing the following: $76 \mathrm{~mm} \mathrm{NaCl}, 75 \mathrm{~mm}$ sucrose, $2.5 \mathrm{~mm}$ $\mathrm{KCl}, 1.25 \mathrm{~mm} \mathrm{NaH}_{2} \mathrm{PO}_{4}, 25 \mathrm{~mm}$ glucose, $7 \mathrm{~mm} \mathrm{MgCl}$, 26 $\mathrm{mm} \mathrm{NaHCO}$, and $0.5 \mathrm{~mm} \mathrm{CaCl} 2$; bubbled with $95 \% \mathrm{O}_{2}$, $5 \% \mathrm{CO}_{2}$ (sucrose-ACSF; $\sim 305 \mathrm{mOsm}$ ). Slices were recovered and imaged in HEPES-buffered ACSF, containing the following: $140 \mathrm{~mm} \mathrm{NaCl}, 2.5 \mathrm{~mm} \mathrm{KCl}, 1 \mathrm{~mm}$ $\mathrm{NaH}_{2} \mathrm{PO}_{4}, 10 \mathrm{~mm}$ glucose, $2 \mathrm{~mm} \mathrm{MgCl}$, $10 \mathrm{~mm}$ HEPES, and $2 \mathrm{mM} \mathrm{CaCl}_{2} ; \mathrm{pH}$ adjusted to 7.4 with $5 \mathrm{M} \mathrm{NaOH}$; and bubbled with 100\% $\mathrm{O}_{2}$ (HEPES-ACSF; $2297 \mathrm{mOsm}$ ). HEPES-ACSF was used in these ATP puff experiments as extracellular solution to precisely control the $\mathrm{pH}$ within the ATP filled pipet, as recommended by (Kyrargyri et al., 2019). For imaging, slices were placed in a perfusion chamber (RC-27L, Warner Instruments), continuously perfused with ACSF at a rate of $\sim 2 \mathrm{ml} / \mathrm{min}$ and imaged at a depth of $\sim 50-100 \mu \mathrm{m}$ to avoid areas damaged from the slicing procedure (Eyo et al., 2014; Kyrargyri et al., 2019).

\section{Pharmacological reagents}

For slice experiments, all drugs were solubilized in DMSO (Sigma) and subsequently diluted 1000 -fold in ACSF for a final concentration of $0.1 \% \mathrm{DMSO}$, which was used as vehicle control. Elinogrel (Oestreich, 2010), Cycholasin D (Krucker et al., 2000), and forskolin (Swiatkowski et al., 2016) were obtained from Tocris, IPI-549 (Evans et al., 2016; Henau et al., 2016) from SelleckChem, and Wortmannin (Wu et al., 2007) from Sigma. Drugs were bath-applied through the perfusate solution, including a $10-$ to 15 -min pretreatment before imaging.

\section{Two-photon imaging}

A custom built two-photon laser scanning microscope (Ti:Sapphire laser, Mai-Tai, Spectra physics; Fluoview confocal scan head, BX61 microscope frame, 20x 0.95 NA water-immersion objective, Olympus) was used to image cortical EGFP+ microglia in vivo and in acute brain slices. Excitation was achieved with $920 \mathrm{~nm}(100 \mathrm{fs}$ pulse at $80 \mathrm{MHz}$ ) and emission was collected through a 580/180 bandpass filter. In ATP-puff experiments, a 565 dichroic mirror was used to separate emission from EGFP (580/180 filter) and rhodamine (578/108 filter). Z-stacks were acquired at $4 \times$ digital zoom (XY pixel distance of $0.25 \mu \mathrm{m})$ with $z$-step size of 1 or $2 \mu \mathrm{m}$. For time lapse imaging, z-stacks were acquired at 1- or 2-min intervals. Image analysis was performed blind to genotype/treatment. The image analysis pipeline consisted of several preprocessing steps in ImageJ followed by thresholding and analysis in MATLAB. Preprocessing in ImageJ consisted of the following consecutive steps: (1) 3D registration to correct for motion using the 3DCorrect plugin (Parslow et al., 2014); (2) Maximum Z-projections encompassing $20 \mu \mathrm{m}$ of tissue in the $z$-direction in slices and $10 \mu \mathrm{m}$ in vivo (the higher density of microglial processes in vivo necessitated a smaller volume) to generate timelapse movies; (3) Despeckling with a median filter; (4) a second registration step using the MultiStackReg plug in (bradbusse.net); and (5) bleach correction using the histogram matching method. Only the generation of Maximum Z-projections (2) requires user input. The resulting "xyt" time series were used for analysis with custom MATLAB scripts. ImageJ macros for batch processing and MATLAB scripts are available on GitHub (https://github. com/majewska-lab).

\section{Motility and surveillance}

Cortical microglia were imaged through a cranial window. Z-stacks were taken every 2 min for $32 \mathrm{~min}$. The principles behind our analysis of microglial motility and 
surveillance have been previously described, by our lab (Sipe et al., 2016) and others (Madry et al., 2018; Bernier et al., 2019). New MATLAB scripts were developed for this paper to streamline the analysis. For each time series image, a threshold was manually selected to include fine processes while excluding background noise. Binarized images of consecutive time points were then overlaid. Positive pixels were classified as either stable (present in both time points, white), extensions (only present in second time point, green), or retractions (only present in first time point, magenta). The motility index was calculated as the sum of extended and retracted pixels divided by the stable pixels, averaged over the course of the imaging session. To calculate surveillance, or the total area surveyed by microglia across the imaging session, the binarized "xyt" image was maximum-projected in the "t" dimension, and the fraction of pixels that are positive is determined.

\section{Laser injury}

Laser injuries were induced by tuning the laser to $780 \mathrm{~nm}$, increasing the power $\sim 5$-fold, and running a point scan for 10-15 s. This generated an auto-fluorescent core indicative of tissue damage. After induction of the laser injury, z-stacks were taken every $2 \mathrm{~min}$, for $30 \mathrm{~min}$. For in vivo laser injury experiments, z-stacks were taken every $2 \mathrm{~min}$ for $62 \mathrm{~min}$.

\section{Focal ATP release}

A 1 mм ATP (Sigma), 4\% tetramethylrhodamine ("rhodamine"; average molecular weight 4400; Sigma) solution was prepared in HEPES-ACSF and backfilled into a glass microelectrode ( 3-4 M $\Omega$ resistance; BF150-110-10 glass pulled with $\mathrm{P}-97$ puller, Sutter). The glass microelectrode was slowly inserted into cortical tissue using a micromanipulator (MP225, Sutter). The end of the pipet was connected to a Picospritzer III (Parker). An initial z-stack was obtained, then a pressure pulse $(100 \mathrm{~ms}, 15 \mathrm{psi})$ released ATP onto the slice during the second time frame ( $t=0 \mathrm{~min})$. Additional $\mathrm{z}$-stacks were acquired for $30 \mathrm{~min}$ (every 1 or $2 \mathrm{~min}$ ).

\section{Image analysis}

\section{Analysis of laser ablation response}

In this study, we have analyzed two aspects of the microglial chemotactic response: the convergence of microglial processes on a central source of ATP, and the coordinated movement of process toward the source. Our measurement of convergence around the laser injury is conceptually similar to what has been previously published (Davalos et al., 2005; Sipe et al., 2016). Images were binarized as described above. A polygon was outlined around the auto-fluorescent core generated by the laser injury, and this area was excluded from analysis. A donut shaped $\mathrm{ROI}$ of thickness 40 pixels $(10 \mu \mathrm{m})$ was generated around the central core, or center. Convergence was calculated as the fraction of this ROI that was occupied by positive pixels, subtracted by the initial occupancy. A negative value for convergence is indicative of fluorescent debris that has disappeared and has not been replaced by microglial processes. To make statistical comparisons across groups, the convergence at $30 \mathrm{~min}$ (and 62 min for in vivo samples) was used. While this is a useful measurement of the microglial process accumulation in the ROI, it does not capture any information about the microglial response outside of the ROI, including directional movement. In order to capture movement throughout the field of view, we used an optic flow-based approach. The "xyt" time series was used to generate optic flow vectors by the method of Farneback (Farnebäck, 2003; MATLAB image processing toolbox). This method compares two consecutive frames and determines, for each pixel, the direction and magnitude of motion in the image (Extended Data Fig. 1-1). To find the degree to which this movement was directed toward the site of injury, the velocity vectors were projected onto the normalized vector pointing toward the injury, generating a measurement of directional velocity. This produced positive numbers for movement toward the injury, and negative numbers for movement away from the injury. In order to isolate microglial movement, a binary mask based on the thresholded images was applied to the vectors. Finally, the average directional velocity was calculated across all microglial pixels. This value is reported as arbitrary units (a.u.). For slice experiments, in which there is limited long-range motility, this analysis was restricted to within 200 pixels $(50 \mu \mathrm{m})$ of the central injury. For the in vivo experiments, we conducted additional analyses on longer-range motility (200-300 pixels; 50-75 $\mu \mathrm{m})$. In order to compare across groups, the average directional velocity from 10 to $20 \mathrm{~min}$ was used. This excluded initial artifacts caused by tissue deformation as well as the period after convergence has largely completed. To examine the spatiotemporal dynamics of the in vivo injury response, we calculated the directional velocity as a function of distance from the center, binning the radii in increments of $5 \mu \mathrm{m}$ (Extended Data Fig. 6-1). For each "xyt" image, this analysis protocol requires the user to select a threshold and to manually outline the central injury. Beyond that, it requires no further user input.

\section{Analysis of directed motility to ATP}

To analyze the microglial response to ATP puff, the protocol was slightly modified. Instead of a drawing a polygon around the central injury, a point was placed at the end of the pipet tip. Next, a polygon was drawn around the pipet, to exclude it from the analysis. For convergence, a circular $\mathrm{ROI}$ of radius 50 pixels $(12.5 \mu \mathrm{m})$ centered on the tip of the pipet was used as the area in which to calculate microglial occupancy, instead of the donut $\mathrm{ROI}$ around the injury core. Over time, microglial processes entered the pipet tip, thus leading to a decreased value of convergence. Thus, to compare across groups, we used the maximum convergence.

For directional velocity, the pipet tip was used as the center. The circular ROI used for convergence was excluded from the directional velocity analysis because of artifacts caused by movement at the tip of the pipet. Quantification of microglial response begins two frames after ATP release ( $t=4 \mathrm{~min}$ at one frame $/ 2 \mathrm{~min} ; t=2 \mathrm{~min}$ at one frame $/ 1 \mathrm{~min}$ ) to avoid artifacts from the dye included in the pipette solution which leaks into the imaging field at earlier time points. For comparisons between groups, the 
average directional velocity from 2 to $10 \mathrm{~min}$ (4-10 min when z-stacks were obtained every $2 \mathrm{~min}$ ) was calculated, encompassing the bulk of the microglial response. After the processes converge and clog the pipet, directional velocity falls to zero.

\section{Microglial-specific PI3K $\gamma$ deletion}

Cx3cr1-CreERT2 mice (referred to as Cx3cr1-Cre; Parkhurst et al., 2013) were crossed with $\mathrm{PI} 3 \mathrm{~K} \gamma \mathrm{fl} / \mathrm{fl}$ (Breasson et al., 2017) mice to generate the tamoxifen inducible microglial deletion of PI3K $\gamma$. Controls used for these experiments were tamoxifen-treated Cx3cr1-Cre/+ heterozygous mice. Tamoxifen (50 $\mathrm{g}$; Sigma) solubilized in corn oil $(2 \mathrm{mg} / \mathrm{ml})$ was administered on three consecutive days to pups aged $\sim$ P2-P4 via oral gavage. Tamoxifen induction of Cre activity was confirmed using fluorescenceassisted cell sorting (FACS) to isolate and genotype microglia. Tamoxifen-treated mice aged P30-P35 were given an overdose of sodium pentobarbital and transcardially perfused with ice cold $0.15 \mathrm{~m}$ phosphate buffer (PB). The brain was rapidly removed and placed in ice cold FACS buffer (0.5\% BSA, Sigma A2153; PBS without $\mathrm{Ca}$ or $\mathrm{Mg}$, Invitrogen 20012-027). Samples were placed on ice for the remainder of the preparation. The cortices were dissected and homogenized manually using a Dounce homogenizer. The homogenate was filtered through a 70- $\mu \mathrm{m}$ cell strainer (Fisher) and centrifuged at $210 \times g$ for $7 \mathrm{~min}$. at $4^{\circ} \mathrm{C}$. The supernatant was discarded, the pellet resuspended in FACS buffer, and Myelin Removal Beads II (Miltenyi) were added. After a 15-min incubation, the solution was passed through a $70-\mu \mathrm{m}$ filter and then primed magnetic LS columns (Miltenyi). The resulting myelin-depleted suspension was centrifuged and re-suspended. An Fc Block (Biolegend) was added for $15 \mathrm{~min}$. The sample was then labeled with anti-CD11b-BV786 (1:200, BD, clone M1/70), anti-CD45-APC (1:400, BD, clone 30-F11) for $30 \mathrm{~min}$ in the dark. After centrifugation and re-suspension, propidium iodide (PI; $10 \mu \mathrm{g} / \mathrm{ml}$ ) was added just before sorting to label dead cells. The following compensation controls were included: unstained cell suspension, anti-CD11b-BV786 beads, anti-CD45-APC beads (eBiosciences, 01-11142), and Triton X-100-treated dead cell suspension (for PI). Samples were run on an 18-color FACSAria II flow cytometer. Microglial cells were identified as CD11b+, CD45lo, PI- (Extended Data Fig. 7-1). Sorted microglia were collected into PBS for DNA isolation using the Qiagen DNAeasy DNA isolation kit. Cx3cr1-Cre/+; $\mathrm{Pl} 3 \mathrm{~K} \gamma \mathrm{fl} / \mathrm{fl}$ mice (PI3K $\gamma \mathrm{CKO}$ ) from three separate litters were included in our confirmation experiments. Sorted microglia from Cx3cr1-Cre/+; PI3K $\gamma$ wild-type (WT), and PI3K $\gamma \mathrm{fl} / \mathrm{fl}$ mice were used as additional controls. Two separate PCR reactions were run on these samples: (1) PCR for the WT (332bp product) and the floxed PI3K $\gamma$ allele (476-bp product; forward, ACACCCAACCCAGAACCAAC; reverse, AAGGG GAGAAGGGAGAGGTG); and (2) PCR for the excision product (635 bp; forward, ACACCCAACCCAGAACCAAC; reverse, CCATGTGTGAAGGTGACATACATT), only present after Cre-mediated excision of the floxed $\mathrm{PI} 3 \mathrm{~K} \gamma$ allele (Extended Data Fig. 7-1). Overall, we observed complete excision of the PI3K $\gamma$ floxed allele in microglial samples from three separate tamoxifen-treated PI3K $\gamma$ fl/fl; Cx3cr1Cre/+ litters, as determined by no visible $\mathrm{Pl} 3 \mathrm{~K} \gamma \mathrm{fl} / \mathrm{fl}$ allele and presence of the excision product.

\section{Monocular deprivation}

Animals in the peak critical period for ocular dominance plasticity (P26-P29; Gordon and Stryker, 1996) were assigned to non-deprived (ND) or $4 \mathrm{~d}$ of monocular deprivation (4D MD) cohorts. For 4D MD, animals were anesthetized with isoflurane (5\% induction; $2 \%$ maintenance), and given carprofen analgesic before surgery $(5 \mathrm{mg} / \mathrm{kg})$. The margins of the right eyelids were removed, and Tobradex antibiotic eye ointment was applied to the eye and margins. The right eyelids were sutured together, and the mice quickly recovered. Before use in intrinsic optical signal (IOS) experiments, the eyelid sutures were carefully examined under a dissection scope. If there was any opening in the suture or visible damage to the eye, the mice were excluded.

\section{IOS imaging}

Two sets of animals were used for these experiments (1) C57/BL6 and PI3K $\gamma$ KO mice to determine the effect of global PI3K $\gamma \mathrm{KO}$; and (2) $\mathrm{C} \times 3 \mathrm{cr} 1-\mathrm{Cre} /+$ and $\mathrm{C} \times 3 \mathrm{cr} 1-$ Cre/+; PI3K $\gamma \mathrm{fl} / \mathrm{fl}$ mice to determine the effect of microglial-specific PI3K $\gamma$ KO. Animals were anesthetized with isoflurane and dosed with chlorprothixene $(2 \mathrm{mg} / \mathrm{kg})$. The sutures were re-opened and the remaining eyelid margins were trimmed. Eyes were covered with clear silicone oil to prevent drying. The scalp was removed and skull cleared of membranes and debris. A flat metal bar was glued onto the right hemisphere, to head-fix the animal, leaving the left hemisphere uncovered. A $0.5 \%$ agarose solution was placed over the skull and sealed with a coverslip. Isoflurane was maintained at $0.75 \%$ during imaging. A custom built IOS imaging rig was used to measure the blood oxygenation level-dependent (BOLD) response of the left visual cortex to a periodic stimulus, as described in (Kalatsky and Stryker, 2003). A camera (DALSA 2M30 CCD) captured light reflected off the skull: $550-\mathrm{nm}$ light for the vasculature and 700-nm light for the intrinsic signal. A horizontal bar drifting vertically $\left(90^{\circ}\right.$ or $\left.270^{\circ}\right)$ was presented to the mice on an LCD screen located $30 \mathrm{~cm}$ from the mouse eyes. The stimulus frequency was $0.1 \mathrm{~Hz}$, presented over $6 \mathrm{~min}$. Each eye was imaged separately with stimulus in both directions. The normalized amplitude maps of the fast-Fourier transform of the intrinsic signal was averaged from both stimulus directions. The ipsilateral (left eye) and contralateral (right eye) maps were compared offline in MATLAB. The ocular dominance index (ODI) was calculated using the equation: $O D I=(a v-$ erage contralateral response - average ipsilateral response)/(average contralateral response + average ipsilateral response).

\section{Statistical analysis}

Statistical comparisons were made between groups using Prism 8 software (GraphPad). Sample size was not predetermined but is consistent with previously published 
studies (Sipe et al., 2016; Madry et al., 2018). All analyses were performed blinded to condition. Individual data points (" $n$ ") represent individual mice, with the exception of drug treatment experiments in acute brain slices. For those, $n$ represents individual slices. Multiple slices were used from each animal (no more than three). However, controls were interleaved within the treated groups such that no two data points for a given condition came from the same animal. For all analyses, $\alpha=0.05$. Statistical comparisons were done using un-paired two-tailed $t$ tests, Welch's $t$ test (for samples with unequal variance), one-way ANOVA with Tukey's post hoc comparisons, and two-way ANOVA with Sidak's multiple comparisons, as indicated in the figure legends and statistics table, where $p$ values are presented (Table 1). Data reported in the text are mean \pm SEM.

To graphically illustrate effect sizes, we used estimation graphics (https://www.estimationstats.com/\#/; Ho et al., 2019). When comparing between two groups, GardnerAltman plots were used. On the left axes, the raw data from both groups were plotted. The mean difference between the two groups was plotted on a floating axes to the right as a bootstrap sampling distribution. The mean difference is depicted as a dot, while the $95 \%$ confidence interval $(\mathrm{Cl})$ is indicated by the vertical bar. For comparisons of three groups, the experimental groups were compared with a shared control and the mean differences were graphed using a Cumming estimation plot. The raw data are plotted on the upper axes, while the mean difference, $95 \% \mathrm{Cl}$, and bootstrap sampling distribution are plotted on the lower axes. Graphs were created using the DABEST package in python (https://github.com/ ACCLAB/DABEST-python).

The DABEST package uses a bootstrapping technique to generate a distribution of mean differences, and then calculates the average and the $95 \% \mathrm{Cl}$ for this distribution, which is graphically displayed and reported in the figure legends. Notably, this is distinct from the mean and Cls of the effect sizes calculated while doing the hypothesis testing mentioned above (e.g., $t$ test, ANOVA) and reported in the statistics table (Table 1). These intervals are derived with the pooled standard error under the assumption of a normal distribution.

\section{Code availability}

The code/software described in the paper is freely available online at https://github.com/majewska-lab. The code is available as Extended Data 1. This code was run on a Macbook pro (early 2015, Intel Core i5) running MacOS 10.14 .

\section{Results}

PI3K $\gamma$ is highly enriched in microglia in the CNS (Zhang et al., 2014; He et al., 2018; Vanlandewijck et al., 2018; Zeisel et al., 2018), and has been shown to be critical for neuroinflammatory function, phagocytosis and chemotaxis toward complement (Passos et al., 2010; Schmidt et al., 2013, 2016; Lima et al., 2015; Schneble et al., 2017). Its role in P2Y12-dependent ATP-mediated directed process motility, which is critical to a number of both physiological and pathologic responses of microglia (Haynes et al., 2006; Eyo et al., 2014; Sipe et al., 2016; Cserép et al., 2020), has not been explored. Previous studies have implicated the PI3K pathway in regulating microglial chemotaxis to purines (Ohsawa et al., 2007; Wu et al., 2007; Irino et al., 2008), making it all the more likely that PI3K $\gamma$ is an effector of P2Y12 signaling. Before specifically testing the role of $\mathrm{PI} 3 \mathrm{~K} \gamma$ in this process, we first wanted to ensure that $\mathrm{PI} 3 \mathrm{~K}$ signaling was indeed required for P2Y12-dependent microglial directed motility. Using Cx3cr1-EGFP mice (Jung et al., 2000), in which microglia are fluorescently tagged with EGFP, we monitored the dynamics of the microglial response to focal sources of ATP (ATP-filled micropipette or focal laser injury; Fig. 1; Movie 1). In order to characterize the microglial response, we developed new analyses to capture two aspects of process motility: the overall directional movement of microglia toward the ATP source (Extended Data Fig. 1-1) and the convergence of microglial processes on the source (for details, see Materials and Methods). The directional velocity measurement, reported as a.u., allows for the analysis of movement farther from the site of convergence, allowing for a more complete characterization of microglial directed motility. The convergence describes the accumulation of microglial processes in a defined region around the ATP source, and is calculated as the fraction of this space occupied subtracted by the initial occupancy. Thus, if an ATP source is only able to recruit nearby processes, microglial convergence may be unimpaired, but the average directional velocity of processes will be decreased.

To test the involvement of the PI3K pathway, we used the pan-PI3K inhibitor wortmannin (5 $\mu \mathrm{M}$; Fig. 1). Slices were pretreated for $10 \mathrm{~min}$ with the inhibitor and the inhibitor was also present in the perfusing solution throughout the imaging sessions. Using the two measures outlined above, we found that the microglial response to focal ATP release was decreased by pan-PI3K inhibition [ $n$ (slices) $=6$ control, 5 wortmannin; Fig. $1 A-G]$, although there was still some degree of motility toward the pipette in the presence of wortmannin (Fig. 1C; Movie 1). The average directional velocity, calculated as the average from 2 to $10 \mathrm{~min}$, in vehicle-treated controls $(1.00 \pm 0.19$ a.u. $)$ was significantly different from that of wortmannin-treated slices ( $0.34 \pm 0.08$ a.u.; Fig. $1 E$; Table 1a). Wortmannin also significantly decreased the maximum convergence of microglial processes on the pipette tip (control $0.73 \pm 0.05$; wortmannin 0.31 \pm 0.07 ; Fig. 1G; Table 1a). These results were in agreement with the finding that wortmannin blocks the microglial response to ATP puff in hippocampal slices (Wu et al., 2007). Furthermore, the microglial response to focal laser injury was also abrogated by $5 \mu \mathrm{M}$ wortmannin treatment $[n$ (slices) $=6$ control, 6 wortmannin-treated; Fig. $1 H-N$ ]. The average velocity, calculated as the average directional velocity from 10 to $20 \mathrm{~min}$, was decreased by wortmannin (control $0.65 \pm$ 0.13 a.u.; wortmannin $-0.12 \pm 0.07$ a.u.; Fig. $1 L$; Table 1b). Similarly, the convergence at $30 \mathrm{~min}$ was also decreased by wortmannin (control $0.17 \pm 0.07$; wortmannin $-0.09 \pm 0.01$; Fig. $1 \mathrm{~N}$; Table $1 \mathrm{~b}$ ). Thus, PI3K is likely 
Table 1: Statistics table

\begin{tabular}{|c|c|c|c|c|c|c|c|}
\hline & Figure & Group comparison & Data structure & Statistical test & $p$ value & Difference of means & $95 \% \mathrm{Cl}$ \\
\hline \multirow[t]{2}{*}{ a } & $1 E$ & Control vs wortmannin $(5 \mu \mathrm{M})$ & Normal & Unpaired $t$ test & $p=0.0139 ; t=3.046 ; \mathrm{df}=9$ & -0.6647 & -1.158 to -0.1711 \\
\hline & $1 G$ & Control vs wortmannin $(5 \mu \mathrm{M})$ & Normal & Unpaired $t$ test & $p=0.0006 ; t=5.216 ; \mathrm{df}=9$ & -0.4174 & -0.5984 to -0.2364 \\
\hline \multirow[t]{2}{*}{$b$} & $1 L$ & Control vs wortmannin $(5 \mu \mathrm{M})$ & Normal & Unpaired $t$ test & $p=0.0005 ; t=5.071 ; \mathrm{df}=10$ & -0.7733 & -1.113 to -0.4335 \\
\hline & $1 N$ & Control vs wortmannin $(5 \mu \mathrm{m})$ & $\begin{array}{l}\text { Normal (unequal } \\
\text { variance) }\end{array}$ & Welch's $t$ test & $p=0.0125 ; t=3.679 ; \mathrm{df}=5.391$ & -0.2633 & -0.4434 to -0.08326 \\
\hline \multirow[t]{4}{*}{ c } & $2 B$ & Density: genoytpe & Normal & One-way ANOVA & $p=0.1752 ; F=1.912$ & & \\
\hline & & Control vs $\mathrm{P} 2 \mathrm{Y} 12 \mathrm{KO}$ & & Tukey's post hoc & $p=0.1520$ & $-74.57 \mathrm{microglia} / \mathrm{mm}^{2}$ & -171.7 to 22.54 \\
\hline & & Control vs $\mathrm{PI} 3 \mathrm{Kg} \mathrm{KO}$ & & Tukey's post hoc & $p=0.5830$ & $-38.40 \mathrm{microglia} / \mathrm{mm}^{2}$ & -135.5 to 58.71 \\
\hline & & P2Y12 KO vs PI3Kg KO & & Tukey's post hoc & $p=0.5725$ & $36.17 \mathrm{microglia} / \mathrm{mm}^{2}$ & -53.74 to 126.1 \\
\hline \multirow[t]{4}{*}{ d } & $2 C$ & Spacing index: genotype & Normal & One-way ANOVA & $p=0.2995 ; F=1.285$ & & \\
\hline & & Control vs $\mathrm{P} 2 \mathrm{Y} 12 \mathrm{KO}$ & & Tukey's post hoc & 0.3074 & -0.01460 & -0.03911 to 0.009914 \\
\hline & & Control vs $\mathrm{PI} 3 \mathrm{Kg} \mathrm{KO}$ & & Tukey's post hoc & 0.4122 & -0.01254 & -0.03706 to 0.01197 \\
\hline & & $\mathrm{P} 2 \mathrm{Y} 12 \mathrm{KO}$ vs PI3Kg KO & & Tukey's post hoc & 0.9714 & 0.002052 & -0.02064 to 0.02474 \\
\hline \multirow[t]{4}{*}{$\mathrm{e}$} & $2 F$ & Max intersections: genotype & Normal & One-way ANOVA & $p=0.6724 ; F=0.4064$ & & \\
\hline & & Control vs $\mathrm{P} 2 \mathrm{Y} 12 \mathrm{KO}$ & & Tukey's post hoc & 0.7245 & 1.123 & -2.608 to 4.854 \\
\hline & & Control vs $\mathrm{PI} 3 \mathrm{Kg} \mathrm{KO}$ & & Tukey's post hoc & 0.9955 & 0.1279 & -3.504 to 3.760 \\
\hline & & P2Y12 KO vs PI3Kg KO & & Tukey's post hoc & 0.7234 & -0.9952 & -4.293 to 2.302 \\
\hline \multirow[t]{4}{*}{$f$} & $2 G$ & Total intersections: genotype & Normal & One-way ANOVA & $p=0.1906 ; F=1.830$ & & \\
\hline & & Control vs P2Y12 KO & & Tukey's post hoc & 0.2044 & 23.51 & -10.28 to 57.29 \\
\hline & & Control vs $\mathrm{PI} 3 \mathrm{Kg} \mathrm{KO}$ & & Tukey's post hoc & 0.8639 & 6.634 & -26.26 to 39.53 \\
\hline & & $\mathrm{P} 2 \mathrm{Y} 12 \mathrm{KO}$ vs PI3Kg KO & & Tukey's post hoc & 0.3391 & -16.87 & -46.73 to 12.99 \\
\hline \multirow[t]{4}{*}{$g$} & $3 B$ & Motility: genotype & Normal & One-way ANOVA & $p=0.0060 ; F=7.174$ & & \\
\hline & & Control vs P2Y12 KO & & Tukey's post hoc & 0.1208 & -0.04231 & -0.09423 to 0.009605 \\
\hline & & Control vs $\mathrm{PI} 3 \mathrm{Kg} \mathrm{KO}$ & & Tukey's post hoc & 0.1032 & 0.04410 & -0.007822 to 0.09601 \\
\hline & & $\mathrm{P} 2 \mathrm{Y} 12 \mathrm{KO}$ vs PI3Kg KO & & Tukey's post hoc & 0.0043 & 0.08641 & 0.02754 to 0.1453 \\
\hline \multirow[t]{4}{*}{$\mathrm{h}$} & $3 C$ & Surveillance: genotype & Normal & One-way ANOVA & $p=0.0432 ; F=3.847$ & & \\
\hline & & Control vs $\mathrm{P} 2 \mathrm{Y} 12 \mathrm{KO}$ & & Tukey's post hoc & 0.2417 & -0.02299 & -0.05824 to 0.01225 \\
\hline & & Control vs $\mathrm{PI} 3 \mathrm{Kg} \mathrm{KO}$ & & Tukey's post hoc & 0.3364 & 0.01992 & -0.01533 to 0.05516 \\
\hline & & $\mathrm{P} 2 \mathrm{Y} 12 \mathrm{KO}$ vs PI3Kg KO & & Tukey's post hoc & 0.0345 & 0.04291 & 0.002947 to 0.08287 \\
\hline \multirow[t]{2}{*}{ i } & $4 E$ & Control vs elinogrel $(2 \mu \mathrm{M})$ & & Unpaired $t$ test & $p=0.0005 ; t=6.702 ; \mathrm{df}=6$ & -1.658 & -2.263 to -1.053 \\
\hline & $4 G$ & Control vs elinogrel $(2 \mu \mathrm{M})$ & & Unpaired $t$ test & $p=0.0048 ; t=4.349 ; \mathrm{df}=6$ & -0.4734 & -0.7398 to -0.2070 \\
\hline \multirow[t]{2}{*}{ j } & 41 & Control vs IPI-549 (1 $\mu \mathrm{M})$ & & Unpaired $t$ test & $p=0.0310 ; t=2.692 ; \mathrm{df}=7$ & -0.5813 & -1.092 to -0.07060 \\
\hline & $4 K$ & Control vs IPI-549 (1 $\mu \mathrm{M})$ & & Unpaired $t$ test & $p=0.1468 ; t=1.632 ; \mathrm{df}=7$ & -0.1158 & -0.2836 to 0.05201 \\
\hline \multirow[t]{4}{*}{$\mathrm{k}$} & $4 M$ & Average velocity: genotype & Normal & One-way ANOVA & $p=0.0003 ; F=20.01$ & & \\
\hline & & Control vs $\mathrm{P} 2 \mathrm{Y} 12 \mathrm{KO}$ & & Tukey's post hoc & 0.0002 & 0.9095 & 0.5138 to 1.305 \\
\hline & & Control vs $\mathrm{PI} 3 \mathrm{Kg} \mathrm{KO}$ & & Tukey's post hoc & 0.0089 & 0.5199 & 0.1445 to 0.8952 \\
\hline & & $\mathrm{P} 2 \mathrm{Y} 12 \mathrm{KO}$ vs PI3Kg KO & & Tukey's post hoc & 0.0421 & -0.3897 & -0.7650 to -0.01428 \\
\hline \multirow[t]{4}{*}{ I } & $4 N$ & Max convergence: genotype & Normal & One-way ANOVA & $p=0.0011 ; F=14.58$ & & \\
\hline & & Control vs $\mathrm{P} 2 \mathrm{Y} 12 \mathrm{KO}$ & & Tukey's post hoc & 0.0010 & 0.5960 & 0.2858 to 0.9062 \\
\hline & & Control vs $\mathrm{PI} 3 \mathrm{Kg} \mathrm{KO}$ & & Tukey's post hoc & 0.2314 & 0.1891 & -0.1052 to 0.4833 \\
\hline & & $\mathrm{P} 2 \mathrm{Y} 12 \mathrm{KO}$ vs PI3Kg KO & & Tukey's post hoc & 0.0090 & -0.4070 & -0.7012 to -0.1127 \\
\hline \multirow[t]{4}{*}{$\mathrm{m}$} & $5 E$ & Average velocity: treatment & Normal & One-way ANOVA & $p<0.0001 ; F=25.42$ & & \\
\hline & & Control vs elinogrel $(2 \mu \mathrm{M})$ & & Tukey's post hoc & $<0.0001$ & 0.8800 & 0.5745 to 1.186 \\
\hline & & Control vs IPI-549 (1 $\mu \mathrm{M})$ & & Tukey's post hoc & 0.0014 & 0.4725 & 0.1743 to 0.7707 \\
\hline & & elingorel $(2 \mu \mathrm{M})$ vs IPI-549 (1 $\mu \mathrm{M})$ & & Tukey's post hoc & 0.0071 & -0.4076 & -0.7132 to -0.1020 \\
\hline \multirow[t]{4}{*}{$\mathrm{n}$} & $5 G$ & Convergence at $30 \mathrm{~min}$ : treatment & Normal & One-way ANOVA & $p<0.0001 ; F=27.90$ & & \\
\hline & & Control vs elinogrel $(2 \mu \mathrm{M})$ & & Tukey's post hoc & $<0.0001$ & 0.1601 & 0.1070 to 0.2132 \\
\hline & & Control vs IPI-549 (1 $\mu \mathrm{M})$ & & Tukey's post hoc & 0.0007 & 0.08762 & 0.03578 to 0.1395 \\
\hline & & $\mathrm{P} 2 \mathrm{Y} 12 \mathrm{KO}$ vs PI3Kg KO & & Tukey's post hoc & 0.0059 & -0.07247 & -0.1256 to -0.01936 \\
\hline o & $5 l$ & Average velocity: genotype & Normal & One-way ANOVA & $p=0.0002 ; F=14.05$ & & \\
\hline & & Control vs P2Y12 KO & & Tukey's post hoc & 0.0001 & 0.8565 & 0.4440 to 1.269 \\
\hline & & Control vs $\mathrm{PI} 3 \mathrm{Kg} \mathrm{KO}$ & & Tukey's post hoc & 0.0312 & 0.4502 & 0.03772 to 0.8627 \\
\hline & & $\mathrm{P} 2 \mathrm{Y} 12 \mathrm{KO}$ vs PI3Kg KO & & Tukey's post hoc & 0.0540 & -0.4063 & -0.8187 to 0.006227 \\
\hline$p$ & $5 K$ & Convergence at $30 \mathrm{~min}$ : genotype & Normal & One-way ANOVA & $p=0.0014 ; F=9.695$ & & \\
\hline & & Control vs $\mathrm{P} 2 \mathrm{Y} 12 \mathrm{KO}$ & & Tukey's post hoc & 0.0030 & 0.1074 & 0.03683 to 0.1780 \\
\hline & & Control vs $\mathrm{PI} 3 \mathrm{Kg} \mathrm{KO}$ & & Tukey's post hoc & 0.9884 & 0.004017 & -0.06655 to 0.07459 \\
\hline & & $\mathrm{P} 2 \mathrm{Y} 12 \mathrm{KO}$ vs PI3Kg KO & & Tukey's post hoc & 0.0041 & -0.1034 & -0.1739 to -0.03281 \\
\hline q & $6 E$ & Convergence at $30 \mathrm{~min}:$ genotype & Normal & One-way ANOVA & $p=0.0003 ; F=12.08$ & & \\
\hline & & Control vs $\mathrm{P} 2 \mathrm{Y} 12 \mathrm{KO}$ & & Tukey's post hoc & 0.0018 & 0.2634 & 0.09725 to 0.4296 \\
\hline & & Control vs $\mathrm{PI} 3 \mathrm{Kg} \mathrm{KO}$ & & Tukey's post hoc & 0.4782 & -0.07407 & -0.2324 to 0.08426 \\
\hline & & $\mathrm{P} 2 \mathrm{Y} 12 \mathrm{KO}$ vs PI3Kg KO & & Tukey's post hoc & 0.0004 & -0.3375 & -0.5197 to -0.1553 \\
\hline r & $6 F$ & Convergence at 62 min: genotype & Normal & $\begin{array}{c}\text { One-way ANOVA } \\
\text { (Continued) }\end{array}$ & $p=0.0553 ; F=3.333$ & & \\
\hline
\end{tabular}


Table 1: Continued

\begin{tabular}{|c|c|c|c|c|c|c|c|}
\hline & Figure & Group comparison & Data structure & Statistical test & $p$ value & Difference of means & $95 \% \mathrm{Cl}$ \\
\hline & & Control vs P2Y12 KO & & Tukey's post hoc & 0.6003 & 0.05798 & -0.09193 to 0.2079 \\
\hline & & Control vs PI3Kg KO & & Tukey's post hoc & 0.1753 & -0.1054 & -0.2482 to 0.03746 \\
\hline & & $\mathrm{P} 2 \mathrm{Y} 12 \mathrm{KO}$ vs PI3Kg KO & & Tukey's post hoc & 0.0516 & -0.1633 & -0.3277 to 0.0009932 \\
\hline \multirow[t]{4}{*}{ s } & $6 H$ & Average velocity $<50 \mu \mathrm{m} 10-20 \mathrm{~min}:$ genotype & Normal & One-way ANOVA & $p=0.0625$ & & \\
\hline & & Control vs $\mathrm{P} 2 \mathrm{Y} 12 \mathrm{KO}$ & & Tukey's post hoc & 0.0559 & 1.052 & -0.02320 to 2.127 \\
\hline & & Control vs $\mathrm{PI} 3 \mathrm{Kg} \mathrm{KO}$ & & Tukey's post hoc & 0.3630 & 0.5656 & -0.4587 to 1.590 \\
\hline & & P2Y12 KO vs PI3Kg KO & & Tukey's post hoc & 0.5605 & -0.4864 & -1.665 to 0.6923 \\
\hline \multirow[t]{4}{*}{$\mathrm{t}$} & $6 l$ & Average velocity $<50 \mu \mathrm{m} 34-62 \mathrm{~min}$ : genotype & Normal & One-way ANOVA & $p<0.0001 ; F=16.37$ & & \\
\hline & & Control vs P2Y12 KO & & Tukey's post hoc & $<0.0001$ & -0.4057 & -0.6056 to -0.2058 \\
\hline & & Control vs $\mathrm{PI} 3 \mathrm{Kg} \mathrm{KO}$ & & Tukey's post hoc & 0.9988 & 0.009845 & -0.1806 to 0.2003 \\
\hline & & $\mathrm{P} 2 \mathrm{Y} 12 \mathrm{KO}$ vs $\mathrm{PI} 3 \mathrm{Kg} \mathrm{KO}$ & & Tukey's post hoc & 0.0002 & 0.4155 & 0.1964 to 0.6347 \\
\hline \multirow[t]{4}{*}{$\mathrm{u}$} & $6 K$ & Average velocity $50-75 \mu \mathrm{m} 10-20 \mathrm{~min}$ : genotype & Normal & One-way ANOVA & $p<0.0001 ; F=17.51$ & & \\
\hline & & Control vs $\mathrm{P} 2 \mathrm{Y} 12 \mathrm{KO}$ & & Tukey's post hoc & 0.0152 & -0.4969 & -0.9042 to -0.08957 \\
\hline & & Control vs $\mathrm{PI} 3 \mathrm{Kg} \mathrm{KO}$ & & Tukey's post hoc & 0.0051 & 0.5476 & 0.1595 to 0.9356 \\
\hline & & $\mathrm{P} 2 \mathrm{Y} 12 \mathrm{KO}$ vs PI3Kg KO & & Tukey's post hoc & $<0.0001$ & 1.044 & 0.5979 to 1.491 \\
\hline \multirow[t]{4}{*}{$v$} & $6 L$ & Average velocity $50-75 \mu \mathrm{m} 34-62 \mathrm{~min}$ : genotype & Normal & One-way ANOVA & $p=0.0003 ; F=11.99$ & & \\
\hline & & Control vs P2Y12 KO & & Tukey's post hoc & 0.0359 & -0.2130 & -0.4133 to -0.01265 \\
\hline & & Control vs $\mathrm{PI} 3 \mathrm{Kg} \mathrm{KO}$ & & Tukey's post hoc & 0.0270 & 0.2130 & 0.02217 to 0.4038 \\
\hline & & $\mathrm{P} 2 \mathrm{Y} 12 \mathrm{KO}$ vs PI3Kg KO & & Tukey's post hoc & 0.0002 & 0.4260 & 0.2064 to 0.6455 \\
\hline \multirow[t]{6}{*}{ w } & $7 C$ & Deprivation $\times$ genotype & Normal & $\begin{array}{l}\text { Two-way ANOVA: i } \\
\text { nteraction }\end{array}$ & $p=0.4505 ; F_{(1,28)}=0.5858$ & & \\
\hline & & Deprivation & & Factor & $p=0.0005 ; F_{(1,28)}=15.49$ & & \\
\hline & & Genotype & & Factor & $p=0.1040 ; F_{(1,28)}=2.824$ & & \\
\hline & & & & & & Predicted (LS) mean diff: & \\
\hline & & WT: ND vs 4D MD & & Sidak's post hoc & 0.0079 & 0.2226 & 0.05521 to 0.3900 \\
\hline & & PI3Kg KO: ND vs 4D MD & & Sidak's post hoc & 0.0472 & 0.1501 & 0.001620 to 0.2986 \\
\hline \multirow[t]{7}{*}{$x$} & $7 D$ & Deprivation $\times$ genotype & Normal & $\begin{array}{c}\text { Two-way ANOVA: } \\
\text { interaction }\end{array}$ & $p=0.3074 ; F_{(1,20)}=1.097$ & & \\
\hline & & Deprivation & & Factor & $p=0.0084 ; F_{(1,20)}=8.554$ & & \\
\hline & & Genotype & & Factor & $p=0.9364 ; F_{(1,20)}=0.006$ & & \\
\hline & & & & & & Predicted (LS) mean diff: & \\
\hline & & Cx3cr1-Cre/+: ND vs 4D mD & & & 0.0275 & 0.2247 & 0.02332 to 0.4260 \\
\hline & & Cx3cr1-Cre/+ PI3Kg fl/fl: ND vs 4D mD & & & 0.3285 & 0.1062 & -0.07880 to 0.2912 \\
\hline & & & & & & Difference of means: & \\
\hline \multirow[t]{2}{*}{ y } & $4-1 B$ & Control vs cytochalasin $\mathrm{D}(1 \mu \mathrm{M})$ & $\begin{array}{l}\text { Normal (unequal } \\
\text { variance) }\end{array}$ & Welch's $t$ test & $p=0.0339 ; t=3.625 ; \mathrm{df}=3.118$ & -0.6931 & -1.289 to -0.09735 \\
\hline & $4-1 D$ & Control vs cytochalasin D $(1 \mu \mathrm{M})$ & Normal & Unpaired $t$ test & $p=0.0002 ; t=6.948 ; \mathrm{df}=7$ & -0.5704 & -0.6801 to -0.3347 \\
\hline \multirow[t]{2}{*}{$z$} & $4-1 F$ & Control vs cytochalasin $\mathrm{D}(1 \mu \mathrm{M})$ & $\begin{array}{l}\text { Normal (unequal } \\
\text { variance) }\end{array}$ & Welch's $t$ test & $p=0.0528 ; t=4.039 ; \mathrm{df}=2.076$ & -1.047 & -2.124 to 0.02993 \\
\hline & $4-1 H$ & Control vs cytochalasin $\mathrm{D}(1 \mu \mathrm{M})$ & $\begin{array}{l}\text { Normal (unequal } \\
\text { variance) }\end{array}$ & Welch's $t$ test & $p=0.0387 ; t=4.727 ; \mathrm{df}=2.084$ & -0.5800 & -1.088 to -0.07202 \\
\hline \multirow[t]{2}{*}{$\mathrm{zz}$} & $4-2 B$ & Control vs forskolin $(10 \mu \mathrm{M})$ & Normal & Unpaired $t$ test & $p=0.069 ; t=2.146 ; \mathrm{df}=7$ & -0.3249 & -0.6829 to 0.0331 \\
\hline & $4-2 D$ & Control vs forskolin $(10 \mu \mathrm{M})$ & Normal & Unpaired $t$ test & $p=0.896 ; t=0.135 ; \mathrm{df}=7$ & 0.0293 & -0.4843 to 0.5430 \\
\hline
\end{tabular}

activated downstream of P2Y12. Because $\mathrm{PI} 3 \mathrm{~K} \gamma$ is the isoform activated by $\mathrm{G} \beta \gamma$, we further investigated how inhibiting or genetically deleting this protein affects microglial characteristics, directed motility, and contributions to synaptic plasticity.

\section{PI3K $\gamma$ KO does not affect microglial morphology or surveillance under homeostatic conditions}

Despite the recent interest in $\mathrm{PI} 3 \mathrm{~K} \gamma$ function in microglia, no studies have described how PI3K $\gamma$ loss impacts basal microglial morphology and distribution in vivo. Previous studies of PI3K $\gamma$ have been conducted either in vitro (Schmidt et al., 2013; Schneble et al., 2017) or in the context of pathology (Frister et al., 2014; Schmidt et al., 2016). Therefore, we first sought to characterize microglia under homeostatic conditions in the $\mathrm{PI} 3 \mathrm{~K} \gamma \mathrm{KO}$ mouse as changes in microglial number, distribution, morphology, and dynamics could affect microglial responses to ATP independently of P2Y12 signaling. Additionally, microglial morphology, as well as changes in microglial numbers and distribution are indicative of microglial activation or inflammatory state (Kettenmann et al., 2011), which could be affected by PI3K $\gamma$ loss. To determine whether loss of $\mathrm{PI} 3 \mathrm{~K} \gamma$ phenocopies loss of P2Y12, we also included $\mathrm{P} 2 \mathrm{Y} 12 \mathrm{KO}$ mice in our studies. We used immunohistochemical labeling of the microglial-specific marker lba1 to investigate morphologic characteristics of microglia in fixed brain slices from healthy adolescent (P28-P34) mice [n (mice) $=6$ control, $8 \mathrm{P} 2 \mathrm{Y} 12 \mathrm{KO}, 8 \mathrm{PI} 3 \mathrm{~K} \gamma \mathrm{KO}$; Fig. 2]. Similar to what has been previously reported for P2Y12 KO mice (Haynes et al., 2006), the density of microglia in binocular visual cortex was unchanged across genotypes (Fig. 2B; in microglia/mm², $406 \pm 20$ for control; $480 \pm 31$ 

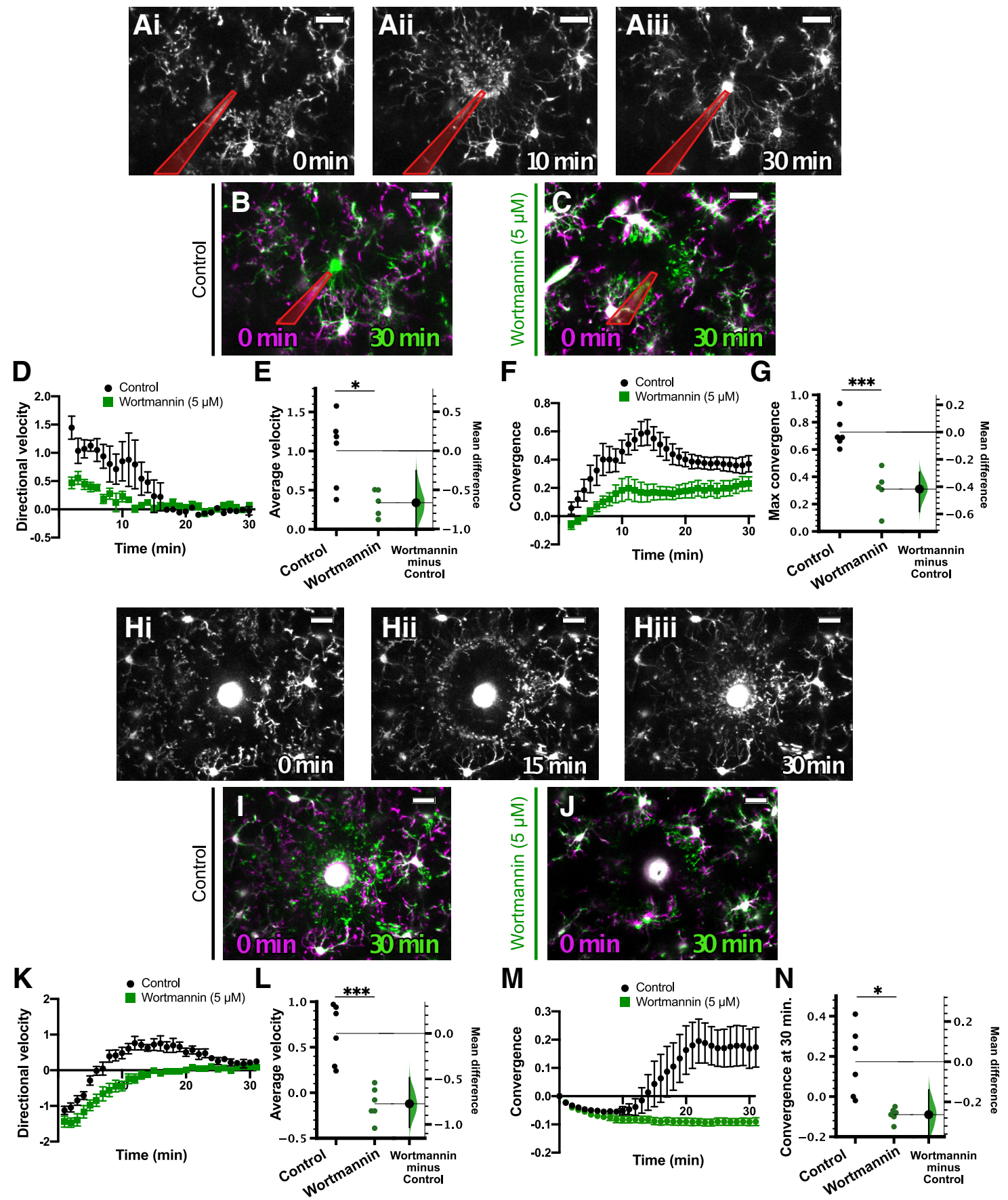

Figure 1. Pan-PI3K inhibition blocked the microglial response to focal laser injury in acute cortical slices. $\boldsymbol{A}$, Representative images of the microglial response to focal ATP release in a control (0.1\% DMSO vehicle) slice at 0 min $(\boldsymbol{A} \boldsymbol{i}), 10 \mathrm{~min}(\boldsymbol{A} i \boldsymbol{i})$, and $30 \mathrm{~min}(\boldsymbol{A} i \boldsymbol{i})$ after ATP puff. $\boldsymbol{B}, \boldsymbol{C}$, Overlays of representative responses from control (B, overlay of $\boldsymbol{A} \boldsymbol{i}$ and $\boldsymbol{A}$ iii), $5 \mu \mathrm{M}$ wortmannin-treated (pan-PI3K inhibitor; $\boldsymbol{C}$ ) slices at the indicated time points. Images at later time points (green) are overlaid with initial images ( $t=0$ min, magenta). In $\boldsymbol{A}-\boldsymbol{C}$, the pipette is outlined in red. $\boldsymbol{D}$, Time course of directional velocity, with one frame acquired every 1 min. Quantification begins at $t=2 \mathrm{~min}$ (two frames after puff) to avoid artifacts from the dye included in the pipette solution which leaks into the imaging field at earlier time points. $\boldsymbol{E}$, The mean difference between control and Wortmannin-treated groups is shown in the Gardner-Altman estimation plot. Both groups are plotted on the left axes; the mean difference is plotted on a floating axes on the right as a bootstrap sampling distribution. The mean difference is depicted as a dot; the $95 \% \mathrm{Cl}$ is indicated by the ends of the vertical error bar. Wortmannin significantly blocked the directional response [comparisons made on average velocity calculated in the interval of 210 min after ATP presentation; unpaired $t$ test, $p=0.014$; unpaired mean difference is $-0.665(95 \% \mathrm{Cl}-0.991,-0.253)]$. $\boldsymbol{F}$, Time course of convergence. Maximum convergence was used for statistical comparisons because microglial processes enter the pipet tip after convergence, decreasing this value. G, Wortmannin reduces the maximum convergence as shown in the Gardner-Altman plot [unpaired $t$ test, $p=0.0006$; unpaired mean difference is $-0.417(95 \% \mathrm{Cl}-0.582,-0.294)$ ]. $\boldsymbol{H}$, Representative images of the microglial response to laser injury (bright circular feature in the center of image) in a control cortical slice immediately after injury (Hi; 


\section{continued}

$0 \mathrm{~min}$ ), as the microglial processes moved toward the injury site (Hii; $15 \mathrm{~min})$, and after the microglial processes converged on the injury site (Hiii; $30 \mathrm{~min})$. I, Overlay of images of the microglial response at 0 min (Hi; magenta) and at 30 min (Hiii; green) demonstrating convergence of processes around the injury after $30 \mathrm{~min}$. $\boldsymbol{J}$, Similar overlay showing the microglial response to laser injury in a wortmannin-treated $(5 \mu \mathrm{M})$ slice at $0 \mathrm{~min}$ (magenta) and $30 \mathrm{~min}$ (green) after the injury. Microglial processes did not converge around injury as shown by the lack of green pixels around the core. $\boldsymbol{K}$, Time course of the directional velocity in control (black circles) and wortmannin-treated (green squares) slices showing that wortmannin substantially decreased the motility directed toward the ablation core. Note that the negative directional velocity that occurs soon after ablation is an artifact of tissue deformation following the laser injury. $\boldsymbol{L}$, Comparison of the average velocity from 10 to 20 min (encompassing the peak of the response) showed significant decrease in the wortmannin-treated group [unpaired $t$ test; $p=0.0005$; unpaired mean difference is $-0.773(95 \% \mathrm{Cl}-1.03,-0.487)$ ]. $\boldsymbol{M}$, Time course of convergence in control and wortmannin-treated slices. $\boldsymbol{N}$, Comparison of the convergence at 30 min showed a significant decrease in the wortmannin-treated group [Welch's $t$ test; $p=0.013$; unpaired mean difference is $-0.263(95 \% \mathrm{Cl}-0.4$, $-0.14)$ ]. $n=6$ control slices, 5 wortmannin-treated slices; from 6 animals total for focal ATP release experiments. $n=6$ control slices, 6 wortmannin-treated slices; from 6 animals total for laser injury experiments; $* p<0.05, * * p<0.01, * * * p<0.001$. Data are presented as mean \pm SEM. Scale bar: $20 \mu \mathrm{m}$. Additional information on the calculation of directional velocity is provided in Extended Data Figure 1-1 and Movie 9.

for P2Y12 KO; $444 \pm 23$ for PI3K $\gamma \mathrm{KO}$; Table 1c). Qualitatively, microglia seemed uniformly distributed throughout the cortex, and a nearest-neighbor analysis showed that the distribution of microglia throughout the cortex was not affected by the loss of PI3K $\gamma$ or P2Y12 (Fig. 2C; spacing index, $0.470 \pm 0.010$ for control; $0.485 \pm 0.004$ for P2Y12 KO; $0.483 \pm 0.006$ for PI3K $\gamma$ KO; Table 1d). To determine how PI3K $\gamma$ affects microglial morphology, we used high-resolution confocal microscopy to assess the branching complexity of microglia using Sholl analysis $[n$ (mice) $=5$ control, 7 P2Y12 KO, 8 PI3K $\gamma$ KO; Fig. 2D-G]. P2Y12 KO microglia showed a trend toward less ramification, as has been previously described (Sipe et al., 2016). A comparison of the maximum number of intersections (Fig. 2F; $26.73 \pm 0.65$ for control; $25.60 \pm 0.93$ for P2Y12 KO; $26.60 \pm 1.04$ for $\mathrm{PI} 3 \mathrm{~K} \gamma \mathrm{KO}$; Table 1e) or total number of intersections (Fig. 2G; $238 \pm 6$ for control; $214 \pm 8$ for P2Y12 KO; $231 \pm 10$ for $\mathrm{PI} 3 \mathrm{~K} \gamma \mathrm{KO}$; Table 1f) showed no differences across genotypes. The discrepancy between our results and those reported in Sipe et al., (2016) regarding the effects of P2Y12

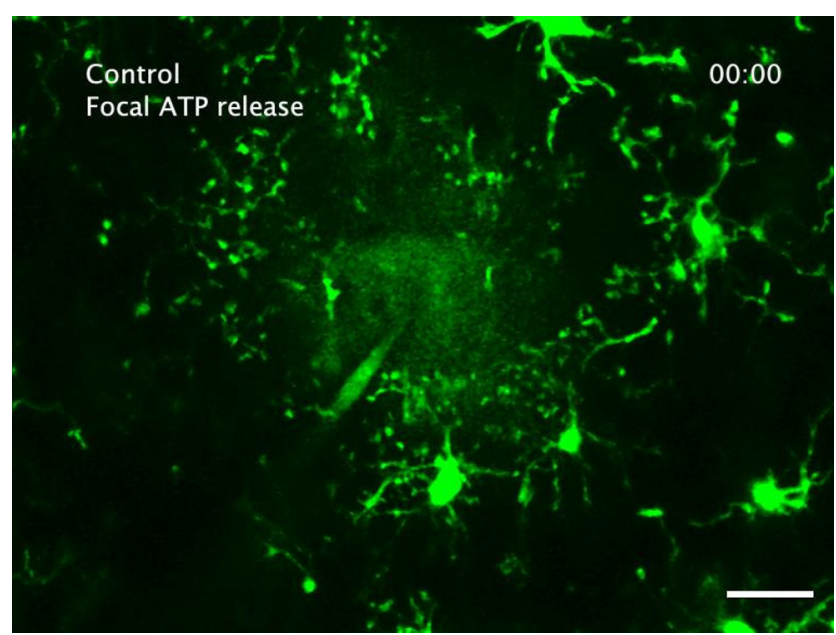

Movie 1. Related to Figure 1. Microglial response to focal ATP release and focal laser injury in a vehicle-treated (0.1\% DMSO) and wortmannin-treated $(5 \mu \mathrm{M})$ acute cortical slice. Scale bar: $20 \mu \mathrm{m}$. One frame per $1 \mathrm{~min}$. [View online]
$\mathrm{KO}$ on microglia morphology might be explained by slightly different imaging and analysis parameters. In this study, we were able to image very fine filopodial processes. If P2Y12 KO microglia have increased filopodial structures but decreased larger processes (possibly because of increased cAMP), increasing image resolution may lead to a normalization of the overall morphologic complexity as measured by Sholl analysis.

In addition to these static measures of microglia at baseline, we also characterized microglial surveillance of cortical layer $2 / 3$ using in vivo two-photon imaging through a chronic cranial window in $\mathrm{PI} 3 \mathrm{~K} \gamma \mathrm{KO}$ and $\mathrm{P} 2 \mathrm{Y} 12$ $\mathrm{KO}$ mice bred with Cx3cr1-EGFP mice to fluorescently label microglia $n$ (mice) $=9$ control, 5 P2Y12 KO, 5 PI3K $\gamma$ KO; Fig. 3; Movie 2). Although P2Y12 does not appear to be involved in baseline microglial dynamics (Haynes et al., 2006; Madry et al., 2018; Sipe et al., 2016), local production of PIP3 has been implicated in pseudopodia formation and dynamics in other cells (Insall, 2010). Thus, dynamics of the pseudopodia-like end tips of microglial processes may be affected by disruptions to $\operatorname{PI} 3 \mathrm{~K} \gamma$. There were no significant differences in the motility index, a composite measure of extension and retraction of microglial processes over time (Fig. $3 A$ ), between controls and either P2Y12 KO or PI3K $\gamma$ KO microglia (Fig. 3B; control $0.478 \pm 0.014 ; \mathrm{P} 2 \mathrm{Y} 12 \mathrm{KO} 0.520 \pm 0.003 ; \mathrm{PI} 3 \mathrm{~K} \gamma \mathrm{KO}$ $0.433 \pm 0.017$; Table 1g). Similarly, surveillance, a measurement of the total area covered by microglia and their processes over time, also showed no differences between control and either $\mathrm{P} 2 \mathrm{Y} 12 \mathrm{KO}$ or $\mathrm{PI} 3 \mathrm{~K} \gamma \mathrm{KO}$ groups (Fig. $3 C$; control $0.661 \pm 0.010$; P2Y12 KO $0.684 \pm 0.003$; $\mathrm{PI} 3 \mathrm{~K} \gamma \mathrm{KO} 0.641 \pm 0.012$; Table $1 \mathrm{~h})$. While PI3K $\gamma$ KO mice had statistically significant lower motility and surveillance relative to P2Y12 KO mice, the fact that neither group was different from control mice leads us to conclude that genetic loss of PI3K $\gamma$ did not have an effect on microglial dynamics under homeostatic conditions.

\section{PI3K $\gamma$ is not a predominant mediator of the response to focal ATP release ex vivo}

Next, we wanted to determine whether PI3K $\gamma$ is involved in mediating microglial P2Y12-dependent directed 

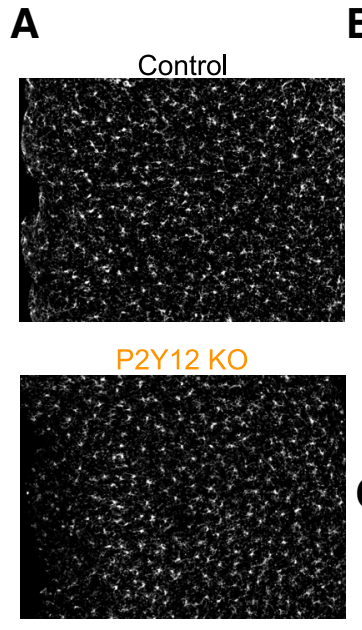

$\mathrm{Pl} 3 \mathrm{Kg} \mathrm{KO}$

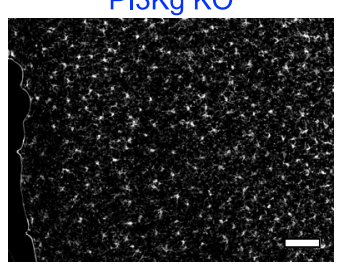

B
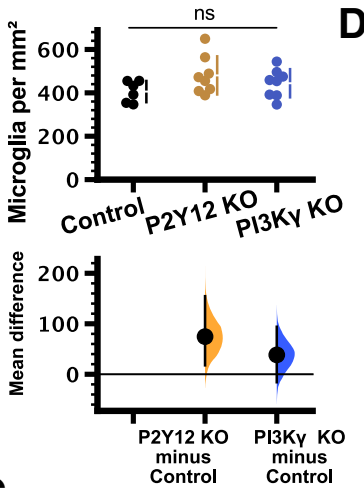

C

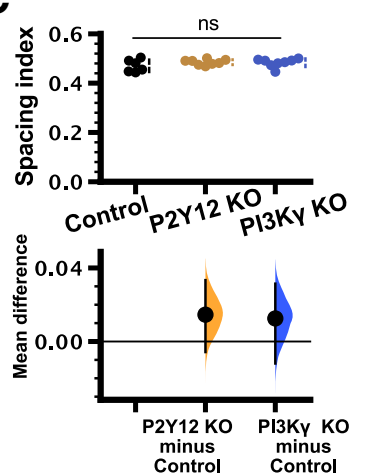

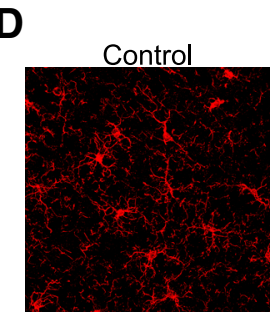

E
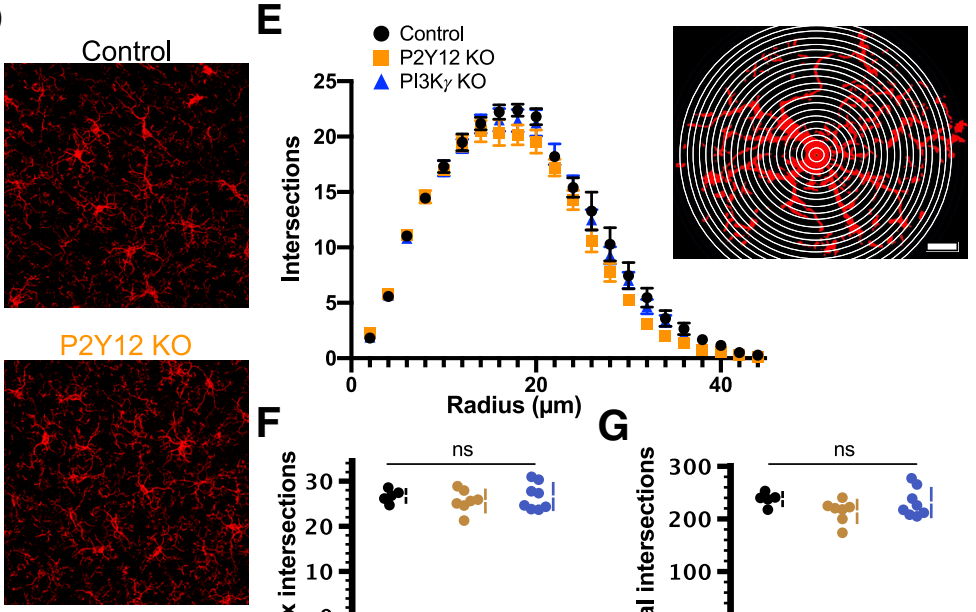

$\mathrm{PI} 3 \mathrm{Kg} \mathrm{KO}$
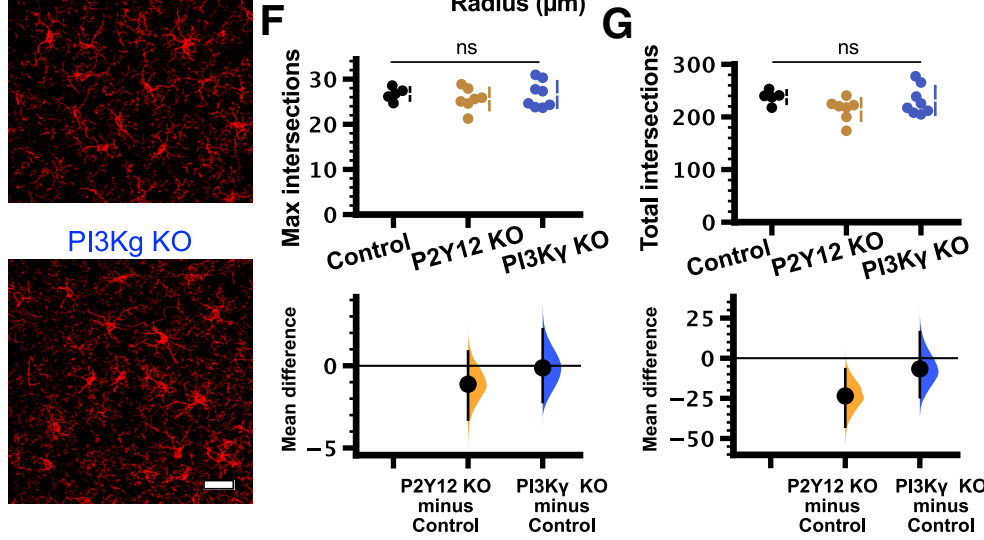

Figure 2. Microglial density, distribution, and morphology was unaffected in PI3K $\gamma$ KO mice. A, Representative $10 \times$ epifluorescent images of Iba1-stained microglia in V1 from C57BL/6 control (top), P2Y12 KO (middle), and PI3K $\gamma$ KO (bottom) mice (scale bar: $100 \mu \mathrm{m}$ ). The mean difference for comparisons against the shared control are shown in the Cumming estimation plots. The raw data are plotted on the upper axes. On the lower axes, mean differences are plotted as bootstrap sampling distributions. Each mean difference is depicted as a dot. Each $95 \% \mathrm{Cl}$ is indicated by the ends of the vertical error bars. Analysis of the number and location of microglial cell bodies [ $n$ (animals) $=5$ control; $7 \mathrm{P} 2 \mathrm{Y} 12 \mathrm{KO}$; $8 \mathrm{PI} 3 \mathrm{~K} \gamma \mathrm{KO}$ ] revealed no differences in either cell density [B; one-way ANOVA $p=0.18$; unpaired mean differences vs control: P2Y12 KO $74.6(95 \% \mathrm{Cl} 17.7,155)$; $\mathrm{PI} 3 \mathrm{~K} \gamma \mathrm{KO} 38.4(95 \% \mathrm{Cl}-15.7,94.1)]$ or the spacing index [C; one-way ANOVA $p=0.30$; unpaired mean differences vs control: P2Y12 $\mathrm{KO} 0.0146(95 \% \mathrm{Cl}-0.00574,0.0334)$; $\mathrm{PI} 3 \mathrm{~K} \gamma \mathrm{KO} 0.0125(95 \% \mathrm{Cl}-0.012,0.0315)]$. D, Representative $40 \times$ confocal images of lba1-stained microglia from the C57BL/6 control (top), P2Y12 KO (middle), and PI3K $\gamma$ KO (bottom) mice (scale bar: $30 \mu \mathrm{m}$ ). $\boldsymbol{E}-\boldsymbol{G}$, Analysis of the branching complexity by Sholl analysis. $\boldsymbol{E}$, Plot of the number of intersections as a function of radius showed no apparent differences between genotypes [14-38 microglia per animal; $n$ (animals) $=5$ control; 7 P2Y12 KO; 8 PI3K $\gamma$ KO]. Inset, Schematic showing a representative microglial cell and the concentric rings (radius increasing in increments of $2 \mu \mathrm{m}$ ) used to calculate the number of processes as a function of distance from the soma (scale bar: $10 \mu \mathrm{m}$ ). Comparisons of the maximum number of intersections $[\boldsymbol{F}$; one-way ANOVA $p=0.67$; unpaired mean differences vs control: P2Y12 KO $-1.12(95 \% \mathrm{Cl}-3.27,0.866)$; PI3K $\gamma \mathrm{KO}-0.128(95 \% \mathrm{Cl}-2.2,2.22)]$ and the total intersections [G; one-way ANOVA $p=0.19$; unpaired mean differences vs control: $\mathrm{P} 2 \mathrm{Y} 12 \mathrm{KO}-23.5(95 \% \mathrm{Cl}-42.6,-6.88)$; $\mathrm{PI} \mathrm{K} \gamma \mathrm{KO}-6.63(95 \% \mathrm{Cl}$ $-24.3,16.2)]$ showed no differences between genotypes; ns, non-significant. Data are presented as mean \pm SEM.

motility. Two-photon imaging of microglia in acutely-prepared brain slices is a valuable tool to investigate microglial dynamics and responses to exogenous stimuli. There are two major advantages to the ex vivo slice preparation that we took advantage of in this study: (1) the ability to test the direct microglial response to focal ATP release using a glass micropipette, and (2) the ability to pharmacologically manipulate receptors and signaling pathways via bath application of drugs (as exhibited for pan-PI3K inhibition in Fig. 1). Acutely-prepared cortical slices were preincubated with drug or vehicle for $\sim 15 \mathrm{~min}$. Imaging began immediately before release of focal ATP through the micropipette. Over the course of $\sim 30 \mathrm{~min}$, microglia responded to focal ATP release by directing processes to the tip of the ATP-containing pipette (Fig. 4A; Movie 3). Rhodamine was included in the pipette solution to visualize the expulsion of solution into the parenchyma.
As a positive control for our pharmacological experiments, we used the P2Y12 inhibitor elinogrel (2 $\mu \mathrm{m}$; Oestreich, 2010). Elinogrel treatment completely blocked the response to focal ATP release $[n$ (slices) $=4$ control, four elinogrel-treated; Fig. 4B,D-F; Movie 3], as demonstrated by negligible directional velocity (control $1.73 \pm$ 0.22 a.u.; elinogrel $0.07 \pm 0.11$ a.u.; Fig. $4 E$; Table 1i) and convergence (control $0.58 \pm 0.10$; elinogrel $0.11 \pm 0.04$; Fig. 4J; Table 1i). This was expected since directed motility to ATP has been shown to be entirely dependent on P2Y12 (Haynes et al., 2006). In addition, the actin polymerization inhibitor cytochalasin D $(1 \mu \mathrm{M})$ also completely blocked the response to ATP (Extended Data Fig. 4-2; Movie 10; Table 1y), confirming that this process is actin dependent. To inhibit PI3K $\gamma$ in slices, we used IPI-549 (1 $\mu \mathrm{M})$ because of its high potency and high selectivity (>100-fold) over other isoforms of PI3K (Evans et al., 2016; Kaneda et al., 2016). Pharmacological inhibition of 
A
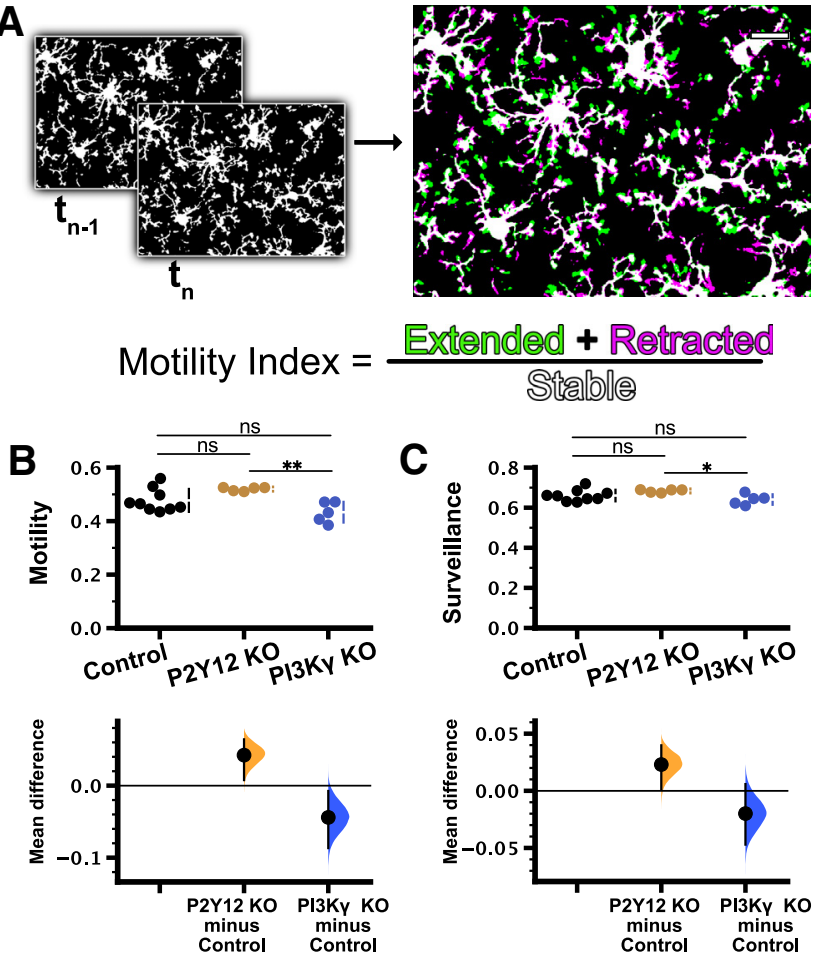

Figure 3. Microglial motility and surveillance were not affected in $\mathrm{PI} 3 \mathrm{~K} \gamma \mathrm{KO}$ mice. $\boldsymbol{A}$, Schematic illustrating the generation of the microglial motility index from time-lapse imaging (see Materials and Methods). B, C, Cumming estimation plots were used to show the mean differences between controls and experimental groups. $\boldsymbol{B}$, Motility in control mice was not significantly different from that in $\mathrm{P} 2 \mathrm{Y} 12 \mathrm{KO}$ or $\mathrm{PI} 3 \mathrm{~K} \gamma \mathrm{KO}$ mice, but significant differences were observed between P2Y12 KO and PI3K $\gamma$ KO groups (one-way ANOVA, $p=0.0060$; Tukey's test: control vs P2Y12KO $p=0.12$; control vs $\mathrm{PI} 3 \mathrm{~K} \gamma \mathrm{KO} p=0.10$; $\mathrm{P} 2 \mathrm{Y} 12 \mathrm{KO}$ vs $\mathrm{PI} 3 \mathrm{~K} \gamma \mathrm{KO} p=0.0043)$. Cumming estimation plot shows mean differences (lower axes) between controls and experimental groups [P2Y12 KO $0.0423(95 \% \mathrm{Cl} 0.00771,0.0642)$; PI3K $\gamma$ KO $-0.0441(95 \% \mathrm{Cl}-0.0867,-0.00742)]$. C, Similar to motility, surveillance in the control group was not different from that in either $\mathrm{P} 2 \mathrm{Y} 12 \mathrm{KO}$ or $\mathrm{PI} 3 \mathrm{~K} \gamma \mathrm{KO}$, but the surveillance of $\mathrm{PI3K} \gamma \mathrm{KO}$ microglia was lower than P2Y12 KO microglia (oneway ANOVA, $p=0.043$; Tukey's test: control vs P2Y12KO $p=0.24$; control vs PI3K $\gamma$ KO $p=0.34$; P2Y12 KO vs PI3K $\gamma$ KO $p=0.034)$. Mean differences versus controls shown in Cumming estimation plot [P2Y12 KO $0.023(95 \% \mathrm{Cl} 0.00123,0.0398)$; $\mathrm{PI} 3 \mathrm{~K} \gamma \mathrm{KO}-0.0199(95 \% \mathrm{Cl}-0.0471,0.00586)] . n$ (animals) $=9$ control; $5 \mathrm{P} 2 \mathrm{Y} 12 \mathrm{KO}$; $5 \mathrm{PI} 3 \mathrm{~K} \gamma \mathrm{KO}) ; \mathrm{ns}$, non-significant; $* p<0.05, * * p<0.01$. Data are presented as mean \pm SEM. Scale bar: $20 \mu \mathrm{m}$.

PI3K $\gamma$ had a modest effect on directional velocity [Fig. $4 H, I$; Movie 4; $n$ (slices) $=5$ control, four IPI-549 treated; average velocity: control $0.96 \pm 0.19$ a.u.; IPI-549 $0.38 \pm$ 0.08 ; Table 1j], but not convergence (Fig. 4J,K; max convergence: control $0.69 \pm 0.04$; IPI-549 $0.58 \pm 0.06$; Table $1 j)$, suggesting slightly impaired process recruitment. In parallel, we conducted similar experiments using $\mathrm{P} 2 \mathrm{Y} 12$ $\mathrm{KO}$; $\mathrm{C} \times 3 \mathrm{cr} 1-\mathrm{EGFP} /+$ or PI3K $\gamma \mathrm{KO}$; $\mathrm{C} \times 3 \mathrm{cr} 1-\mathrm{EGFP} /+$ mice and compared them to Cx3cr1-EGFP/+ animals. Consistent with our previous findings, the response of P2Y12 KO microglia to ATP was almost completely

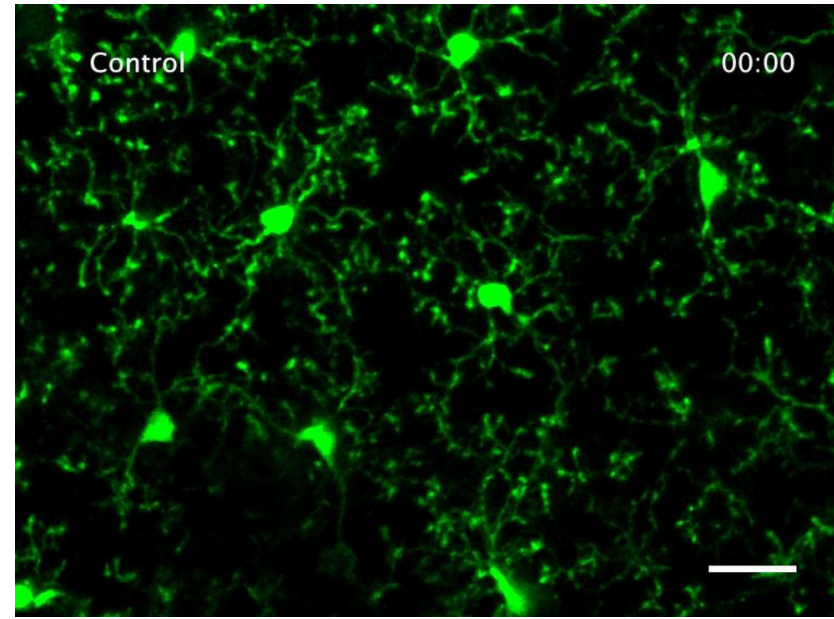

Movie 2. Related to Figure 3. In vivo time-lapse imaging of cortical layer $2 / 3$ microglia in the Cx3cr1-EGFP/+, P2Y12 KO Cx3cr1-EGFP/+, or PI3K $\gamma$ KO Cx3cr1-EGFP/+ mouse under baseline conditions through a chronic cranial window. Scale bar: $20 \mu \mathrm{m}$. One frame per $2 \mathrm{~min}$. [View online]

absent [Fig. 4L-O, orange; Movie 5; $n$ (animals) $=4$ control, $4 \mathrm{P} 2 \mathrm{Y} 12 \mathrm{KO}, 5 \mathrm{PI} 3 \mathrm{~K} \gamma \mathrm{KO}$. PI3K $\gamma \mathrm{KO}$ microglia had modestly decreased directional velocity (control $1.08 \pm 0.13 \mathrm{a}$. u.; P2Y12 KO $0.17 \pm 0.03$ a.u.; PI3K $\gamma$ KO $0.56 \pm 0.10$ a. u.; Fig. 4M; Table 1k), while the maximum convergence was not affected (Fig. $4 L-O$, blue; Movie 5; control $0.73 \pm 0.06 ; \mathrm{P} 2 \mathrm{Y} 12 \mathrm{KO} 0.13 \pm 0.02 ; \mathrm{PI} 3 \mathrm{~K} \gamma \mathrm{KO} 0.54 \pm$ 0.10 ; Fig. 4N; Table 11). Our results from both pharmacological and genetic manipulations show a subtle decrease in directional velocity when $\mathrm{PI} 3 \mathrm{~K} \gamma$ is inhibited, but the overall chemotactic response to ATP is still intact. This is in line with findings in peripheral immune cells showing that $\mathrm{PI} 3 \mathrm{~K} \gamma$ is not absolutely required for certain forms of chemotaxis, but may help to fine tune and amplify chemotactic processes (Afonso and Parent, 2011).

In addition to its activity as a lipid kinase, $\mathrm{PI} 3 \mathrm{~K} \gamma$ can also act as an A kinase anchoring protein (AKAP), forming a macromolecular complex with PKA and phosphodiesterase 3 (PDE3) to suppress cAMP signaling (Perino et al., 2011; Schmidt et al., 2013). Increasing microglial cAMP, either through inhibition of PDE3B (Bernier et al., 2019) or stimulation of Gs-coupled $\beta 2$-adrenergic receptors ( $\beta 2$ ARs; Liu et al., 2019; Stowell et al., 2019), leads to retraction of microglial processes. Thus, the observed effects of PI3K $\gamma$ blockade on directed microglial motility might be because of increased cAMP. To test this hypothesis, we used a pharmacological activator of adenylate cyclase (AC), forskolin (10 $\mu \mathrm{M}$; Swiatkowski et al., 2016) to globally increase cAMP in microglia. We found that forskolin had no significant effect on either directional velocity (control $0.73 \pm 0.14$; forsklin $0.41 \pm 0.08$; Extended Data Fig. 4$2 A, B$; Table $1 \mathrm{zz}$ ) or convergence (control $0.52 \pm 0.13$; forskolin $0.55 \pm 0.16$; Extended Data Fig. 4-2C,D; Movie 11; Table 1zz) of microglial processes to focal ATP release. These results suggest that CAMP signaling does not play a major role in regulating ATP-mediated directed motility and the effects of inhibition or deletion of $\mathrm{PI} 3 \mathrm{~K} \gamma$ are related to its kinase activity. 

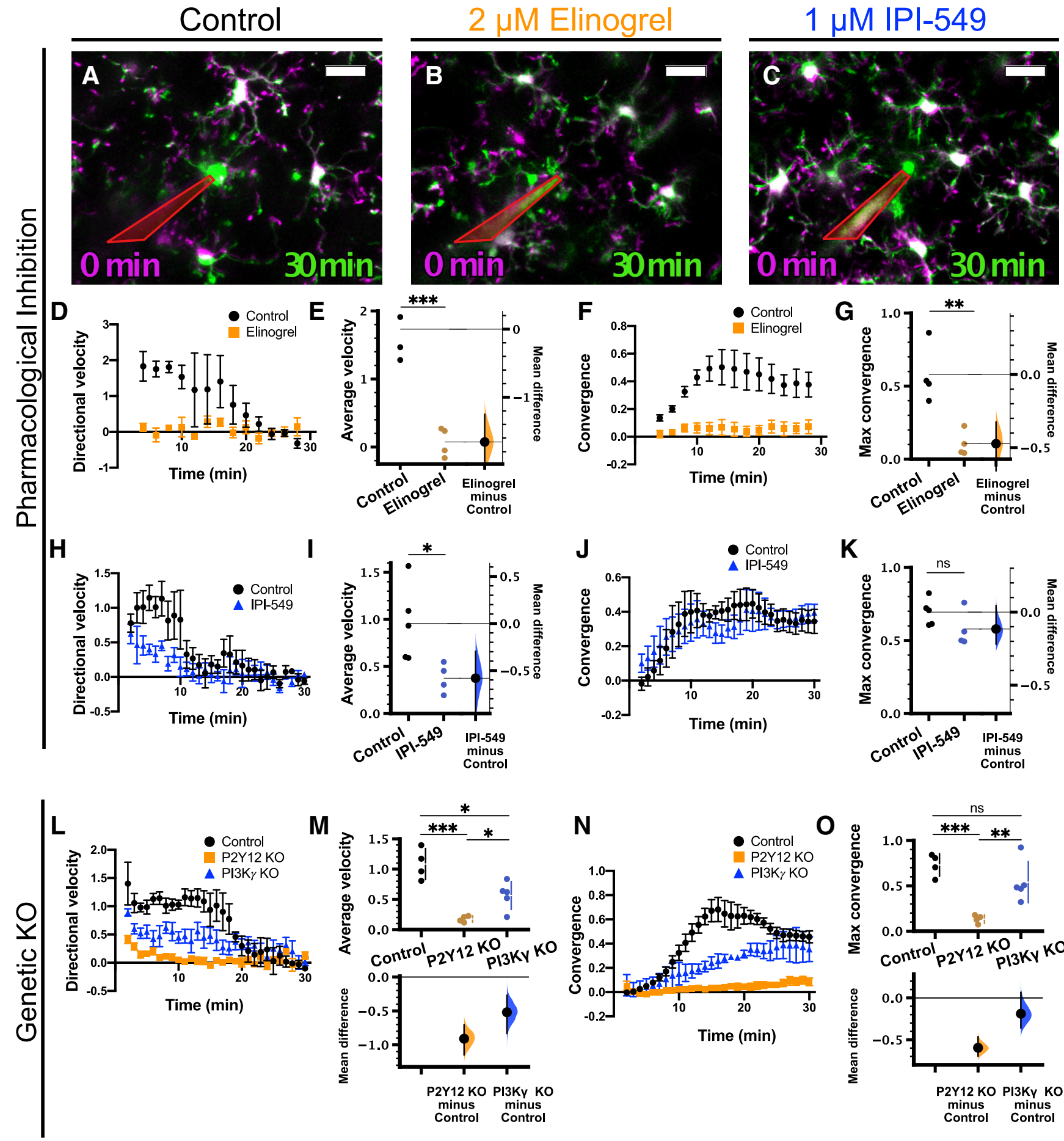

Figure 4. $\mathrm{PI} 3 \mathrm{~K} \gamma$ is not required for the microglial response to focal ATP release in acute cortical slices. Overlays of representative responses from control $(\boldsymbol{A}), 2 \mu \mathrm{M}$ elinogrel-treated (P2Y12 inhibitor; $\boldsymbol{B})$, and $1 \mu \mathrm{M}$ IPI-549-treated (PI3K $\gamma$ inhibitor; $\boldsymbol{C})$ slices at the time points indicated. Images at later time points (green) are overlaid with initial images ( $t=0$ min, magenta). In $\boldsymbol{A}-\boldsymbol{C}$, the pipette is outlined in red. $\boldsymbol{D}-\mathbf{G}$, Effects of $2 \mu \mathrm{m}$ elinogrel on the microglial response to focal ATP release $[n$ (slices) $=4 \mathrm{control}, 4$ elinogrel; from 4 animals total]. $\boldsymbol{D}$, Time course of directional velocity, with one frame acquired every 2 min. Quantification begins at $t=4$ min (two frames after puff) to avoid artifacts from the dye included in the pipette solution which leaks into the imaging field at earlier time points. $\boldsymbol{E}$, Elinogrel completely blocks the directional response [comparisons made on average velocity calculated in the interval of 4-10 min after ATP presentation; unpaired $t$ test, $p=0.0005$; mean difference is $-1.66(95 \% \mathrm{Cl}-2.11,-1.25)]$. $\boldsymbol{F}$, Time course of convergence. G, Elinogrel reduces the maximum convergence [unpaired $t$ test, $p=0.0048$; unpaired mean difference is -0.473 $(95 \% \mathrm{Cl}-0.708,-0.325)]$. $\boldsymbol{H}-\boldsymbol{K}$, Effects of $1 \mu \mathrm{M} \mathrm{IPI}-549$ on the microglial response to focal ATP release $[n$ (slices) $=5 \mathrm{control}, 4 \mathrm{IPI}-$ 549; from 5 animals total]. $\boldsymbol{H}$, Time course of directional velocity, with one frame acquired every minute. Quantification begins at $t=2 \mathrm{~min}$ (two frames after puff). I, IPI-549 partially reduces the directional response [comparisons made on average velocity 
continued

calculated in the interval of $2-10$ min after ATP puff; two-tailed $t$ test $p=0.031$; mean difference is $-0.581(95 \% \mathrm{Cl}-0.995,-0.296)]$. $\boldsymbol{J}$, Time course of convergence. $\boldsymbol{K}$, IPI-549 does not affect the maximum convergence [two-tailed $t$ test, $p=0.15$; mean difference is $-0.116(95 \% \mathrm{Cl}-0.219,0.0431)]$. $L-O$, Effects of P2Y12 KO (orange) or PI3K $\gamma$ KO (blue) on microglial response to focal ATP release in slices $[n$ (animals) $=4$ control; $4 \mathrm{P} 2 \mathrm{Y} 12 \mathrm{KO} ; 5 \mathrm{PI} 3 \mathrm{~K} \gamma \mathrm{KO}$. $\boldsymbol{L}$, Time course of directional velocity with one frame acquired every 1 min. $\boldsymbol{M}, \mathrm{P} 2 \mathrm{Y} 12 \mathrm{KO}$ and PI3K $\gamma \mathrm{KO}$ reduce the directional velocity compared with control [comparisons made on average velocity calculated in the interval of 2-10 min after ATP presentation; one-way ANOVA $p=0.0003$; Tukey's test: control vs P2Y12 KO $p=0.0002$; control vs PI3K $\gamma$ KO $p=0.0089$; P2Y12 KO vs PI3K $\gamma$ KO $p=0.042$; mean differences vs controls: $\mathrm{P} 2 \mathrm{Y} 12 \mathrm{KO}-0.909$ (95\% Cl -1.15, -0.706); PI3K $\gamma \mathrm{KO}-0.52(95 \% \mathrm{Cl}-0.832,-0.27)]$, although the magnitude of the effect is larger in P2Y12 KOs. $\mathbf{N}$, Time course of convergence. $\mathbf{O}, \mathrm{P} 2 \mathrm{Y} 12 \mathrm{KO}$ decreases maximum convergence, while PI3K $\gamma \mathrm{KO}$ does not affect maximum convergence [one-way ANOVA $p=0.0011$; Tukey's test: control vs P2Y12 KO $p=0.0010$; control vs PI3K $\gamma$ KO $p=0.23$; P2Y12 KO vs $\mathrm{PI} 3 \mathrm{~K} \gamma \mathrm{KO} p=0.0090$; mean differences vs controls: P2Y12 KO $-0.596(95 \% \mathrm{Cl}-0.693,-0.465)$; PI3K $\gamma \mathrm{KO}-0.189(95 \% \mathrm{Cl}$ $-0.358,0.0652)$; $n s$, non-significant; $* p<0.05, * * p<0.01, * * * p<0.001$. Data presented as mean \pm SEM. Scale bar: $20 \mu \mathrm{m}$. Additional data on the effects of inhibition of actin polymerization or activation of AC on directed microglial motility are presented in Extended Data Figures 4-1, 4-2, respectively.

\section{PI3K $\gamma$ is not a predominant mediator of the focal damage response}

We also analyzed the microglial response to focal laser injury using the directional velocity and convergence analyses. Although microglial responses to focal injury and direct application of ATP are likely influenced by different extracellular cues, both responses involve the rapid movement of microglial processes toward the site of injury in a P2Y12-dependent manner (Haynes et al., 2006). We first repeated our pharmacological and genetic manipulations to disrupt $\mathrm{P} 2 \mathrm{Y} 12$ and $\mathrm{PI} 3 \mathrm{~K} \gamma$ function in acute brain slices and observed the effects on microglial directed motility toward the ablation. As expected, the recruitment of microglial processes to the injury core was dependent on actin remodeling, and treatment with cytochalasin D blocked microglial directed motility (Extended Data Fig. 4-2; Movie 10; Table 1z). Inhibition with elinogrel $(2 \mu \mathrm{M})$ or genetic deletion of P2Y12 also completely abolished the microglial response (Fig. 5, orange; Movies 6, 7), as expected from our experiments with focal ATP application and previous experiments in the literature. The role of $\mathrm{PI} 3 \mathrm{~K} \gamma$ was less pronounced. PI3K $\gamma$ inhibition with

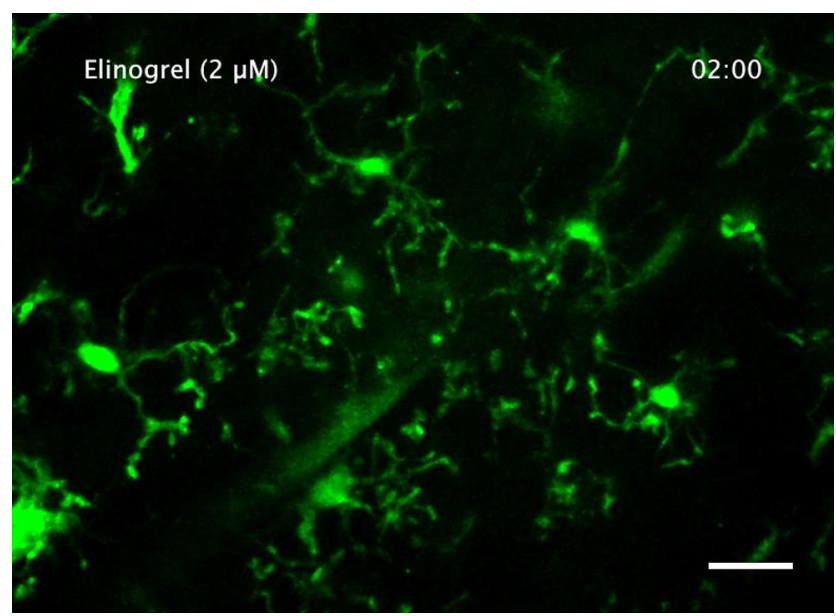

Movie 3. Related to Figure 4. Effect of pharmacological inhibition of P2Y12 with $2 \mu \mathrm{m}$ elinogrel on microglial response to focal ATP release in an acute cortical slice. Scale bar: $20 \mu \mathrm{m}$. One frame per 2 min. [View online]
IPI-549 (1 $\mu \mathrm{M}$; Fig. 5, blue; Movies 6, 7) had an intermediate effect on both directional velocity (control $0.65 \pm 0.10$ a.u.; elinogrel $-0.22 \pm 0.06$ a.u.; IPI-549 treatment $0.18 \pm$ 0.09 a.u.; Table $1 \mathrm{~m}$ ) and convergence (control $0.096 \pm 0.015$; elinogrel $-0.063 \pm 0.010$; IPI-549 $0.009 \pm 0.018$; Table 1n), while $\mathrm{PI} 3 \mathrm{~K} \gamma \mathrm{KO}$ microglia showed a slightly decreased directional velocity (control $0.99 \pm 0.15$ a.u.; P2Y12 KO $0.13 \pm 0.10$ a.u.; PI3K $\gamma$ KO $0.54 \pm 0.36$ a.u.; Table 10) without an effect on convergence (control $0.091 \pm 0.015$; P2Y12 $\mathrm{KO}-0.017 \pm 0.025$; PI3K $\gamma$ KO $0.086 \pm 0.016$; Table 1p).

We then examined the microglial response to focal injury in vivo, imaging layer $2 / 3$ cortical microglia through a chronic cranial window. Interestingly, microglial responses to injury were slower and more sustained in vivo when compared with those in acute slices (Figs. 5 vs 6) suggesting either changes in microglial function after acute slice preparation, or in chemotactic gradients and injury. We therefore monitored the microglial response for $1 \mathrm{~h}$ after injury was induced, to fully capture the chemotactic response $[n$ (animals) $=11$ control, 6 P2Y12 KO, 7 $\mathrm{PI} 3 \mathrm{~K} \gamma \mathrm{KO}$. Consistent with the results of our previous ex vivo experiments, rapid convergence (at $30 \mathrm{~min}$ ) was impaired in the P2Y12 KO animals, but not in the $\mathrm{PI} 3 \mathrm{~K} \gamma \mathrm{KO}$

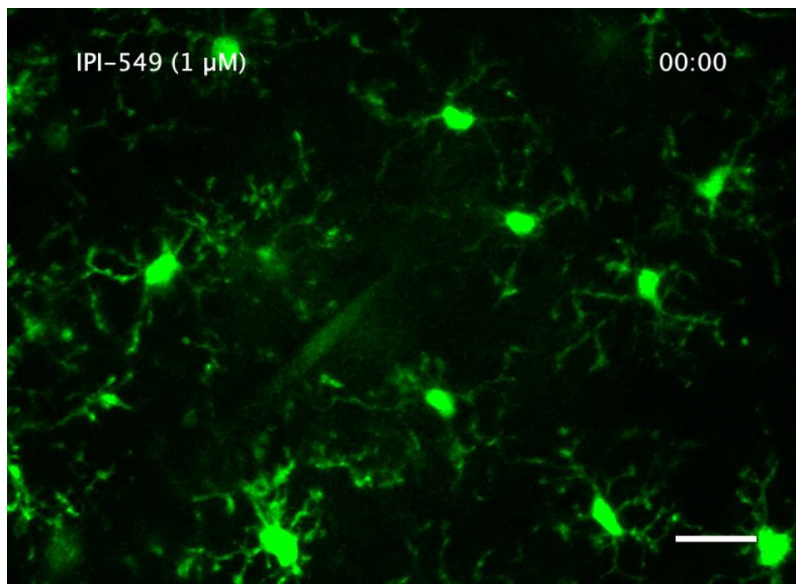

Movie 4. Related to Figure 4. Effect of pharmacological inhibition of PI3K $\gamma$ with $1 \mu \mathrm{M} \mathrm{IPI-549} \mathrm{on} \mathrm{microglial} \mathrm{response} \mathrm{to} \mathrm{focal}$ ATP release in an acute cortical slice. Scale bar: $20 \mu \mathrm{m}$. One frame per $1 \mathrm{~min}$. [View online] 


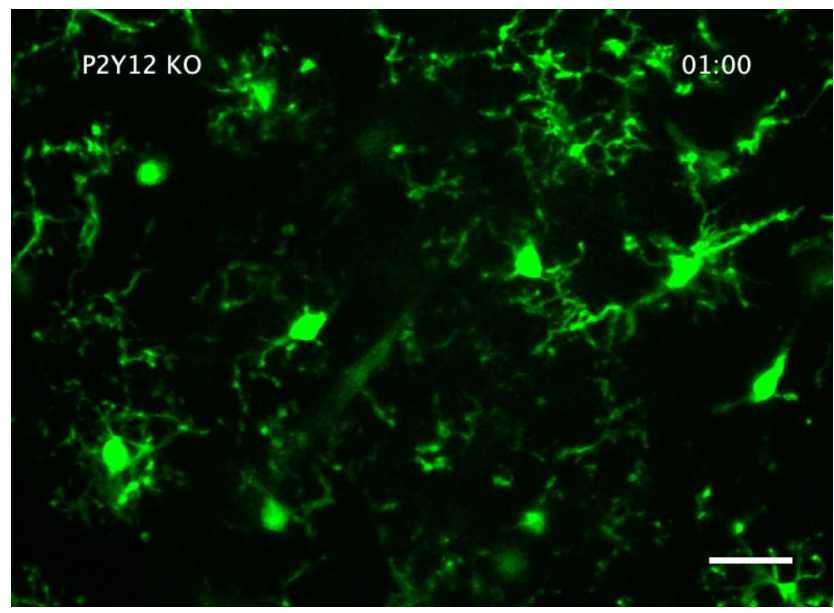

Movie 5. Related to Figure 4. Effects of genetic KO of P2Y12 or $\mathrm{PI} 3 \mathrm{~K} \gamma$ on microglia response to focal ATP release in an acute cortical slice. Scale bar: $20 \mu \mathrm{m}$. One frame per $1 \mathrm{~min}$. [View online]

animals (Fig. 6D,E; Movie 8; control $0.296 \pm 0.036$; P2Y12 $\mathrm{KO} 0.033 \pm 0.062 ; \mathrm{PI} 3 \mathrm{~K} \gamma \mathrm{KO} 0.370 \pm 0.049$; Table 1q). By the end of the imaging session, the P2Y12 KO microglia did converge around the injury site (Fig. 6F; convergence at $62 \mathrm{~min}$ : control $0.335 \pm 0.032$; P2Y12 KO $0.277 \pm$ 0.057 ; PI3K $\gamma$ KO $0.441 \pm 0.043$; Table 1r), consistent with previous findings that the $\mathrm{P} 2 \mathrm{Y} 12$-independent response is much slower than the response mediated by P2Y12 (Haynes et al., 2006). The in vivo response to focal injury was more robust and complex than in acute brain slices, as evidenced by a much larger magnitude of convergence, possibly because of the absence of confounding injury signals from the slicing procedure and restricted diffusion in the intact brain. We therefore more closely analyzed the relationship between the directional velocity, time, and distance from the injury site to tease out the involvement of $\mathrm{P} 2 \mathrm{Y} 12$ and $\mathrm{PI} 3 \mathrm{~K} \gamma$ in different aspects of the response (Extended Data Fig. 6-1). In control animals, there was an initial wave of coordinated process movement, in which processes were recruited from an area relatively proximal to the injury (within $\sim 45 \mu \mathrm{m}$ ) and converged on the ablation core in $\sim 20-30 \mathrm{~min}$. However, there was also considerable process movement farther from the injury site $(>50 \mu \mathrm{m})$ that had a different dynamic profile, was sustained throughout the imaging session and persisted beyond the time when convergence had plateaued. Thus, in our comparisons across genotypes, we separated out the directional velocity by distance from the center to capture these complex dynamics (magenta vs cyan; Fig. 6G-L). Surprisingly, we found a high directional velocity in the P2Y12 KO animals (average velocity $<50 \mu \mathrm{m}$ from injury site: $10-20 \mathrm{~min}$ : control $02.34 \pm 0.32$ a.u.; P2Y12 KO $1.29 \pm 0.20$ a.u.; PI3K $\gamma$ KO $1.77 \pm 0.23$ a. u; Table 1s; 34-62 min: control $0.34 \pm 0.03$ a.u.; P2Y12 $\mathrm{KO} 0.75 \pm 0.09$ a.u.; PI3K $\gamma \mathrm{KO} 0.33 \pm 0.06$ a.u.; Table 1t). $\mathrm{P} 2 \mathrm{Y} 12 \mathrm{KO}$ microglial processes oriented and moved toward the focal injury especially during the early response, but their convergence was impaired. Likely because of this impaired convergence, the long-range directional velocity in $\mathrm{P} 2 \mathrm{Y} 12 \mathrm{KO}$ microglia was higher than control or PI3K $\gamma$ KO groups (Fig. $6 \mathrm{~J}-L$; average velocity $50-75 \mu \mathrm{m}$ from injury site: $10-20 \mathrm{~min}$ : control $0.96 \pm 0.09$ a.u.; P2Y12 KO $1.46 \pm 0.17$ a.u.; PI3K $\gamma$ KO $0.41 \pm 0.10$ a.u.; Table 1u; 34-62 min: control $0.62 \pm 0.04$ a.u.; P2Y12 KO $0.83 \pm 0.08$ a.u.; PI3K $\gamma$ KO $0.40 \pm 0.06$ a.u.; Table 1v), as the initially responsive microglial processes remained farther away from the center. These differences in the spatiotemporal dynamics of the response in the P2Y12 KO mice can be appreciated by examining the plot of directional velocity as a function of both time and distance from the injury site (Extended Data Fig. 6-1B). Accompanying these dynamics, there was a change in the appearance of the microglial process end tips, which become broader as they approach the injury site. This underscores the fact that P2Y12 KO microglia were still able to react to the tissue damage, although in a substantially impaired manner. For the PI3K $\gamma \mathrm{KO}$ animals, the directional velocity within $50 \mu \mathrm{m}$ was not different from control animals (Fig. 6G-l). However, the recruitment of more distant processes appeared to be impaired, as demonstrated by a decreased directional velocity $>50 \mu \mathrm{m}$ from the injury that was persistent over the course of $60 \mathrm{~min}$ (Fig. $6 \mathrm{~J}-L$ ). Our in vivo data suggest that while the overall response to focal injury is not impaired in $\mathrm{PI} 3 \mathrm{~K} \gamma \mathrm{KO}$ mice, there are subtle defects in long-range process recruitment, where the chemotactic signals are likely weaker than in proximal areas.

Overall, inhibition or absence of $\mathrm{PI} 3 \mathrm{~K} \gamma$ caused subtle defects in microglial process recruitment toward sources of ATP. Given the effects of pharmacological inhibition or genetic KO experiments were similar across multiple experimental paradigms, $\mathrm{PI} 3 \mathrm{~K} \gamma$ likely plays a minor role in ATP-mediated directed microglial motility.

\section{PI3K $\gamma$ is not required for ocular dominance plasticity}

We observed a subtle defect in process recruitment when PI3K $\gamma$ was inhibited or genetically deleted. However, these experiments involve either exogenous ATP or pathologic injury and thus likely involve high levels of P2Y12 signaling. Thus, we sought to determine whether $\mathrm{PI} 3 \mathrm{~K} \gamma$ is required for critical-period ocular dominance plasticity, a P2Y12-dependent process (Sipe et al., 2016) that is widely used as a model of physiological experience-dependent synaptic plasticity with neuronal mechanisms resembling long-term potentiation and depression (Cooke and Bear, 2014). The mouse binocular primary visual cortex (V1b) receives stronger inputs from the contralateral eye than the ipsilateral eye, thus giving it a positive ODI (see Materials and Methods). However, during a critical period in adolescence ( P25P35), 4D MD of the contralateral eye causes a shift in the ODI toward zero because of depression of the contralateral response (Gordon and Stryker, 1996; Kalatsky and Stryker, 2003). This shift is absent in P2Y12 KO animals and when P2Y12 signaling is inhibited pharmacologically (Sipe et al., 2016). To determine whether loss of PI3K $\gamma$ also disrupted ocular dominance plasticity, we monocularly deprived $\mathrm{PI} 3 \mathrm{~K} \gamma \mathrm{KO}$ mice for $4 \mathrm{~d}$ and used IOS imaging to monitor the cortical responses to visual stimulation of each eye independently (Fig. 7). We found that PI3K $\gamma$ KO mice demonstrated a significant shift in ODI after 4D MD [Fig. 7C; 


\section{Control}
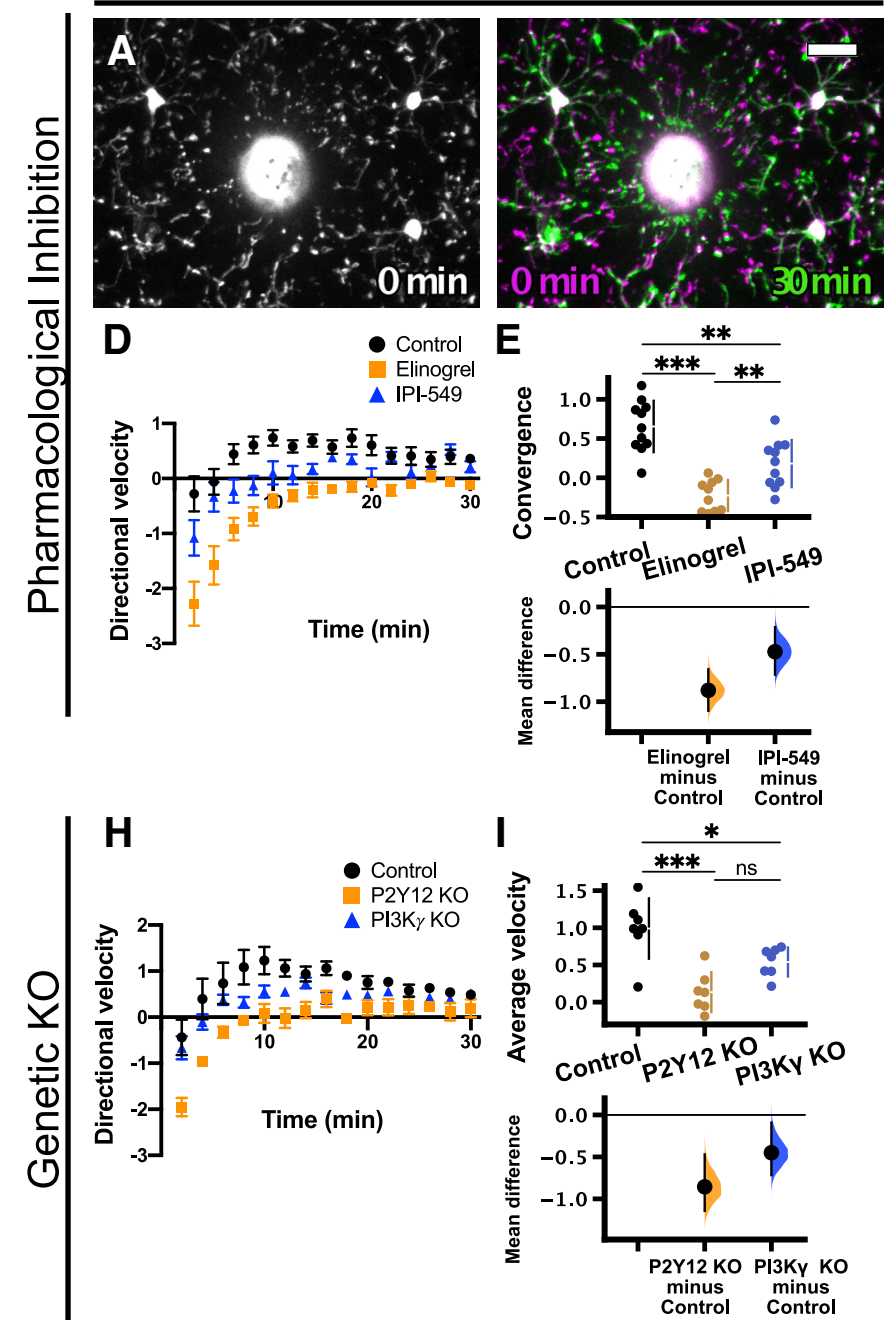

2 uM Elinogrel

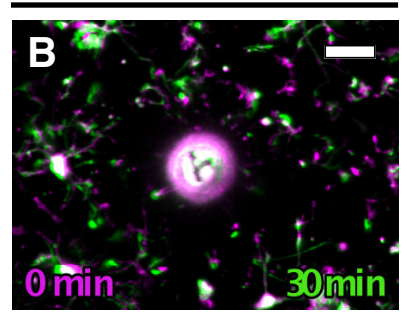

$\mathbf{F}$

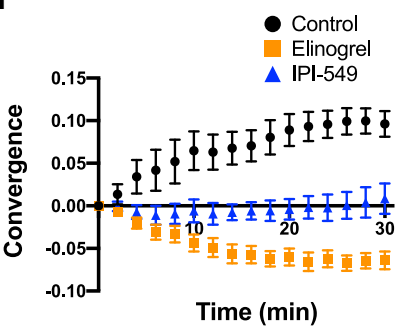

J

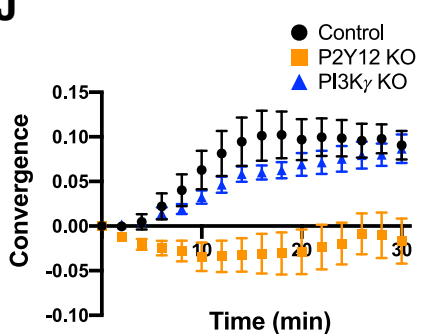

$1 \mu \mathrm{M}$ IPI-549

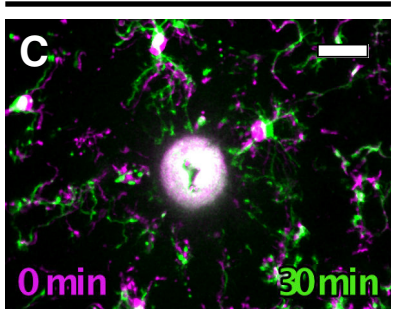

G

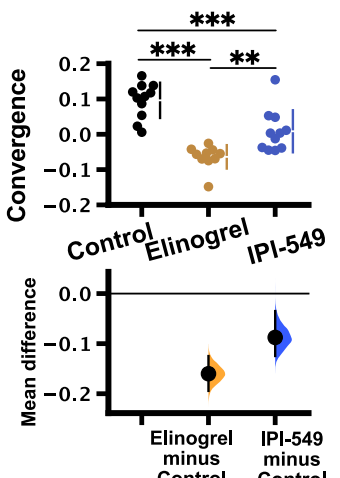

K

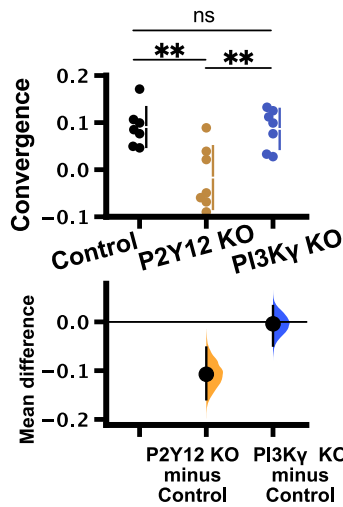

Figure 5. PI3K $\gamma$ is not required for the microglial response to laser injury in acute cortical slices. Representative images of the microglial response to laser injury in control $(\boldsymbol{A}), 2 \mu \mathrm{m}$ elinogrel-treated (P2Y12 inhibitor; $\boldsymbol{B}$ ), and $1 \mu \mathrm{M}$ IPI-549-treated $(\mathrm{PI} 3 \mathrm{~K} \gamma$ inhibitor; $\boldsymbol{C})$ slices at the time points indicated. Images at $30 \mathrm{~min}$ after injury (green) are overlaid with initial images ( $t=0 \mathrm{~min}$, magenta). $\boldsymbol{D}-\mathbf{G}$, Effects of $2 \mu \mathrm{m}$ elinogrel (orange squares) or $1 \mu \mathrm{M}$ IPI-549 (blue triangles) on the microglial response to laser injury [ $n$ (slices) $=11$ control, 10 elinogrel, 11 IPI-549 from 11 animals total]. $\boldsymbol{D}$, Time course of directional velocity, one frame every $2 \mathrm{~min}$. Note that the negative directional velocity that occurs soon after ablation is an artifact of tissue deformation following the laser injury. $\boldsymbol{E}$, IPI-549 partially inhibits the directional response, whereas elinogrel completely blocks it [average velocity quantified at the interval of 10-20 min after injury; one-way ANOVA $p<0.0001$; Tukey's test: control vs elinogrel $p<0.0001$; control vs IPI-549 $p=0.0014$; elinogrel vs IPI-549 $p=0.0071$; mean differences vs controls: elinogrel $-0.88(95 \% \mathrm{Cl}-1.1,-0.659) ; \mathrm{IPI}-549-0.472(95 \% \mathrm{Cl}-0.715,-0.214)]$. $\boldsymbol{F}$, Time course for convergence. $\mathbf{G}$, IPI-549 has an intermediate effect on convergence at $30 \mathrm{~min}$, while elinogrel completely blocks convergence [one-way ANOVA $p<0.0001$; Tukey's test: control vs elinogrel $p<0.0001$; control vs IPI-549 $p=0.0007$; elinogrel vs IPI-549 $p=0.0059$; mean differences vs controls: elinogrel $-0.16(95 \% \mathrm{Cl}-0.194,-0.125)$; IPI-549 $-0.0876(95 \% \mathrm{Cl}-0.125,-0.035)]$. $\boldsymbol{H}-\boldsymbol{K}$, Effects of $\mathrm{P} 2 \mathrm{Y} 12 \mathrm{KO}$ (orange) or $\mathrm{PI} 3 \mathrm{~K} \gamma \mathrm{KO}$ (blue) on microglial response to focal injury [ $n$ (animals) $=7 \mathrm{control}, 7 \mathrm{P} 2 \mathrm{Y} 12 \mathrm{KO}, 7 \mathrm{PI} 3 \mathrm{~K} \gamma$ $\mathrm{KO}$ ]. $\boldsymbol{H}$, Time course for directional velocity. I, P2Y12 KO and PI3K $\gamma$ KO reduce the directional velocity compared with control [comparison based on average velocity in the interval of 10-20 min after injury; one-way ANOVA $p=0.0002$; Tukey's test: control vs P2Y12 KO $p=0.0001$; control vs PI3K $\gamma$ KO $p=0.031$; P2Y12 KO vs PI3K $\gamma$ KO $p=0.054$; mean differences vs controls: P2Y12 KO $-0.856(95 \% \mathrm{Cl}-1.14,-0.47)$; PI3K $\gamma \mathrm{KO}-0.45(95 \% \mathrm{Cl}-0.717,-0.0926)]$. J, Time course for convergence. $K$, P2Y12 KO decreases convergence at $30 \mathrm{~min}$, while PI3K $\gamma$ KO has no effect [one-way ANOVA $p=0.0014$; Tukey's test: control vs P2Y12 KO $p=0.0030$; control vs PI3K $\gamma$ KO $p=0.99$; P2Y12 KO vs PI3K $\gamma$ KO $p=0.0041$; mean differences vs control: P2Y12 KO $-0.107(95 \% \mathrm{Cl}-0.159,-0.0526)$; PI3K $\gamma \mathrm{KO}-0.00402(95 \% \mathrm{Cl}-0.0487$, 0.0325)]; ns, non-significant; $* p<0.05, * * p<0.01, * * * p<0.001$. Data presented as mean \pm SEM. Scale bar: $20 \mu \mathrm{m}$. 


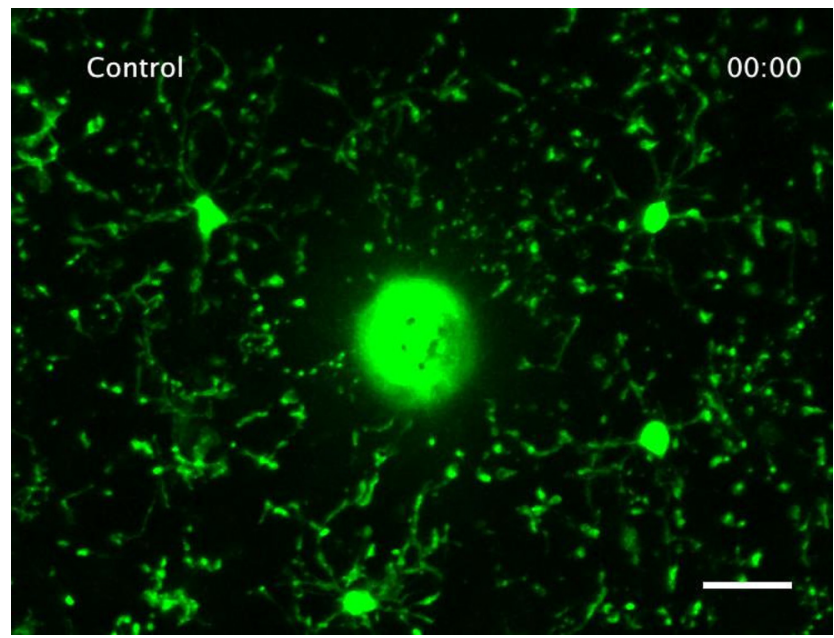

Movie 6. Related to Figure 5. Effects of pharmacological inhibition of P2Y12 (with $2 \mu \mathrm{m}$ elinogrel) or PI3K $\gamma$ (with $1 \mu \mathrm{M}$ IPI-549) on the microglial response to focal laser injury in an acute cortical slice. Scale bar: $20 \mu \mathrm{m}$. One frame per $2 \mathrm{~min}$. [View online]

Extended Data Figs. 7-1, 7-2; genotype ( $n$ animals) ODI: WT ND $(n=6) 0.26 \pm 0.04$; WT 4DMD $(n=7) 0.04 \pm 0.05$; PI3K $\gamma$ KO ND $(n=6) \quad 0.30 \pm 0.05 ; \mathrm{PI} 3 \mathrm{~K} \gamma$ KO 4DMD $(n=13)$ $0.15 \pm 0.05$; Table $1 \mathrm{w}]$, although the magnitude of the shift appeared to be qualitatively smaller than that in control C57BI/6 mice.

While PI3K $\gamma$ expression is largely restricted to microglia in the CNS as assessed by RNAseq of acutely isolated cells (Zhang et al., 2014), there is evidence that it is also expressed in subsets of neurons (Kim et al., 2011; D'Andrea et al., 2015). ODP is a complex process involving the coordinated activity of inhibitory and excitatory neurons (Kuhlman et al., 2013) and is influenced by neuromodulators (Stowell et al., 2019). Thus, global KO of $\mathrm{PI} 3 \mathrm{~K} \gamma$ could have unintended effects in the context of ODP. In order to preserve any non-microglial $\mathrm{PI} 3 \mathrm{~K} \gamma$

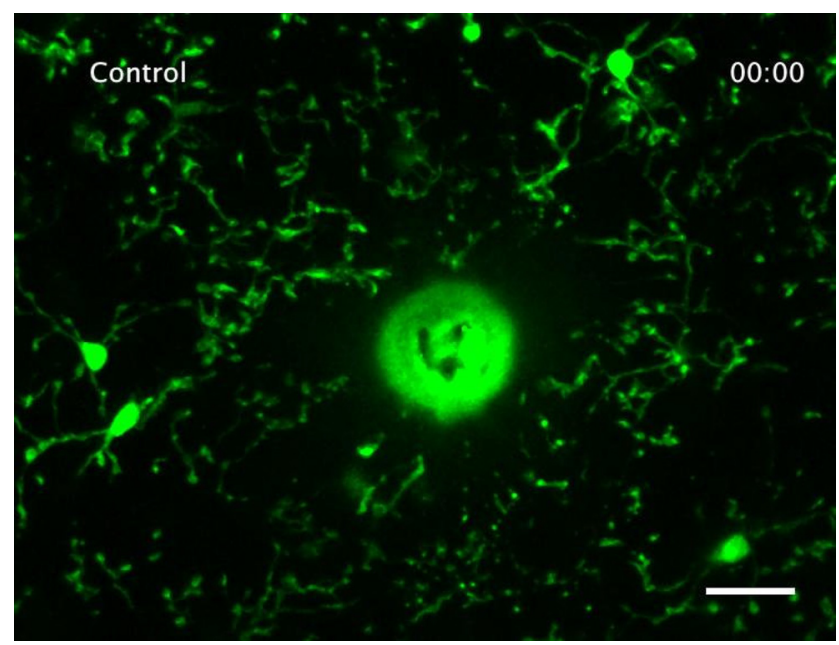

Movie 7. Related to Figure 5. Effects of genetic KO of P2Y12 or $\mathrm{PI} 3 \mathrm{~K} \gamma$ on the microglial response to focal laser injury in an acute cortical slice. Scale bar: $20 \mu \mathrm{m}$. One frame per $2 \mathrm{~min}$. [View online] signaling and prevent any compensation mechanisms that may be activated in early development because of a global KO, we crossed the PI3K $\gamma$ floxed mouse (PI3K $\gamma$-fl/ fl) with the Cx3cr1-CreERT2 mouse to generate a microglial-specific $\mathrm{PI} 3 \mathrm{~K} \gamma \mathrm{KO}$ mouse line (Cx3cr1-Cre/+; $\mathrm{PI} 3 \mathrm{~K} \gamma$ $\mathrm{fl} / \mathrm{fl})$. Cre-mediated excision of $\mathrm{PI} 3 \mathrm{~K} \gamma$ was initiated by three daily doses of tamoxifen delivered via oral gavage on P2-P4. We subjected these microglia-specific PI3K $\gamma$ $\mathrm{KO}$ mice to $4 \mathrm{D} \mathrm{MD}$ and measured the cortical responses to visual stimuli with IOS imaging (Fig. 7D; Extended Data Fig. 7-2C,D). We found that tamoxifen-treated Cx3cr1Cre/+ control mice showed a significant shift in the ODI following 4D MD. In tamoxifen-treated Cx3cr1-Cre/+; $\mathrm{PI} 3 \mathrm{~K} \gamma \mathrm{fl} / \mathrm{fl}$ mice, 4D MD decreased the ODI compared with the ND group, but this was not statistically significant after correction for multiple comparisons [genotype ( $n$ animals) ODI: Cx3cr1-Cre/+ ND $(n=5) 0.29 \pm 0.04$; Cx3cr1$\mathrm{Cre} /+4 \mathrm{DMD}(n=6) 0.06 \pm 0.07 ; \mathrm{C} \times 3 \mathrm{cr} 1-\mathrm{Cre} /+\mathrm{PI} 3 \mathrm{~K} \gamma \mathrm{fl} / \mathrm{fl}$ ND $(n=6) 0.23 \pm 0.03 ; \mathrm{Cx} 3 \mathrm{cr} 1-\mathrm{Cre} /+\mathrm{PI} 3 \mathrm{~K} \gamma$ fl/fl 4DMD $(n=7) 0.13 \pm 0.06$; Table $1 \mathrm{x}]$. This suggests that MD-induced ODI shifts may still occur in these mice but may be less robust than when $\mathrm{PI} 3 \mathrm{~K} \gamma$ is present in microglia.

Thus, the results from both the global and microgliaspecific $\mathrm{PI} 3 \mathrm{~K} \gamma \mathrm{KO}$ are similar: in the absence of $\mathrm{PI} 3 \mathrm{~K} \gamma$, ODI shifts still occurred following monocular deprivation, but were not as prominent as in control animals. We conclude that $\mathrm{PI} 3 \mathrm{~K} \gamma$ is not required for ocular dominance plasticity, although its activity may regulate some aspects of plasticity and thus its absence may have subtle effects.

\section{Discussion}

Many recent studies have shown that the $G_{i}$-coupled receptor P2Y12 mediates microglia-neuron interactions in both physiological and pathologic contexts (Eyo et al., 2014; Sipe et al., 2016; Fekete et al., 2018; Zhang and Li, 2019; Cserép et al., 2020). P2Y12 mediates the microglial chemotactic response to exogenous ATP in vitro, ex vivo, and in vivo (Haynes et al., 2006), suggesting that ATP may be released by neurons or glia to attract microglial processes via P2Y12 activation. Despite the breadth of research on the many functional roles of P2Y12 in the CNS, relatively little is known about the intracellular signaling that mediates these P2Y12-dependent processes in microglial cells when they perform their regular functions. In this study, we sought to interrogate the role of $\mathrm{PI} 3 \mathrm{~K} \gamma$ as a putative downstream effector of P2Y12 in both ATPmediated microglial directed motility and experience-dependent synaptic plasticity. Understanding the mechanisms underlying P2Y12 signaling in microglia can provide insight into how extracellular nucleotides are used in the CNS to facilitate communication and interactions between diverse cell types.

\section{PI3K $\gamma$ in microglia}

We investigated $\mathrm{PI} 3 \mathrm{~K} \gamma$ as a possible downstream mediator of P2Y12 signaling because of its activation by $\mathrm{G} \beta \gamma$, which drives many chemotactic pathways downstream of $G_{i}$ activation (Lin and Smrcka, 2011). Thus, $\mathrm{PI} 3 \mathrm{~K} \gamma$ could serve as a link between G-protein activation and a variety of downstream regulators of chemotaxis 
Cx3cr1-EGFP control
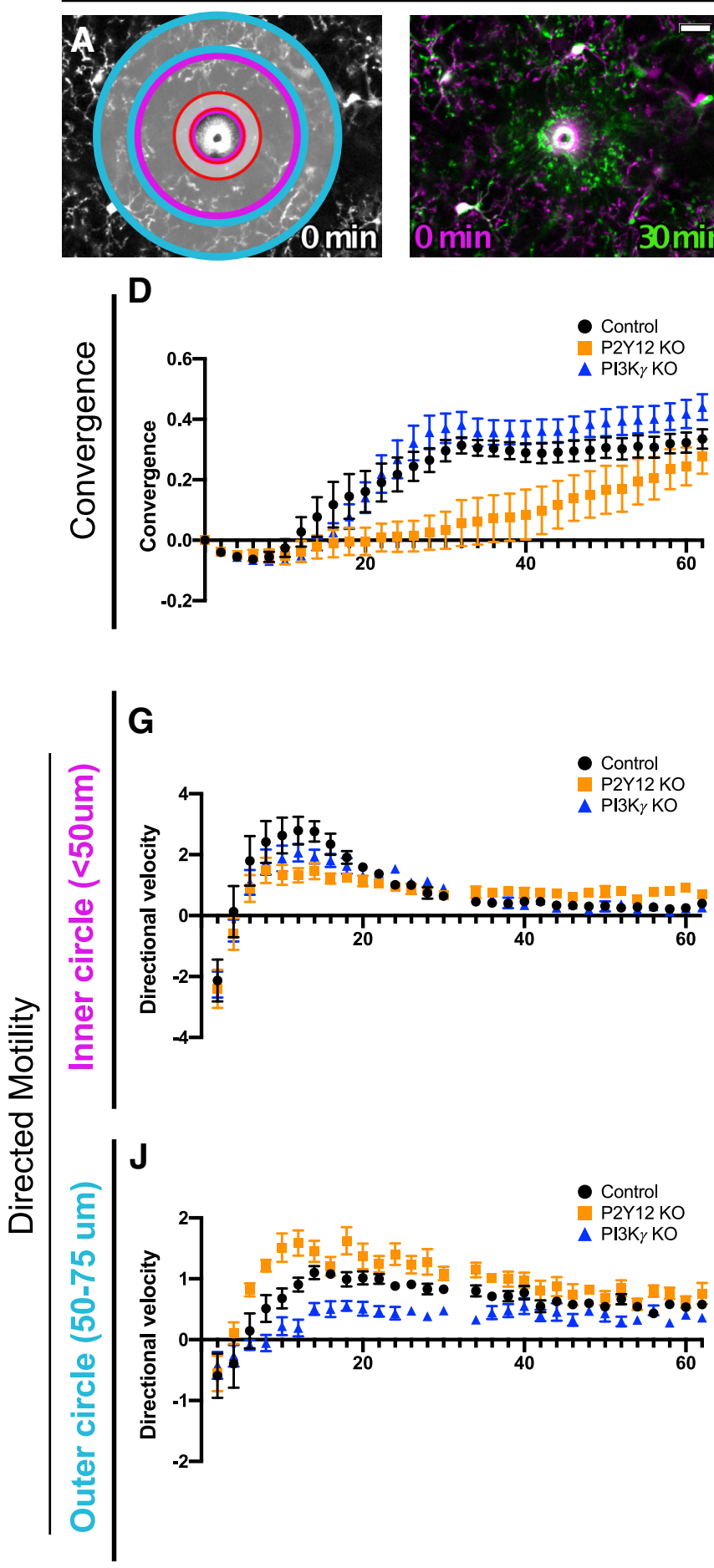
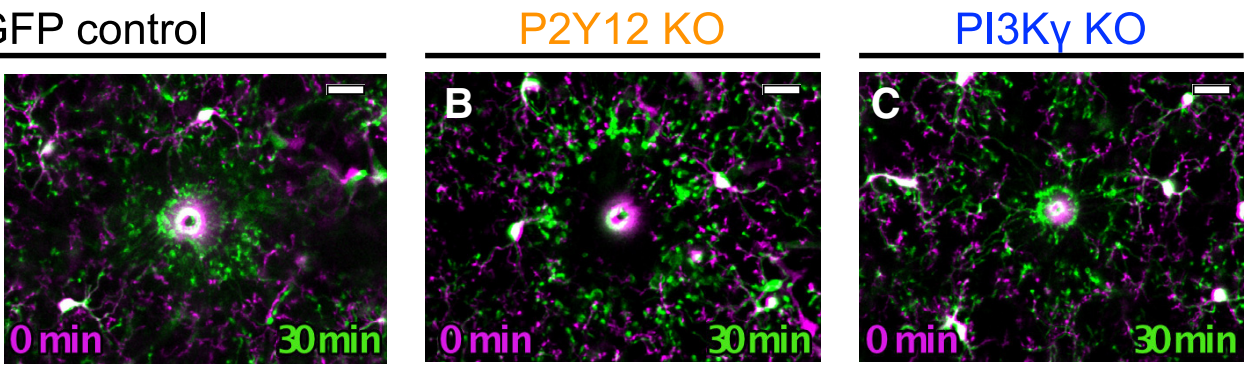

E

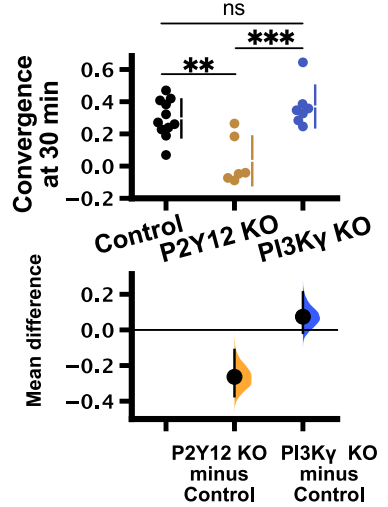

H
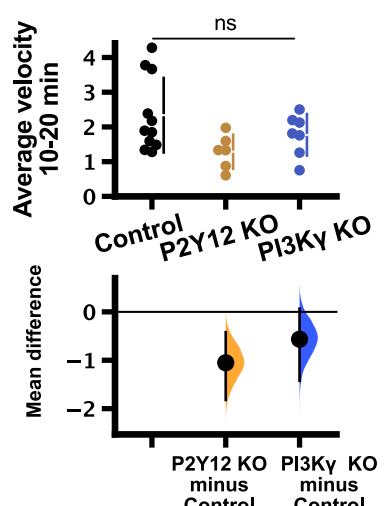

K

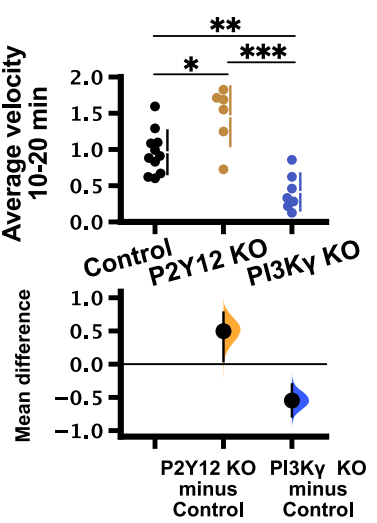

I

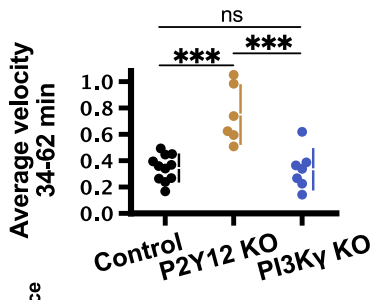

$F$
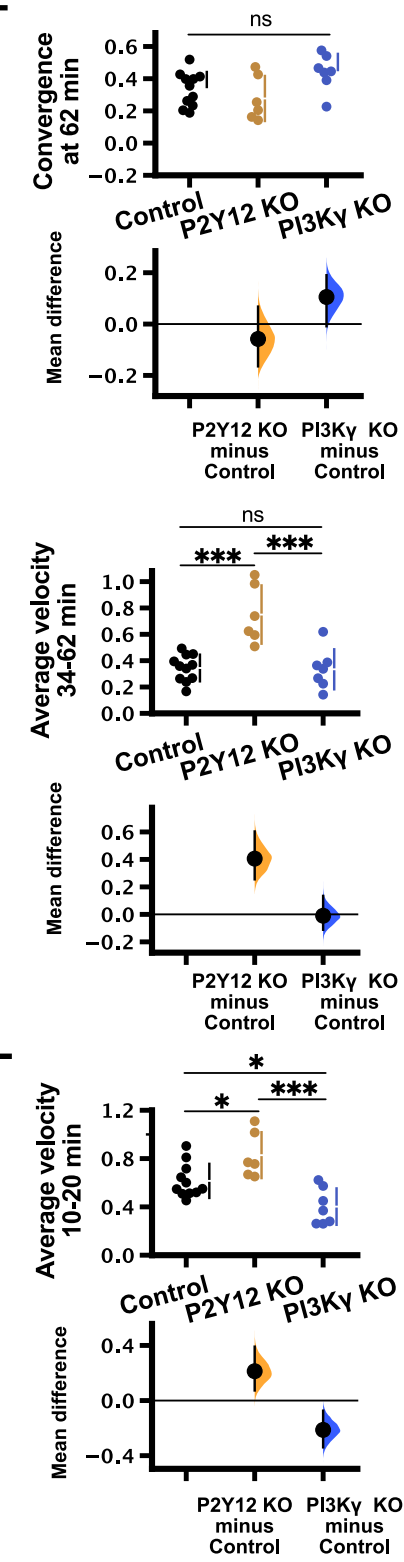

Figure 6. PI3K $\gamma$ is not required for the microglial response to laser injury in vivo. Representative images of the microglial response to laser injury in vivo in control $(\boldsymbol{A}, n=11$ mice), P2Y12 KO (B, $n=6$ mice), and PI3K $\gamma \mathrm{KO}(\boldsymbol{C}, n=7$ mice) at the time points indicated. Images at $30 \mathrm{~min}$ after injury (green) are overlaid with initial images ( $t=0 \mathrm{~min}$, magenta). The first panel shows the approximate regions of interest used for each type of analysis: convergence (red), inner circle motility (purple), and outer circle motility (cyan). $\boldsymbol{D}$, Time course of convergence over a 62-min imaging session. $\boldsymbol{E}$, Convergence at $30 \mathrm{~min}$ is similar in control and $\mathrm{PI} 3 \mathrm{~K} \gamma \mathrm{KO}$ groups, while P2Y12 KO microglia do not converge at this time point [one-way ANOVA $p=0.0003$; Tukey's test: control vs P2Y12 KO $p=0.0018$; control vs PI3K $\gamma$ KO $p=0.48$; P2Y12 KO vs PI3K $\gamma$ KO $p=0.0004$; mean differences vs control: P2Y12 KO -0.263 (95\% $\mathrm{Cl}-0.372,-0.112)$; PI3K $\gamma$ KO $0.0741(95 \% \mathrm{Cl}-0.0165,0.211)]$. $\boldsymbol{F}$, By $62 \mathrm{~min}$, convergence across all groups is similar [one-way 
continued

ANOVA, $p=0.055$; mean differences vs control: P2Y12 KO $-0.058(95 \% \mathrm{Cl}-0.165,0.068) ; \mathrm{PI} 3 \mathrm{~K} \mathrm{KO} 0.105(95 \% \mathrm{Cl}-0.00849$, 0.19)]. G, Time course of directional velocity within the inner circle ( $<50 \mu \mathrm{m}$ from center of injury). Note there is a missing time point at $t=32 \mathrm{~min}$ because of a discontinuity in image acquisition that affects the optic flow calculations. $\boldsymbol{H}$, There were no differences between genotypes in the directional velocity during the peak of the response [average velocity calculated in the interval of 10-20 min after injury; one-way ANOVA $p=0.063$; mean differences vs control: P2Y12 KO $-0.058(95 \% \mathrm{Cl}-0.165,0.068)$; PI3K $\gamma \mathrm{KO} 0.105$ $(95 \% \mathrm{Cl}-0.00849,0.19)]$. I, However, P2Y12 KO microglia had sustained movement toward the injury site, which was significantly higher than control or $\mathrm{PI} 3 \mathrm{~K} \gamma \mathrm{KO}$ groups [average velocity calculated in the interval of 34-62 min; one-way ANOVA $p<0.0001$; Tukey's test: control vs P2Y12 KO $p<0.0001$; control vs PI3K $\gamma$ KO $p=0.99$; P2Y12 KO vs PI3K $\gamma$ KO $p=0.0002$; mean differences vs control: P2Y12 KO $0.406(95 \% \mathrm{Cl} 0.255,0.603)$; PI3K $\gamma \mathrm{KO}-0.00985(95 \% \mathrm{Cl}-0.112,0.134)]$. J, Time course of directional velocity within the outer circle $(50-75 \mu \mathrm{m}$ from injury center). $K$, P2Y12 KO mice showed increased directional velocity during the peak of the response $(10-20 \mathrm{~min})$ compared with control, while $\mathrm{PI} 3 \mathrm{~K} \gamma \mathrm{KO}$ show decreased directional velocity during this time [one-way ANOVA $p<0.0001$; Tukey's test: control vs P2Y12 KO $p=0.0152$; control vs PI3K $\gamma$ KO $p=0.0051$; P2Y12 KO vs PI3K $\gamma$ KO $p<0.0001$; mean differences vs control: P2Y12 KO $0.497(95 \% \mathrm{Cl} 0.0439,0.776)$; $\mathrm{PI} 3 \mathrm{~K} \gamma \mathrm{KO}-0.548(95 \% \mathrm{Cl}-0.787,-0.305)]$. L, These differences in directional response were sustained later in the injury response [34-62 min; one-way ANOVA $p=0.0003$; Tukey's test: control vs P2Y12 KO $p=0.036$; control vs PI3K $\gamma$ KO $p=0.027$; P2Y12 KO vs PI3K $\gamma$ KO $p=0.0002$; mean differences vs control: P2Y12 KO $0.213(95 \% \mathrm{Cl} 0.0734,0.391)$; PI3K $\gamma$ KO $-0.213(95 \% \mathrm{Cl}-0.339,-0.0739)]$. Comparisons $(\boldsymbol{E}, \boldsymbol{F}, \boldsymbol{H}, \boldsymbol{I}, \boldsymbol{K}, \boldsymbol{L})$ done using one-way ANOVA with Tukey's post hoc comparisons; ns, non-significant; $* p<0.05, * * p<0.01, * * * p<0.001$. Data presented as mean \pm SEM. Scale bar: $20 \mu \mathrm{m}$. Heat maps of directional velocity as a function of both time and distance from injury are presented in Extended Data Figure 6-1.

and directed motility. PI3K $\gamma$ has been shown to be an important mediator of functions that are critical to microglial roles in the CNS in both physiological and pathologic settings such as motility, phagocytosis, and microglial responses to pathologic insults. In vitro, PI3K $\gamma$-mediated phosphorylation of PIP2 to generate PIP3 in the plasma membrane is required for $\mathrm{C} 5 \mathrm{a}$-induced microglial motility (Schneble et al., 2017). C5a is a potent chemoattractant for microglia that acts via the $\mathrm{G}_{\mathrm{i}}$-coupled $\mathrm{C5a}$ receptor, suggesting $\mathrm{PI} 3 \mathrm{~K} \gamma$ is activated downstream of some $\mathrm{G}_{\mathrm{i}}$-coupled proteins in microglia (Schneble et al., 2017). Also in vitro, deletion of PI3K $\gamma$ impairs phagocytosis (Schmidt et al., 2013). Furthermore, inhibition of PI3K $\gamma$ can ameliorate some of the proinflammatory and neurotoxic effects of amyloid- $\beta$ peptides in vivo (Passos et al., 2010), suggesting PI3K $\gamma$ may play a role in neurodegeneration.

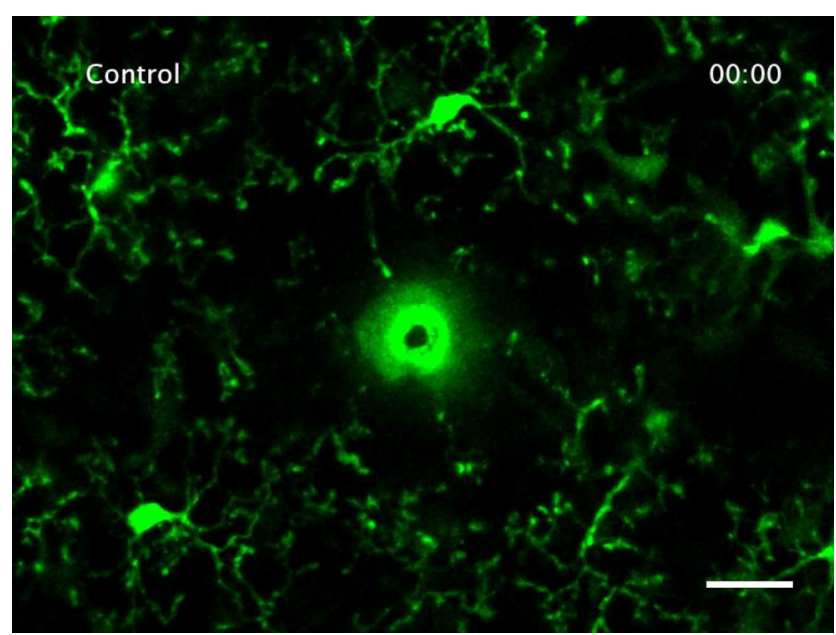

Movie 8. Related to Figure 6. Effects of genetic KO of P2Y12 or $\mathrm{PI} 3 \mathrm{~K} \gamma$ on the microglial response to focal laser injury in cortical layer $2 / 3$ microglia in vivo. Scale bar: $20 \mu \mathrm{m}$. One frame per 2 min. [View online]
While canonical PI3K $\gamma$ signaling involves its kinase activity, such as during C5a-induced motility (Schneble et al., 2017), some of the functions ascribed to PI3K $\gamma$ in microglia, especially in pathologic contexts, have been linked to its kinase-independent activity as a scaffolding protein, where it acts as a regulator of cAMP signaling. $\mathrm{PI} 3 \mathrm{~K} \gamma$ is an AKAP, forming a macromolecular complex with PKA and PDE3 (Perino et al., 2011). This interaction allows PKA to phosphorylate and activate PDE3, which degrades CAMP, and leads to termination of CAMP signaling, albeit in a highly localized fashion (Perino et al., 2011). In cultured microglia, deletion of PI3K $\gamma$ leads to increased cAMP levels and impaired phagocytosis, a phenotype that is rescued by the expression of a knock-in kinasedead mutant PI3K $\gamma$ that has preserved scaffolding function (Schmidt et al., 2013). This kinase-independent

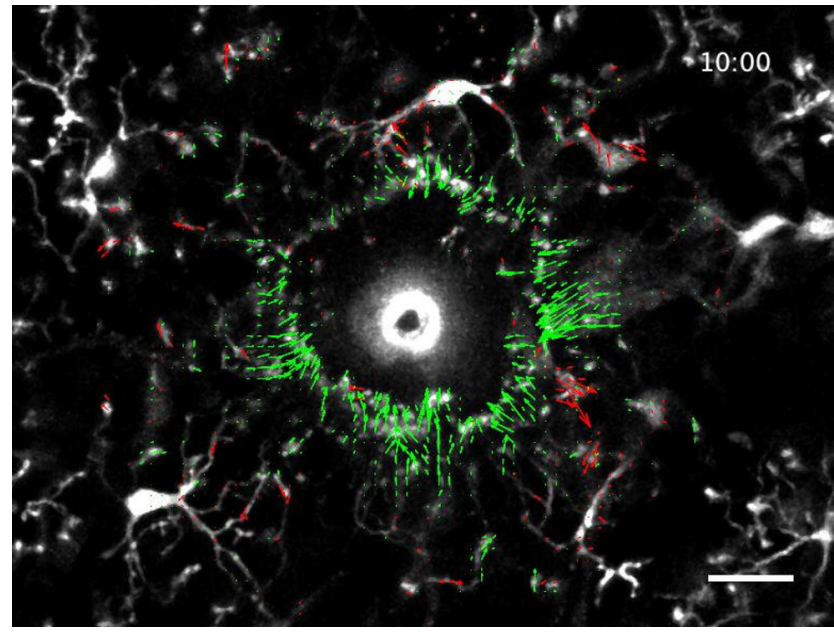

Movie 9. Related to Extended Data Figure 1-1. Color coded velocity vectors (green = net towards center; red = net away from center) overlaid on top of a video of the microglial response to focal injury in vivo. Scale bar: $20 \mu \mathrm{m}$. One frame per $2 \mathrm{~min}$. [View online] 


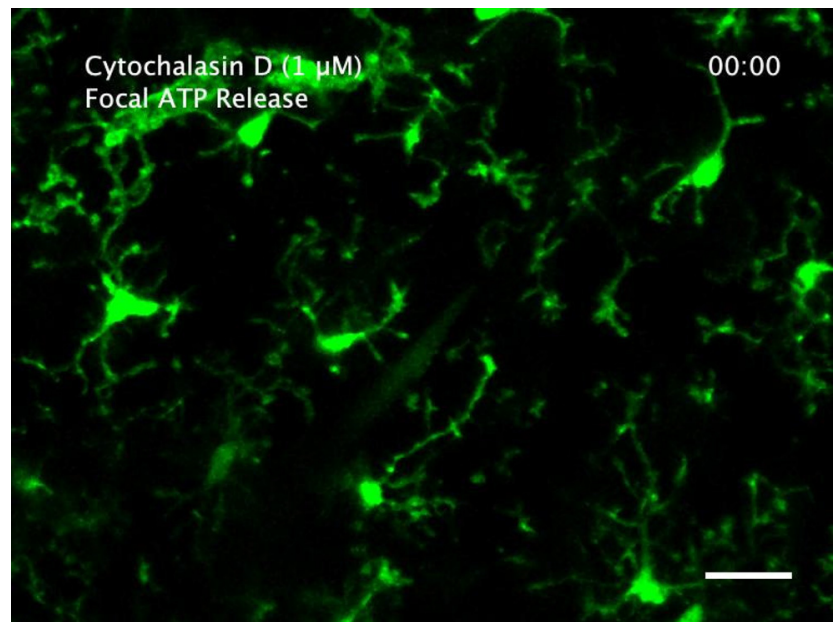

Movie 10. Related to Extended Data Figure 4-1. Effects of inhibition of actin polymerization (with $1 \mu \mathrm{m}$ cytochalasin $\mathrm{D}$ ) on the response of microglia to focal ATP release and focal laser injury in an acute cortical slice. Scale bar: $20 \mu \mathrm{m}$. One frame per 1 min. [View online]

function of $\mathrm{PI} 3 \mathrm{~K} \gamma$ seems to restrict pathology in disease models by regulating matrix metalloproteinase expression (Frister et al., 2014; Schmidt et al., 2016). Thus, this kinase-independent scaffolding function of $\mathrm{PI} 3 \mathrm{~K} \gamma$ and its regulation of cAMP may be induced in response to pathologic insults, as has been described in cardiomyocytes (Perino et al., 2011). We found that pharmacological inhibition (with IPI-549) or genetic deletion of PI3K $\gamma$ affected ATP-mediated directed microglial motility in a similar fashion (Figs. 4, 5). While the kinase-independent activity of $\mathrm{PI} 3 \mathrm{~K} \gamma$ was not measured during the development of IPI-549, we can speculate that IPI-549 does not have a large effect on kinase-independent activity because it is likely an ATP-competitive inhibitor (Evans et al., 2016). We conclude that $\mathrm{PI} 3 \mathrm{~K} \gamma$ is likely to subtly regulate directed motility through

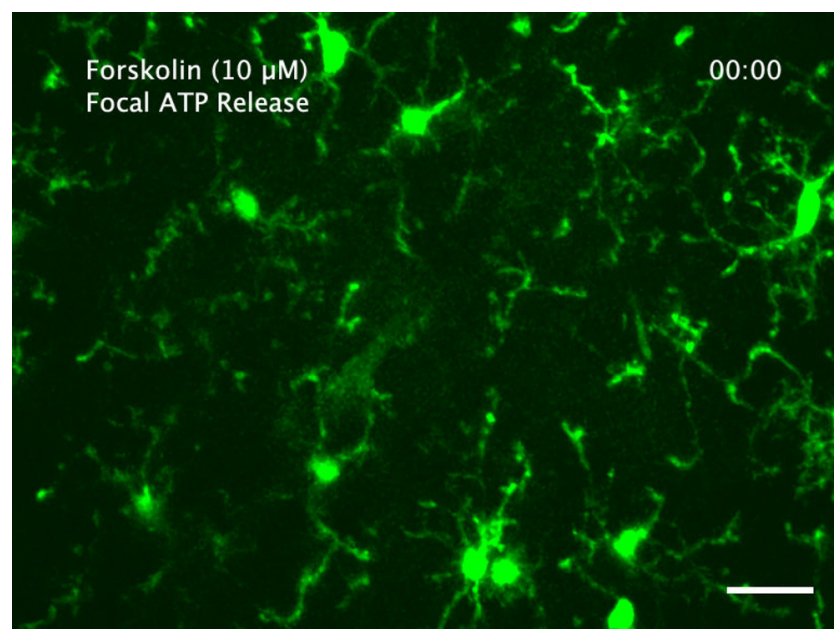

Movie 11. Related to Extended Data Figure 4-2. Effects of activation of AC (with $10 \mu \mathrm{m}$ forskolin) on the response of microglia to focal ATP release in an acute cortical slice. Scale bar: $20 \mu \mathrm{m}$. One frame per $1 \mathrm{~min}$. [View online] a kinase-dependent mechanism, although effects of IPI-549 on kinase-independent activity cannot be absolutely ruled out.

\section{Intracellular signaling in P2Y12-dependent chemotaxis and directed motility}

The microglial response to exogenous ATP was first characterized in vitro, where gradients of ATP induce membrane ruffles and actin polymerization in microglia along with whole-cell migration toward the nucleotide source (Honda et al., 2001). These effects on the cytoskeleton and motility of microglia are dependent on P2Y12 (Haynes et al., 2006). In the context of in vitro whole-cell chemotaxis, it seems ATP (via P2Y12) activates PI3K and phospholipase C (PLC), which in turn act synergistically to activate Akt to drive chemotaxis (Ohsawa et al., 2007; Irino et al., 2008). Precisely how activation of these intracellular signals translates to directional cell movement in microglia has not been tested. One possibility is that this pathway leads to the focal activation of integrins, which promote adhesion to the extracellular matrix and are important for certain types of cellular migration (Yamada and Sixt, 2019). In microglial cultures, P2Y12 activation induces integrin- $\beta 1$ translocation to sites of actin polymerization and integrin- $\beta 1$ is required for ADP-induced chemotaxis (Nasu-Tada et al., 2005; Ohsawa et al., 2010).

It is unclear how much the pathways delineated in vitro contribute to directed motility of microglia in their native brain environment. Relative to their in vivo counterparts, microglia in culture have a substantially different transcriptomic profile (Butovsky et al., 2014) and the response to ATP is qualitatively different. Microglia in acute slices or in vivo react to ATP through the rapid extension of their processes toward the source (Davalos et al., 2005; Nimmerjahn et al., 2005; Haynes et al., 2006), a phenomenon that is absent in cultured microglia, which show very little process ramification. Despite these differences, we found that this form of directed motility, which is more physiological, also requires PI3K activity (Fig. 1), as has been previously shown (Wu et al., 2007). However, inhibition or deletion of PI3K $\gamma$ had only subtle effects on ATPmediated directed motility in acute slices or in vivo (Figs. 4-6), suggesting that direct activation of $\mathrm{PI} 3 \mathrm{~K} \gamma$ by $\mathrm{G} \beta \gamma$ is not strictly necessary for directed motility, and that other $\mathrm{PI} 3 \mathrm{~K}$ isoforms may be activated indirectly by P2Y12 signaling. In peripheral immune cells, there are positive feedback loops between $\mathrm{PI} 3 \mathrm{~K}$ and actin polymerization, such that PI3K can act as a downstream amplifier of the chemotactic response independent of the initial signaling event (Charest and Firtel, 2006; Yoo et al., 2010). A similar mechanism may help to explain the discrepancy in the effects of pan-PI3K and PI3K $\gamma$-specific inhibition on the ATP-mediated microglial directed motility.

In parallel to PI3K signaling, several alternative signaling modules can also mediate chemotaxis in eukaryotic cells (Artemenko et al., 2014), acting synergistically or independently of PI3K to elicit the directed motility of microglial processes. Inhibition of the mitogen-associated protein kinase (MAPK) Erk, which constitutes one such pathway, did not affect ATP-mediated directed motility in 

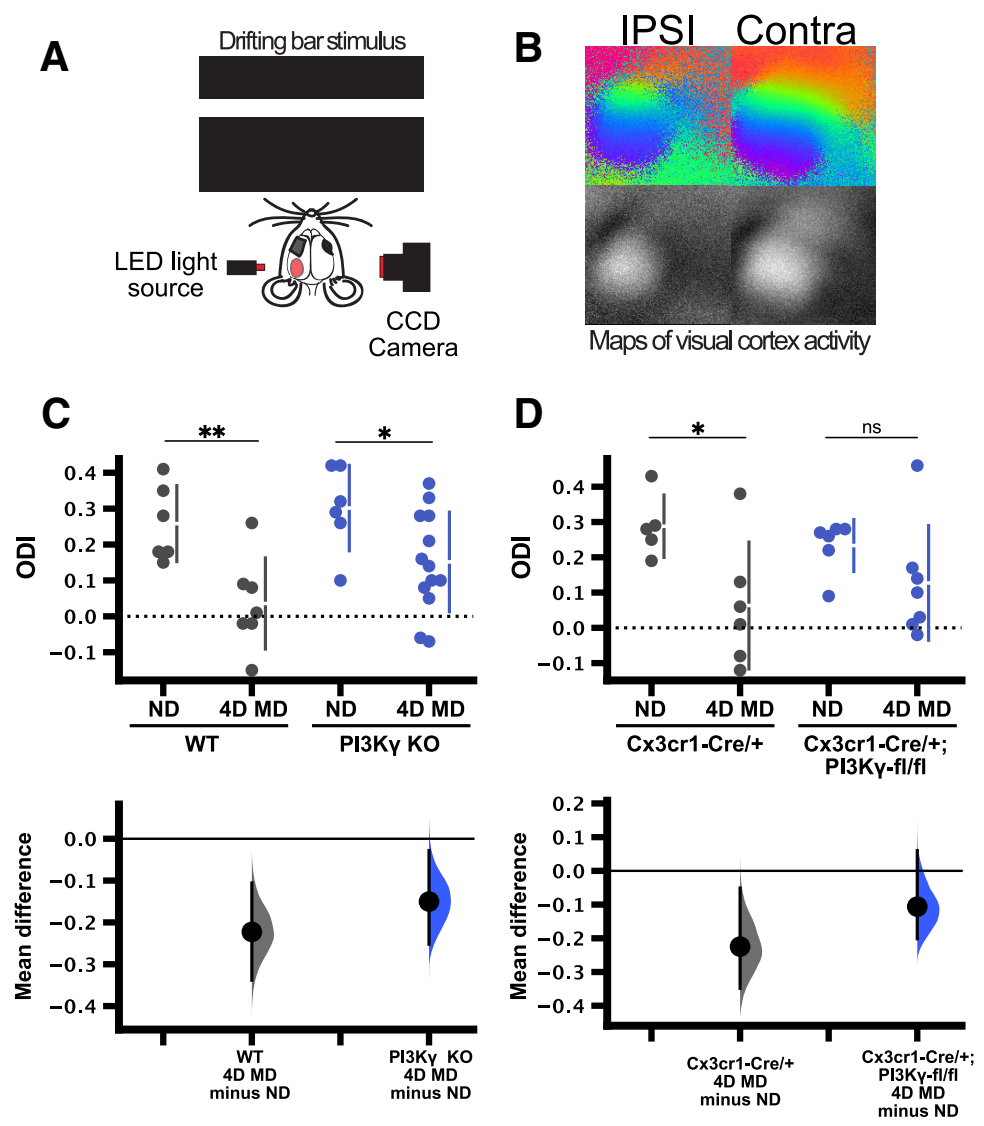

Figure 7. PI3K $\gamma$ is not required for ocular dominance plasticity. $\boldsymbol{A}$, Schematic of IOS imaging rig (see Materials and Methods). $\boldsymbol{B}$, Representative phase (top) and amplitude (bottom) maps of V1 in response to visual stimulus for the ipsilateral (left) and contralateral (right) eyes. Phase maps demonstrate retinotopic organization, while amplitude maps show normalized hemodynamic response to the stimulus. $\boldsymbol{C}$, Effects of global PI3K $\gamma$ KO on ocular dominance plasticity [n (animals) $=6$ WT ND; 7 WT 4D MD; 6 PI3K $\gamma$ KO ND; 13 PI3K $\gamma$ KO 4D MD]. WT (gray) and PI3K $\gamma$ KO (blue) mice were either ND or underwent 4D MD, and the ODI for each mouse was calculated as ODI $=$ (contra response - ipsi response)/(contra response + ipsi response). Both the WT and the PI3K $\gamma \mathrm{KO}$ showed significant shifts in ODI following 4D MD [two-way ANOVA; main effect of deprivation $p=0.0005$; Sidak's test: WT ND vs 4D MD $p=0.0079$; PI3K $\gamma$ KO ND vs 4D MD $p=0.0472$; main effect of genotype $p=0.10$; mean differences: WT ND vs 4D MD $-0.223(95 \% \mathrm{Cl}-0.338,-0.106) ; \mathrm{PI} 3 \mathrm{~K} \gamma \mathrm{KO}$ ND vs $4 \mathrm{D} \mathrm{MD}-0.15(95 \% \mathrm{Cl}-0.252,-0.0282)]$. $\boldsymbol{D}$, Effects of microglial specific PI3K $\gamma$ $\mathrm{KO}$ on ocular dominance plasticity. Tamoxifen-treated $\mathrm{Cx} 3 \mathrm{cr} 1-\mathrm{Cre} /+$ control mice (control, gray) or $\mathrm{Cx} 3 \mathrm{cr} 1-\mathrm{Cre} /+\mathrm{PI} 3 \mathrm{~K} \gamma \mathrm{fl} / \mathrm{fl}$ mice (PI3K $\gamma$ cKO, blue) underwent ND or 4D MD $[n$ (animals) $=5 \mathrm{Cx3cr1-Cre/+ND;6} \mathrm{Cx3cr1-Cre/+4D} \mathrm{MD;} 6 \mathrm{Cx3cr1-Cre/+} \mathrm{PI3K} \gamma$ fl/fl $\mathrm{ND} ; 7 \mathrm{Cx} 3 \mathrm{cr} 1-\mathrm{Cre} /+\mathrm{PI} 3 \mathrm{~K} \gamma \mathrm{fl} / \mathrm{fl}$ 4D MD]. Control mice showed a significant shift in ODI after 4D MD, while microglia-specific PI3K $\gamma$ KO mice showed a trend toward a decrease in ODI [two-way ANOVA: main effect of deprivation $p=0.0084$, Sidak's test: Cx3cr1$\mathrm{Cre} /+\mathrm{ND}$ vs 4D MD $p=0.0275$; Cx3cr1-Cre/ + PI3K $\gamma$ fl/fl ND vs 4D MD $p>0.05$; main effect of genotype $p=0.94$; mean differences Cx3cr1-Cre/+ ND vs 4D MD $-0.225(95 \% \mathrm{Cl}-0.348,-0.051)$; Cx3cr1-Cre/+ PI3K $\gamma$ fl/fl $-0.106(95 \% \mathrm{Cl}-0.201,0.0602)]$; ns, non-significant; $* p<0.05, * * p<0.01$. Data presented as mean $\pm \mathrm{SEM}$. Confirmation of PI3K $\gamma \mathrm{fl} / \mathrm{fl}$ excision and representative amplitude maps for each sample are shown in Extended Data Figures 7-1, 7-2, respectively.

acute slices (Wu et al., 2007). Another candidate may be the p38 MAPK pathway, which was shown to be activated downstream of P2Y12 in spinal cord microglia in models of neuropathic pain (Kobayashi et al., 2008; Tatsumi et al., 2015). The role of p38 MAPK in microglial directed motility remains to be tested. Release of intracellular $\mathrm{Ca}^{2+}$ stores downstream of PLC activation may also play a role. In vitro, ATP induces intracellular $\mathrm{Ca}^{2+}$ signals and inhibition of PLC blocks ATP-mediated chemotaxis. (Irino et al., 2008). In vivo, microglial $\mathrm{Ca}^{2+}$ signals are induced by ATP or tissue damage (Eichhoff et al., 2011; Pozner et al., 2015). However, the presence of $\mathrm{Ca}^{2+}$ signals does not affect the speed of directed microglial motility toward focal injury (Pozner et al., 2015), and whether inhibition of
PLC affects directed microglial motility has not been investigated. Separately, negative regulation of CAMP signaling by P2Y12 could also play a role in directed microglial motility, as increasing CAMP is linked to alterations in microglial motility and surveillance (Bernier et al., 2019; Liu et al., 2019; Stowell et al., 2019). However, pharmacological activation of AC to increase cAMP had little effect on directed microglial motility toward focal ATP (Extended Data Fig. 4-2), which suggests $G \alpha_{i}$-mediated regulation of $A C$ does not play a role in directed motility toward ATP. An additional target of P2Y12 signaling is THIK-1, a $\mathrm{K}^{+}$channel that mediates an ATP-induced outward current (Wu et al., 2007; Madry et al., 2018). While THIK-1 regulates basal microglial morphology and 
surveillance, it is not required for directed motility toward ATP sources. THIK-1-mediated $\mathrm{K}^{+}$efflux after P2Y12 stimulation amplifies inflammasome activity (Madry et al., 2018), suggesting a motility-independent effect of P2Y12 signaling. Precisely which of the parallel and possibly redundant second-messenger pathways is active during P2Y12-mediated directed motility and their downstream effectors remains to be determined. We found that actin polymerization was essential (Extended Data Fig. 4-1), and others have shown that volume-sensitive chloride channels are required (Hines et al., 2009). More work is needed to define the cellular machinery that mediates ATP-dependent directed motility.

Unlike the microglial response to ATP, the loss of P2Y12 did not abolish the response to focal injury. P2Y12 $\mathrm{KO}$ microglia robustly responded to focal injury in vivo, although rapid convergence on the injury site was severely impaired (Fig. 6; Extended Data Fig. 6-1; Movie $8)$. The delayed convergence (1-2 $\mathrm{h}$ after injury) has also been previously described (Haynes et al., 2006). However, the degree of directed motility even early in the injury response has not, to our knowledge, been previously reported. One feature of this P2Y12-independent injury response was the ability of microglial processes to orient and move toward the injury until they were about $\sim 40 \mu \mathrm{m}$ from the center, at which point the they appeared to pause and only slowly converge on the core toward the end of the imaging session (Movie 8). Another striking feature was the appearance of the process end tips in P2Y12 $\mathrm{KO}$ microglia converging on the core which were wider and less bulbous than the tips of control microglia, reminiscent more of lamellipodia versus filopodia (Fig. 6). Interestingly, cells can switch modes of migration depending on the extracellular environment and activation of different intracellular signaling cascades (Yamada and Sixt, 2019). Thus, the absence of P2Y12 signaling during this damage response may lead to a qualitatively different form of motility and likely relies on non-purinergic chemotactic cues, given the absence of any response to focal ATP release in P2Y12 KO mice (Fig. 4; Haynes et al., 2006). A recent study of the in vivo response of peritoneal wall macrophages to laser-induced focal injury suggests a two-step process, in which macrophage processes initially move toward the injury via purinergic signaling, and then require receptor for advanced glycation endproducts (RAGE) for ultimate convergence (Uderhardt et al., 2019). Whether a similar two-stage process in microglia remains to be investigated. There are numerous molecules released from damaged cells that elicit immune responses, collectively known as damage-associated molecular patterns (DAMPs), which include DNA, reactive oxygen species, and proinflammatory proteins (Kigerl et al., 2014). For example, in sterile injury in zebrafish embryos, the presence of a gradient of $\mathrm{H}_{2} \mathrm{O}_{2}$ is required for recruitment of leukocytes to the injury site (Niethammer et al., 2009). Whether $\mathrm{H}_{2} \mathrm{O}_{2}$ or other DAMPs regulate $\mathrm{P} 2 \mathrm{Y} 12$-independent motility in the context of laser-induced injury remains unknown. P2Y12-independent motility, as well as different modes of microglial motility more generally, warrants further investigation.

\section{Interaction between microglial P2Y12 and adrenergic signaling}

Several recent studies both in vivo and ex vivo have shown that the $\mathrm{G}_{\mathrm{i}}$-coupled P2Y12 receptor and Gscoupled $\beta 2$-AR have opposing roles regulating microglial morphology and dynamics, suggesting cAMP has a key role in regulating microglia function. In vivo or in acute brain slices, extracellular ATP causes extension of microglial processes in the form of bulbous end tips, via P2Y12 (Davalos et al., 2005; Haynes et al., 2006; Gyoneva and Traynelis, 2013; Dissing-Olesen et al., 2014). In contrast, activation of $\beta 2$-AR leads to microglial process retraction and reduced tissue surveillance (Gyoneva and Traynelis, 2013; Liu et al., 2019; Stowell et al., 2019). With elevated cAMP, as would be expected with $\beta 2-A R$ stimulation, larger microglial processes retract while highly motile thin filopodial processes become more abundant (Bernier et al., 2019).

The activation of these antagonistic pathways likely controls microglial roles in the remodeling of synapses during activity-dependent plasticity. This is supported by the idea that neuronal activity controls the release of their ligands, ATP and norepinephrine (NE). In acute slices, activation of NMDA-type glutamate receptors is sufficient to elicit P2Y12-dependent microglial process extension (Dissing-Olesen et al., 2014; Eyo et al., 2014). In vivo, chemogenetic excitation of neurons induces microglial process recruitment to neuronal cell bodies (Cserép et al., 2020). Furthermore, in line with ATP being a ubiquitous signaling molecule that can act very locally, NMDA receptor activation of a single neuron is sufficient to induce process extension (Dissing-Olesen et al., 2014). Ocular dominance plasticity requires both NMDA receptors (Cooke and Bear, 2014) and microglial P2Y12 (Sipe et al., 2016), suggesting this form of experience-dependent plasticity may rely on NMDA-mediated ATP-dependent recruitment of microglial processes to specific neurons or synapses. In contrast, $\beta 2$-ARs are activated by NE, a neuromodulator predominantly synthesized by neurons located in the locus coeruleus (LC) with long range projections throughout the brain (Schwarz and Luo, 2015). Increased activity of the LC (representative of an alert brain state), leads to release of NE, which acts on microglial $\beta 2-A R s$ to induce process retraction and impaired surveillance (Liu et al., 2019; Stowell et al., 2019). Activation of microglial $\beta 2$-ARs blocks ocular dominance plasticity suggesting that noradrenergic regulation of microglia regulates synaptic plasticity (Stowell et al., 2019). Thus, $\beta 2$-AR signaling may reflect the regulation of microglia by large-scale state-dependent changes in brain activity while P2Y12 signaling allows microglia to respond to stimuli on the subcellular level, both of which influence microglial surveillance and experience-dependent synaptic plasticity. While the idea that $\beta 2$-AR signaling directly counteracts P2Y12 in this context has not been tested, PI3K $\gamma$ is differentially regulated by Gs (through PKA) and $\mathrm{G}_{\mathrm{i}}$ signaling (Perino et al., 2011; Vanhaesebroeck et al., 2012), and thus could mediate some of the antagonistic effects of P2Y12 and $\beta 2-A R$ signaling in microglia. However, we found that loss of PI3K $\gamma$ does not affect 
microglial surveillance (Fig. 3) or ocular dominance plasticity (Fig. 7), and has only subtle effects on ATP-mediated directed motility (Figs. 4-6). Thus, it is likely not a point of convergence of $\mathrm{P} 2 \mathrm{Y} 12$ and $\beta 2-\mathrm{AR}$ signaling in microglia in vivo.

The intracellular effectors of the multifaceted microglial $\mathrm{P} 2 \mathrm{Y} 12$ receptor remain largely unknown. While PI3K $\gamma$ has a subtle role in ATP-mediated directed motility, we found that it was not a major mediator of P2Y12 signaling. Future studies will have to determine how P2Y12 activation is translated into microglial movement to better understand its complex role in the CNS.

\section{References}

Afonso PV, Parent CA (2011) PI3K and chemotaxis: a priming issue? Sci Signal 4:pe22.

Artemenko Y, Lampert TJ, Devreotes PN (2014) Moving towards a paradigm: common mechanisms of chemotactic signaling in Dictyostelium and mammalian leukocytes. Cell Mol Life Sci 71:3711-3747.

Bernier L-P, Bohlen CJ, York EM, Choi HB, Kamyabi A, DissingOlesen L, Hefendehl JK, Collins HY, Stevens B, Barres BA, MacVicar BA (2019) Nanoscale surveillance of the brain by microglia via cAMP-regulated filopodia. Cell Rep 27:2895-2908.e4.

Breasson L, Becattini B, Sardi C, Molinaro A, Zani F, Marone R, Botindari F, Bousquenaud M, Ruegg C, Wymann MP, Solinas G (2017) PI3K $\gamma$ activity in leukocytes promotes adipose tissue inflammation and early-onset insulin resistance during obesity. Sci Signal 10:eaaf2969.

Butovsky O, Jedrychowski MP, Moore CS, Cialic R, Lanser AJ, Gabriely G, Koeglsperger T, Dake B, Wu PM, Doykan CE, Fanek Z, Liu L, Chen Z, Rothstein JD, Ransohoff RM, Gygi SP, Antel JP, Weiner HL (2014) Identification of a unique TGF- $\beta$-dependent molecular and functional signature in microglia. Nat Neurosci 17:131143.

Charest PG, Firtel RA (2006) Feedback signaling controls leadingedge formation during chemotaxis. Curr Opin Genet Dev 16:339347.

Cooke SF, Bear MF (2014) How the mechanisms of long-term synaptic potentiation and depression serve experience-dependent plasticity in primary visual cortex. Philos Trans R Soc Lond B Biol Sci 369:20130284.

Cserép C, Pósfai B, Lénárt N, Fekete R, László ZI, Lele Z, Orsolits B, Molnár G, Heindl S, Schwarcz AD, Ujvári K, Környei Z, Tóth K, Szabadits E, Sperlágh B, Baranyi M, Csiba L, Hortobágyi T, Maglóczky Z, Martinecz B, et al. (2020) Microglia monitor and protect neuronal function via specialized somatic purinergic junctions. Science 367:eaax6752.

D'Andrea I, Fardella V, Fardella S, Pallante F, Ghigo A, lacobucci R, Maffei A, Hirsch E, Lembo G, Carnevale D (2015) Lack of kinaseindependent activity of $\mathrm{PI} 3 \mathrm{~K} \gamma$ in locus coeruleus induces $A D H D$ symptoms through increased CREB signaling. EMBO Mol Med 7:904-917.

Davalos D, Grutzendler J, Yang G, Kim JV, Zuo Y, Jung S, Littman DR, Dustin ML, Gan W-B (2005) ATP mediates rapid microglial response to local brain injury in vivo. Nat Neurosci 8:752-758. PMC]

Devreotes P, Horwitz AR (2015) Signaling networks that regulate cell migration. Cold Spring Harb Perspect Biol 7:a005959.

Diaz-Aparicio I, Paris I, Sierra-Torre V, Plaza-Zabala A, RodríguezIglesias N, Márquez-Ropero M, Beccari S, Huguet $P$, Abiega $O$, Alberdi E, Matute C, Bernales I, Schulz A, Otrokocsi L, Sperlagh B, Happonen KE, Lemke G, Maletic-Savatic M, Valero J, Sierra A (2020) Microglia actively remodel adult hippocampal neurogenesis through the phagocytosis secretome. J Neurosci 40:1453-1482.

Dissing-Olesen L, LeDue JM, Rungta RL, Hefendehl JK, Choi HB, MacVicar BA (2014) Activation of neuronal NMDA receptors triggers transient ATP-mediated microglial process outgrowth. J Neurosci 34:10511-10527.

Eichhoff G, Brawek B, Garaschuk O (2011) Microglial calcium signal acts as a rapid sensor of single neuron damage in vivo. Biochim Biophys Acta 1813:1014-1024.

Evans CA, Liu T, Lescarbeau A, Nair SJ, Grenier L, Pradeilles JA, Glenadel Q, Tibbitts T, Rowley AM, DiNitto JP, Brophy EE, O'Hearn EL, Ali JA, Winkler DG, Goldstein SI, O'Hearn P, Martin CM, Hoyt JG, Soglia JR, Cheung C, et al. (2016) Discovery of a selective phosphoinositide-3-kinase (PI3K)- $\gamma$ inhibitor (IPI-549) as an immuno-oncology clinical candidate. ACS Med Chem Lett 7:862867.

Eyo UB, Peng J, Swiatkowski P, Mukherjee A, Bispo A, Wu LJ (2014) Neuronal hyperactivity recruits microglial processes via neuronal NMDA receptors and microglial P2Y12 receptors after status epilepticus. J Neurosci 34:10528-10540.

Eyo UB, Mo M, Yi MH, Murugan M, Liu J, Yarlagadda R, Margolis DJ, Xu P, Wu LJ (2018) P2Y12R-dependent translocation mechanisms gate the changing microglial landscape. Cell Rep 23:959-966.

Farnebäck G (2003) Two-frame motion estimation based on polynomial expansion. Image Anal 2749:363-370.

Fekete R, Cserép C, Lénárt N, Tóth K, Orsolits B, Martinecz B, Méhes E, Szabó B, Németh V, Gönci B, Sperlágh B, Boldogkői Z, Kittel Á, Baranyi M, Ferenczi S, Kovács K, Szalay G, Rózsa B, Webb C, Kovacs GG, Hortobágyi T, West BL, Környei Z, Dénes Á (2018) Microglia control the spread of neurotropic virus infection via P2Y12 signalling and recruit monocytes through P2Y12-independent mechanisms. Acta Neuropathol 136:461-482.

Frister A, Schmidt C, Schneble N, Brodhun M, Gonnert FA, Bauer M, Hirsch E, Müller JP, Wetzker R, Bauer R (2014) Phosphoinositide 3-kinase $\gamma$ affects LPS-induced disturbance of blood-brain barrier via lipid kinase-independent control of cAMP in microglial cells. Neuromolecular Med 16:704-713.

Gordon JA, Stryker MP (1996) Experience-dependent plasticity of binocular responses in the primary visual cortex of the mouse. $J$ Neurosci 16:3274-3286.

Gyoneva S, Traynelis SF (2013) Norepinephrine modulates the motility of resting and activated microglia via different adrenergic receptors. J Biol Chem 288:15291-15302.

Haastert PJMV, Devreotes PN (2004) Chemotaxis: signalling the way forward. Nat Rev Mol Cell Biol 5:626-634.

Haynes SE, Hollopeter G, Yang G, Kurpius D, Dailey ME, Gan W-B, Julius D (2006) The P2Y12 receptor regulates microglial activation by extracellular nucleotides. Nat Neurosci 9:1512-1519.

He L, Vanlandewijck M, Mäe MA, Andrae J, Ando K, Del Gaudio F, Nahar K, Lebouvier T, Laviña B, Gouveia L, Sun Y, Raschperger E, Segerstolpe Å, Liu J, Gustafsson S, Räsänen M, Zarb Y, Mochizuki N, Keller A, Lendahl U, et al. (2018) Single-cell RNA sequencing of mouse brain and lung vascular and vessel-associated cell types. Sci Data 5:180160.

Henau OD, Rausch M, Winkler D, Campesato LF, Liu C, Cymerman DH, Budhu S, Ghosh A, Pink M, Tchaicha J, Douglas M, Tibbitts T, Sharma S, Proctor J, Kosmider N, White K, Stern H, Soglia J, Adams J, Palombella VJ, et al. (2016) Overcoming resistance to checkpoint blockade therapy by targeting $\mathrm{PI} 3 \mathrm{~K} \gamma$ in myeloid cells. Nature 539:443-447.

Hines DJ, Hines RM, Mulligan SJ, MacVicar BA (2009) Microglia processes block the spread of damage in the brain and require functional chloride channels. Glia 57:1610-1618.

Hirsch E, Katanaev VL, Garlanda C, Azzolino O, Pirola L, Silengo L, Sozzani S, Mantovani A, Altruda F, Wymann MP (2000) Central role for $G$ protein-coupled phosphoinositide 3-kinase in inflammation. Science 287:1049-1053.

Ho J, Tumkaya T, Aryal S, Choi H, Claridge-Chang A (2019) Moving beyond $P$ values: data analysis with estimation graphics. Nat Methods 16:565-566.

Honda S, Sasaki Y, Ohsawa K, Imai Y, Nakamura Y, Inoue K, Kohsaka S (2001) Extracellular ATP or ADP induce chemotaxis of cultured microglia through Gi/o-coupled P2Y receptors. J Neurosci 21:1975-1982. 
Illes P, Burnstock G, Tang Y (2019) Astroglia-derived ATP modulates CNS neuronal circuits. Trends Neurosci 42:885-898.

Insall RH (2010) Understanding eukaryotic chemotaxis: a pseudopod-centred view. Nat Rev Mol Cell Biol 11:1-6.

Irino Y, Nakamura Y, Inoue K, Kohsaka S, Ohsawa K (2008) Akt activation is involved in P2Y12 receptor-mediated chemotaxis of microglia. J Neurosci 86:1511-1519.

Jung S, Aliberti J, Graemmel P, Sunshine MJ, Kreutzberg GW, Sher A, Littman DR (2000) Analysis of fractalkine receptor CX(3)CR1 function by targeted deletion and green fluorescent protein reporter gene insertion. Mol Cell Biol 20:4106-4114.

Kalatsky VA, Stryker MP (2003) New paradigm for optical imaging: temporally encoded maps of intrinsic signal. Neuron 38:529-545.

Kaneda MM, Messer KS, Ralainirina N, Li H, Leem CJ, Gorjestani S, Woo G, Nguyen AV, Figueiredo CC, Foubert P, Schmid MC, Pink M, Winkler DG, Rausch M, Palombella VJ, Kutok J, McGovern K, Frazer KA, Wu X, Karin M, et al. (2016) PI3K $\gamma$ is a molecular switch that controls immune suppression. Nature 539:437-442.

Kettenmann H, Hanisch UK, Noda M, Verkhratsky A (2011) Physiology of microglia. Physiol Rev 91:461-553.

Kigerl KA, de Rivero Vaccari JP, Dietrich WD, Popovich PG, Keane RW (2014) Pattern recognition receptors and central nervous system repair. Exp Neurol 258:5-16.

Kim JI, Lee HR, Sim S, Baek J, Yu NK, Choi JH, Ko HG, Lee YS, Park SW, Kwak C, Ahn SJ, Choi SY, Kim H, Kim KH, Backx PH, Bradley CA, Kim E, Jang DJ, Lee K, Kim SJ, et al. (2011) PI3K $\gamma$ is required for NMDA receptor-dependent long-term depression and behavioral flexibility. Nat Neurosci 14:1447-1454.

Kobayashi K, Yamanaka H, Fukuoka T, Dai Y, Obata K, Noguchi K (2008) P2Y12 receptor upregulation in activated microglia is a gateway of p38 signaling and neuropathic pain. J Neurosci 28:2892-2902.

Krucker T, Siggins GR, Halpain S (2000) Dynamic actin filaments are required for stable long-term potentiation (LTP) in area CA1 of the hippocampus. Proc Natl Acad Sci USA 97:6856-6861.

Kuhlman SJ, Olivas ND, Tring E, Ikrar T, Xu X, Trachtenberg JT (2013) A disinhibitory microcircuit initiates critical-period plasticity in the visual cortex. Nature 501:543-546.

Kyrargyri V, Attwell D, Jolivet RB, Madry C (2019) Analysis of signaling mechanisms regulating microglial process movement. Methods Mol Biol 2034:191-205.

Li Q, Barres BA (2018) Microglia and macrophages in brain homeostasis and disease. Nat Rev Immunol 18:225-242.

Lima IV, Campos AC, Miranda AS, Vieira ÉL, Amaral-Martins F, Vago JP, Santos RP, Sousa LP, Vieira LB, Teixeira MM, Fiebich BL, Moraes MF, Teixeira AL, de Oliveira AC (2015) PI3K $\gamma$ deficiency enhances seizures severity and associated outcomes in a mouse model of convulsions induced by intrahippocampal injection of pilocarpine. Exp Neurol 267:123-134.

Lin Y, Smrcka AV (2011) Understanding molecular recognition by G protein $\beta \gamma$ subunits on the path to pharmacological targeting. Mol Pharmacol 80:551-557.

Liu YU, Ying Y, Li Y, Eyo UB, Chen T, Zheng J, Umpierre AD, Zhu J, Bosco DB, Dong H, Wu LJ (2019) Neuronal network activity controls microglial process surveillance in awake mice via norepinephrine signaling. Nat Neurosci 22:1771-1781.

Madry C, Kyrargyri V, Arancibia-Cárcamo IL, Jolivet R, Kohsaka S, Bryan RM, Attwell D (2018) Microglial ramification, surveillance, and interleukin $-1 \beta$ release are regulated by the two-pore domain K+ channel THIK-1. Neuron 97:299-312.e6.

Nasu-Tada K, Koizumi S, Inoue K (2005) Involvement of beta1 integrin in microglial chemotaxis and proliferation on fibronectin: different regulations by ADP through PKA. Glia 52:98-107.

Niethammer P, Grabher C, Look AT, Mitchison TJ (2009) A tissuescale gradient of hydrogen peroxide mediates rapid wound detection in zebrafish. Nature 459:996-999.

Nimmerjahn A, Kirchhoff F, Helmchen F (2005) Resting microglial cells are highly dynamic surveillants of brain parenchyma in vivo. Science 308:1314-1318.
Oestreich JH (2010) Elinogrel, a reversible P2Y12 receptor antagonist for the treatment of acute coronary syndrome and prevention of secondary thrombotic events. Curr Opin Investig Drugs 11:340348.

Ohsawa K, Irino Y, Nakamura Y, Akazawa C, Inoue K, Kohsaka S (2007) Involvement of P2X 4 and P2Y 12 receptors in ATP-induced microglial chemotaxis. Glia 55:604-616.

Ohsawa K, Irino Y, Sanagi T, Nakamura Y, Suzuki E, Inoue K, Kohsaka S (2010) P2Y12 receptor-mediated integrin-beta1 activation regulates microglial process extension induced by ATP. Glia 58:790-801.

Parkhurst CN, Yang G, Ninan I, Savas JN, Yates JR 3rd, Lafaille JJ, Hempstead BL, Littman DR, Gan WB (2013) Microglia promote learning-dependent synapse formation through brain-derived neurotrophic factor. Cell 155:1596-1609.

Parslow A, Cardona A, Bryson-Richardson RJ (2014) Sample drift correction following 4D confocal time-lapse imaging. $\mathrm{J}$ Vis Ext. Advance online publication. Retrieved April 12, 2014 . doi: 10.3791/51086.

Passos GF, Figueiredo CP, Prediger RDS, Silva KABS, Siqueira JM, Duarte FS, Leal PC, Medeiros R, Calixto JB (2010) Involvement of phosphoinositide 3-kinase $\gamma$ in the neuro-inflammatory response and cognitive impairments induced by $\beta$-amyloid $1-40$ peptide in mice. Brain Behav Immun 24:493-501.

Perino A, Ghigo A, Ferrero E, Morello F, Santulli G, Baillie GS, Damilano F, Dunlop AJ, Pawson C, Walser R, Levi R, Altruda F, Silengo L, Langeberg LK, Neubauer G, Heymans S, Lembo G, Wymann MP, Wetzker R, Houslay MD, et al. (2011) Integrating cardiac PIP3 and CAMP signaling through a PKA anchoring function of $1110 \gamma$. Mol Cell 42:84-95.

Pozner A, Xu B, Palumbos S, Gee JM, Tvrdik P, Capecchi MR (2015) Intracellular calcium dynamics in cortical microglia responding to focal laser injury in the PC::G5-tdT reporter mouse. Front Mol Neurosci 8:12.

Schmidt C, Schneble N, Müller JP, Bauer R, Perino A, Marone R, Rybalkin SD, Wymann MP, Hirsch E, Wetzker R (2013) Phosphoinositide 3-kinase $\gamma$ mediates microglial phagocytosis via lipid kinase-independent control of cAMP. Neuroscience 233:4453.

Schmidt C, Frahm C, Schneble N, Müller JP, Brodhun M, Franco I, Witte OW, Hirsch E, Wetzker R, Bauer R (2016) Phosphoinositide 3-kinase $\gamma$ restrains neurotoxic effects of microglia after focal brain ischemia. Mol Neurobiol 53:5468-5479.

Schneble N, Schmidt C, Bauer R, Müller JP, Monajembashi S, Wetzker R (2017) Phosphoinositide 3-kinase $\gamma$ ties chemoattractant- and adrenergic control of microglial motility. Mol Cell Neurosci 78:1-8.

Schwarz LA, Luo L (2015) Organization of the locus coeruleus-norepinephrine system. Curr Biol 25:R1051-R1056.

Sipe GO, Lowery RL, Tremblay M-Ė, Kelly EA, Lamantia CE, Majewska AK (2016) Microglial P2Y12 is necessary for synaptic plasticity in mouse visual cortex. Nat Commun 7:10905-10915.

Stowell RD, Sipe GO, Dawes RP, Batchelor HN, Lordy KA, Whitelaw BS, Stoessel MB, Bidlack JM, Brown E, Sur M, Majewska AK (2019) Noradrenergic signaling in the wakeful state inhibits microglial surveillance and synaptic plasticity in the mouse visual cortex. Nat Neurosci 22:1782-1792.

Swiatkowski P, Murugan M, Eyo UB, Wang Y, Rangaraju S, Oh SB, Wu LJ (2016) Activation of microglial P2Y12 receptor is required for outward potassium currents in response to neuronal injury. Neuroscience 318:22-33.

Tatsumi E, Yamanaka H, Kobayashi K, Yagi H, Sakagami M, Noguchi K (2015) RhoA/ROCK pathway mediates p38 MAPK activation and morphological changes downstream of P2Y12/ 13 receptors in spinal microglia in neuropathic pain. Glia 63:216-228.

Uderhardt S, Martins AJ, Tsang JS, Lämmermann T, Germain RN (2019) Resident macrophages cloak tissue microlesions to prevent neutrophil-driven inflammatory damage. Cell 177:541-555. e17. 
Vainchtein ID, Molofsky AV (2020) Astrocytes and microglia: in sickness and in health. Trends Neurosci 43:144-154.

Vanhaesebroeck B, Stephens L, Hawkins P (2012) PI3K signalling: the path to discovery and understanding. Nat Rev Mol Cell Biol 13:195-203.

Vanlandewijck M, He L, Mäe MA, Andrae J, Ando K, Del Gaudio F, Nahar K, Lebouvier T, Laviña B, Gouveia L, Sun Y, Raschperger E, Räsänen M, Zarb Y, Mochizuki N, Keller A, Lendahl U, Betsholtz C (2018) A molecular atlas of cell types and zonation in the brain vasculature. Nature 554:475-480.

Wu LJ, Vadakkan KI, Zhuo M (2007) ATP-induced chemotaxis of microglial processes requires $\mathrm{P} 2 \mathrm{Y}$ receptor-activated initiation of outward potassium currents. Glia 55:810-821.

Yamada KM, Sixt M (2019) Mechanisms of 3D cell migration. Nat Rev Mol Cell Biol 20:738-752.
Yoo SK, Deng Q, Cavnar PJ, Wu YI, Hahn KM, Huttenlocher A (2010) Differential regulation of protrusion and polarity by $\mathrm{PI}(3) \mathrm{K}$ during neutrophil motility in live zebrafish. Dev Cell 18:226-236.

Zeisel A, Hochgerner $H$, Lönnerberg $P$, Johnsson A, Memic F, van der Zwan J, Häring M, Braun E, Borm LE, La Manno G, Codeluppi S, Furlan A, Lee K, Skene N, Harris KD, Hjerling-Leffler J, Arenas E, Ernfors P, Marklund U, Linnarsson S (2018) Molecular architecture of the mouse nervous system. Cell 174:999-1014.e22.

Zhang X, Li G (2019) P2Y receptors in neuropathic pain. Pharmacol Biochem Behav 186:172788.

Zhang Y, Chen K, Sloan SA, Bennett ML, Scholze AR, O'Keeffe S, Phatnani HP, Guarnieri P, Caneda C, Ruderisch N, Deng S, Liddelow SA, Zhang C, Daneman R, Maniatis T, Barres BA, Wu JQ (2014) An RNA-sequencing transcriptome and splicing database of glia, neurons, and vascular cells of the cerebral cortex. J Neurosci 34:11929-11947. 